\title{
Local agency traffic sign retroreflectivity case study and model of observed traffic sign light intensity
}

\author{
Mark L. Franz \\ West Virginia University
}

Follow this and additional works at: https://researchrepository.wvu.edu/etd

\section{Recommended Citation}

Franz, Mark L., "Local agency traffic sign retroreflectivity case study and model of observed traffic sign light intensity" (2009). Graduate Theses, Dissertations, and Problem Reports. 4465.

https://researchrepository.wvu.edu/etd/4465

This Thesis is protected by copyright and/or related rights. It has been brought to you by the The Research Repository @ WVU with permission from the rights-holder(s). You are free to use this Thesis in any way that is permitted by the copyright and related rights legislation that applies to your use. For other uses you must obtain permission from the rights-holder(s) directly, unless additional rights are indicated by a Creative Commons license in the record and/ or on the work itself. This Thesis has been accepted for inclusion in WVU Graduate Theses, Dissertations, and Problem Reports collection by an authorized administrator of The Research Repository @ WVU. For more information, please contact researchrepository@mail.wvu.edu. 


\title{
LOCAL AGENCY TRAFFIC SIGN RETROREFLECTIVITY CASE STUDY AND MODEL OF OBSERVED TRAFFIC SIGN LIGHT INTENSITY
}

\author{
By
}

\begin{abstract}
Mark L. Franz
Thesis submitted to the College of Engineering and Mineral Resources

at West Virginia University

in partial fulfillment of the requirements for the degree of

Master of Science

in
\end{abstract}

Civil Engineering

John P. Zaniewski, Ph.D., Chair

Ronald W. Eck, Ph.D.

Gary L. Winn, Ph.D.

Department of Civil and Environmental Engineering

Morgantown, West Virginia

2009

Key Words

Retroreflectivity, Traffic signs, Visibility, Highway user benefits 


\section{Abstract \\ Local Agency Traffic Sign Retroreflectivity Case Study and Model of Observed Traffic Sign Light Intensity \\ Mark L. Franz \\ Committee: \\ Dr. John Zaniewski, CEE (Chair), Dr. Ronald Eck, and Dr. Gary Winn}

Despite the lower traffic volumes, nearly 50 percent of America's fatal motor vehicle crashes occur at night. A contributing factor to the higher fatality rate at night is the reduced ability of motorists to be informed by visual cues. Therefore, motorists often rely on traffic control devices (TCD) under dark conditions for information, warnings, and guidance. This study focused on the visibility of traffic signs under dark conditions.

The new MUTCD standards on traffic sign retroreflectivity have been promulgated to improve nighttime driving safety on all roads open to public travel. This includes roads under the jurisdiction of local road agencies which may lack the resources such as management systems, money, and personnel to comply with these new standards. To assess the impact of the new MUTCD minimum retroreflectivity levels on local road agencies in West Virginia, the current state of traffic sign management practices at the local agency level was determined via survey. Knowing the state of traffic sign management practices in the state of West Virginia, it was then possible to design a case study to assess the effort needed to effectively comply with the new MUTCD traffic sign retroreflectivity standards.

Additionally, this thesis presents a theoretical model for predicting observed light intensity from traffic signs. Ultimately, the model could be used to determine traffic sign size, sheeting material and location to maximize retroreflectivity at critical distances at which motorists are safely and effectively informed. The observed luminance model is a function of the target traffic sign size and sheeting material, the vehicle headlamp intensity pattern, and the horizontal, vertical, and lateral offsets between the motorist's eye, each respective vehicle headlamp, and the target traffic sign. 


\section{Acknowledgements}

I would like to thank my advisor, Dr. John Zaniewski, for his knowledge, patience, guidance, and support throughout the development of this paper. I would like to thank Dr. Zaniewski for teaching me the fundamentals of designing and conducting a scientific study. Thank you to my defense committee, Dr. Ronald Eck and Dr. Gary Winn for their constructive comments and review of this document.

Additional thanks goes to the West Virginia Local Technical Assistance Program for the opportunity to become their research assistant. Thanks to Kevin Butler and Justin Parnicza for their help in data collection. I would also like to thank Ms. Kim Carr for her unconditional guidance and support throughout my pursuit of a master's degree.

Lastly, I would like to express my gratitude to my family, Mom, Dad, Sean, Heather, and Hailey for always believing in me and helping me through the challenging times in my life. 


\section{TABLE OF CONTENTS}

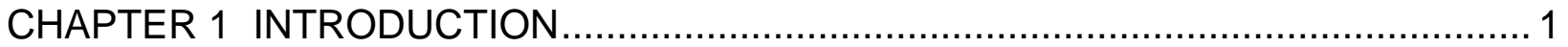

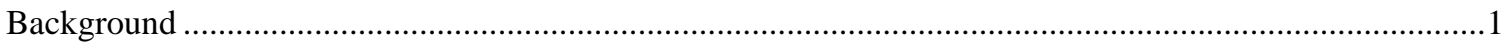

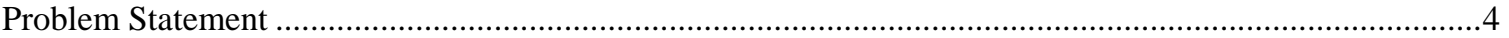

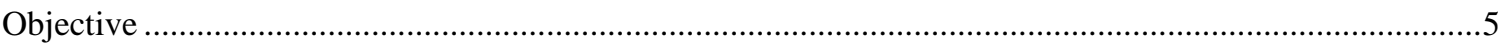

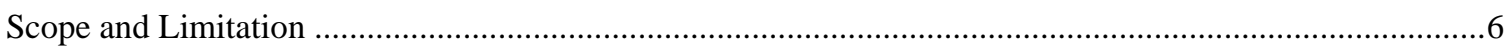

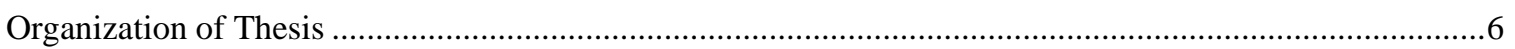

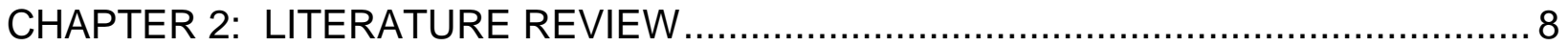

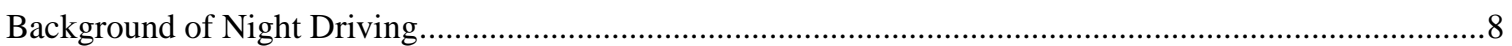

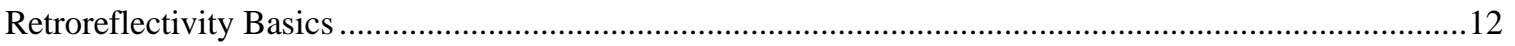

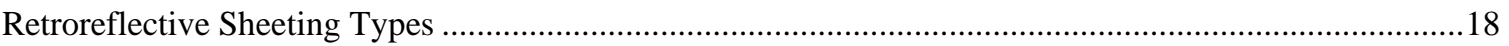

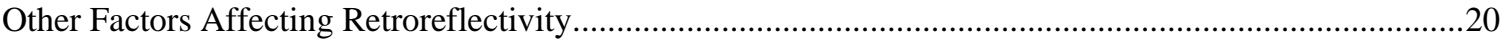

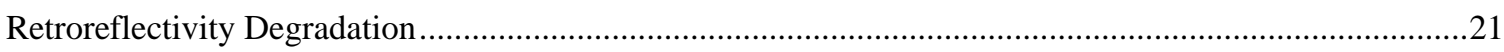

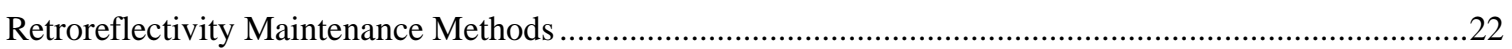

Impact Case Studies of Retroreflectivity Standards ...............................................................................24

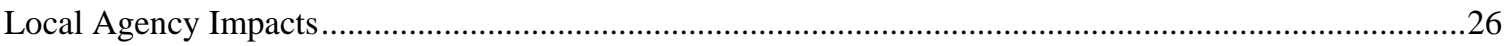

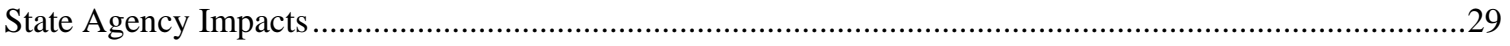

Sign Management Systems and Sign Inventories....................................................................................

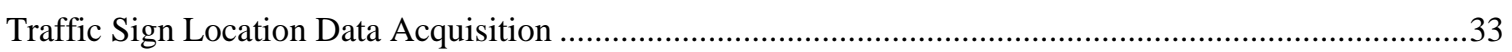

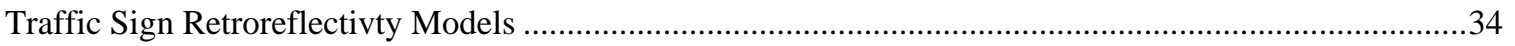

Summary of Literature Review ……………………….........................................................................35

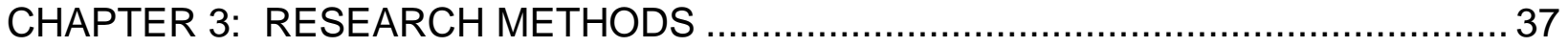

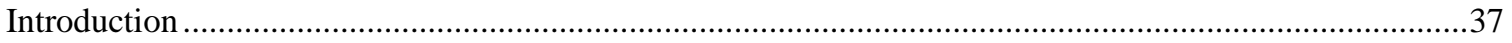

Local Road Agency Survey...............................................................................................................37

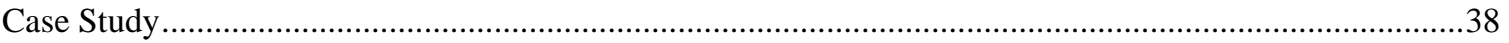

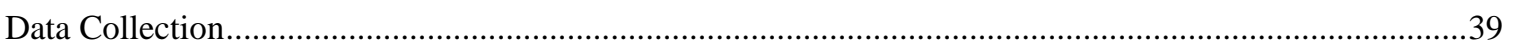

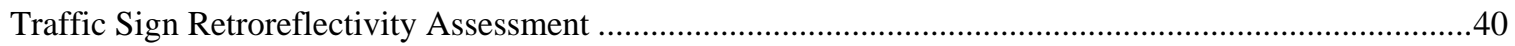

Microsoft Excel Spreadsheet Inventory ……...........................................................................................40

CHAPTER 4: RESULTS AND ANALYSIS OF TRAFFIC SIGN INVENTORY SURVEY

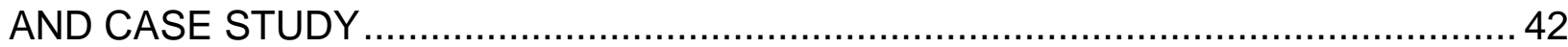

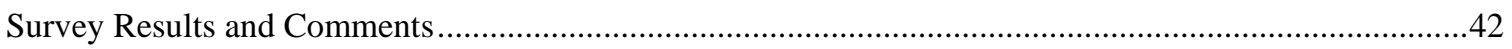

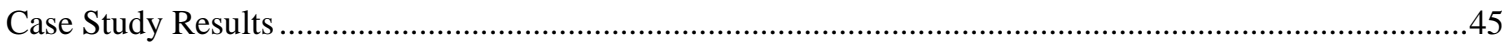


Case Study Traffic Sign Populations and Retroreflectivity Assessment .....................................................45

CHAPTER 5: THEORETICAL MODEL OF OBSERVED LIGHT INTENSITY FROM

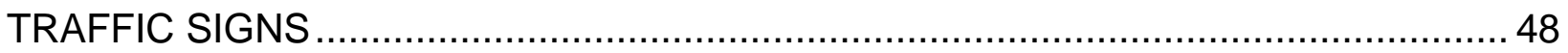

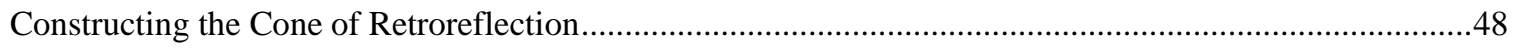

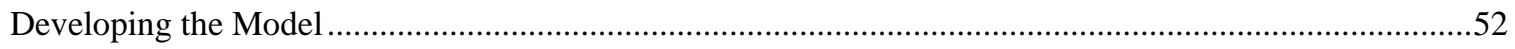

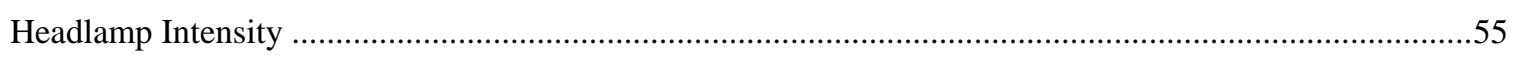

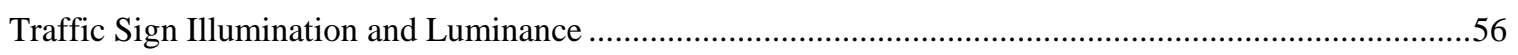

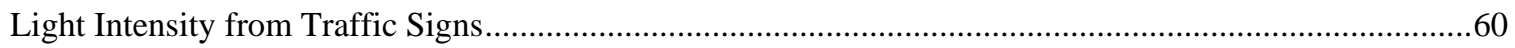

Theoretical Observed Light Intensity from Traffic Signs Reduced by Distance from Illumination Axis.....60

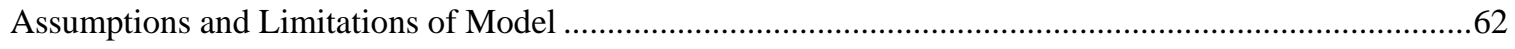

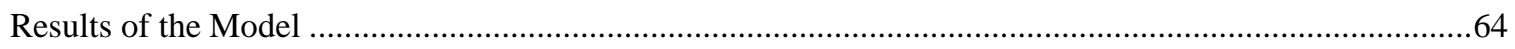

CHAPTER 6: CONCLUSIONS AND RECOMMENDATIONS .................................. 74

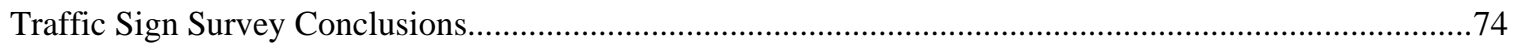

Traffic Sign Inventory and Retroreflectivity Assessment Conclusions........................................................74

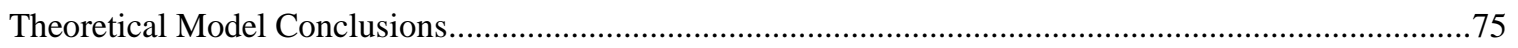

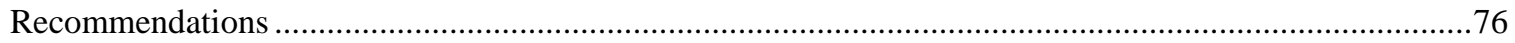

Traffic Sign Inventory and Retroreflectivity Management ..............................................................76

Modeling Observed In-Field Traffic Sign Intensity ………............................................................77

Other Ideas for Improving Traffic Sign Recognition Under Dark Conditions.................................77

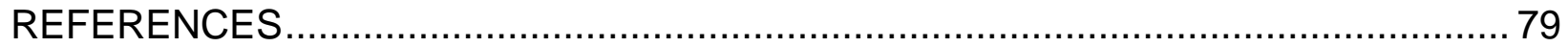

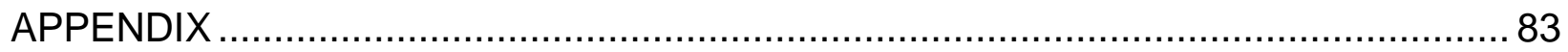

\section{LIST OF TABLES}

Table 1: Minimum Maintained Retroreflectivity Levels .................................................... 9

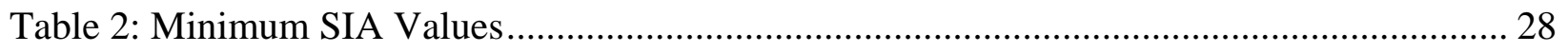

Table 3: West Virginia Incorporated Municipality Survey: Traffic Sign Inventory Statistics..... 43

Table 4: West Virginia Incorporated Municipality Survey: Traffic Sign Retroreflectivity

Compliance Method Statistics....

Table 5: West Virginia Incorporated Road Agency Survey: Traffic Sign Maintenance Annual

Budget Statistics 
Table 6: Summary of Shinnston’s in-field Traffic Sign Retroreflectivity 47

Table 7: Design Vehicle Dimensions 63

\section{LIST OF FIGURES}

Figure1: Retroreflective Optical Systems .......................................................................... 2

Figure 2: Retroreflective Degradation Over Time (Type III Yellow Signs) .............................. 3

Figure 3: National Day and Night Fatal Crash Rates ....................................................... 10

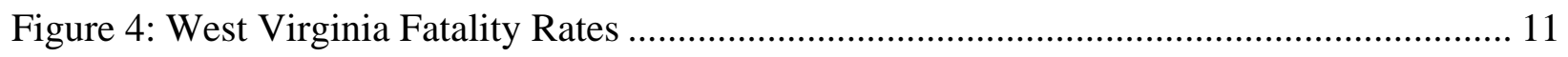

Figure 5: West Virginia Motor Vehicle Night Fatality Percentage of State Total Fatality Data.. 12

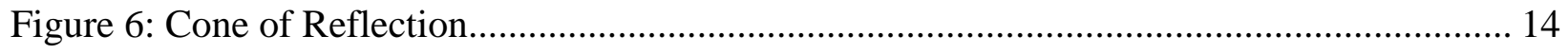

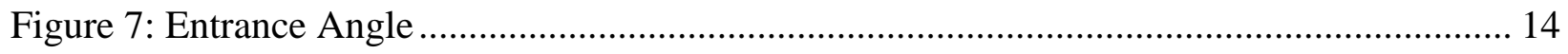

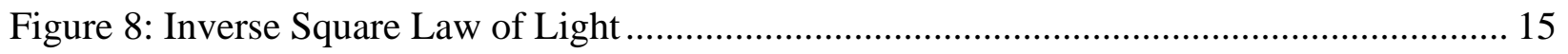

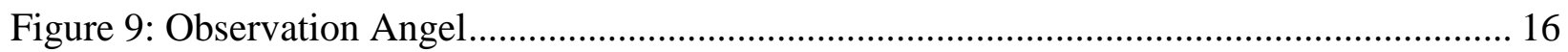

Figure 10: Retroreflectivity Dependence on Entrance Angle............................................. 17

Figure 11: Retroreflectivity Dependence on Observation Angle ......................................... 18

Figure 12: Sealed Beam (Left) and Modern Cutoff Headlamp (Right) Patterns ........................ 21

Figure 13: U.S. Road Ownership by Agency ...................................................................... 25

Figure 14: Integrated Traffic Sign Management System................................................... 31

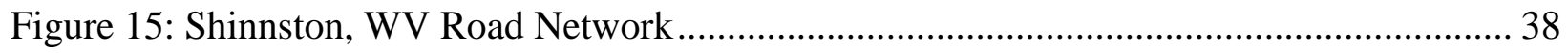

Figure 16: Point Aperture Instrument Angles.................................................................. 41

Figure 17: Lighting and Reflective Parameters .............................................................. 48

Figure 18: Visualization of Superposition of Cone of Retroreflection..................................... 50

Figure 19: Superposition Resultant Cone ..................................................................... 51

Figure 20: Geometry of Cone of Retroreflection.............................................................. 52 
Figure 21: Isocandela Plot for the CARTS Median Headlamp. .............................................. 53

Figure 22: Observation Angle as a Function of Vertical and Longitudinal Offsets ................... 54

Figure 23: Original TIN Surface of Headlamp Intensity Terminating at 1000 Candela ............. 57

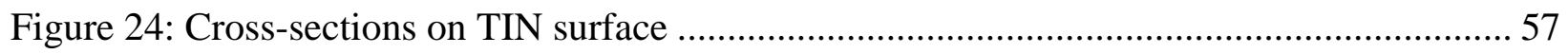

Figure 25: Extending the Intensity Curve to Zero Candela .................................................... 58

Figure 26: Measuring X Axis Distance Between 1000 and Zero Candela at Horizontal Angle of -

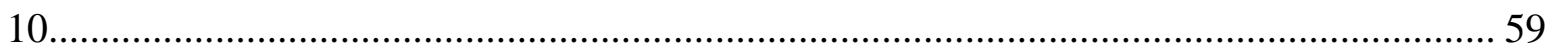

Figure 27: Constructing the Zero Candela Contour........................................................... 59

Figure 28: Fitting a Function to the Observation Angle Curve ............................................ 61

Figure 29: Observation Angle Dependence on Longitudinal Distance .................................... 65

Figure 30: Vertical Angle Dependence of Longitudinal Distance at Lateral Offset $=12$ feet vs.

Longitudinal Distance (Passenger Car) .................................................................. 66

Figure 31: Horizontal Angle Dependence of Longitudinal Distance at Lateral Offset = 12 feet vs.

Longitudinal Distance (Passenger Car) ............................................................... 66

Figure 32: Headlamp Intensity Striking Traffic Sign for Passenger Car at Lateral Offset = 12 feet

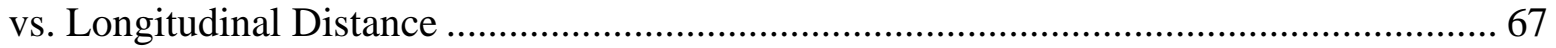

Figure 33: Headlamp Intensity Striking Traffic Sign for SUV at Lateral Offset $=12$ feet vs.

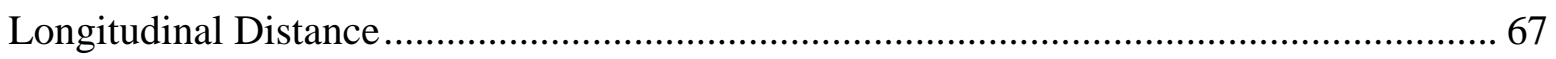

Figure 34: Headlamp Intensity Striking Traffic Sign for Heavy Truck at Lateral Offset $=12$ feet vs. Longitudinal Distance 68

Figure 35: Traffic Sign Illumination for Passenger Car at Lateral Offset $=12$ feet vs.

Longitudinal Distance 68

Figure 36: Luminosity from Driver’s Perspective at Lateral Offset $=12 \mathrm{ft}$ vs. Longitudianl

Distance

Figure 37: Luminosity from Driver's Perspective at Lateral at Longitudinal Distance $=240$ feet vs. Lateral Distance. 70 
Figure 38: Luminosity from Driver's Perspective at Lateral at Longitudinal Distacne $=640$ feet

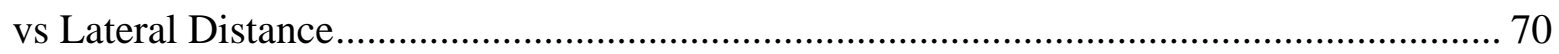

Figure 39: Observed Light Intensity from Traffic Signs at Lateral Offset $=12$ feet vs.

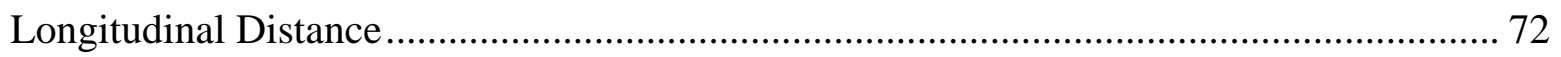

Figure 40: Observed Light Intensity from Traffic Signs at Longitudinal Distance $=240$ feet vs.

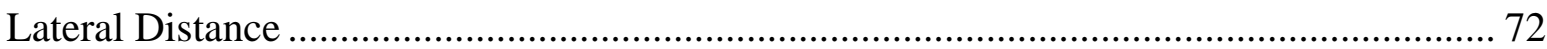

Figure 41: Observed Light Intensity from Traffic Signs at Longitudinal Distance = 640 feet vs.

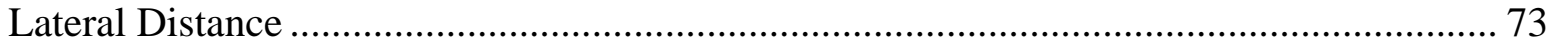




\section{CHAPTER 1 INTRODUCTION}

\section{BACKGROUND}

For the years of 2000-2007, about 45 percent of America's fatal motor vehicle crashes occurred at night in spite of the reduced traffic volume (Fatality Analysis Reporting System, 2009). According to a 2001 household travel survey conducted by the Federal Highway Administration (FHWA) and the Bureau of Transportation Statistics (BTS), 23.3\% of vehicle miles traveled (VMT) occurred between 7 pm and 6 am. Estimating that 25 percent of the VMT occur at night, the nighttime driving fatality rate is nearly three times as high as the daytime fatality rate (Nighttime Visibility Fact and Statistics, 2008). A contributing factor to the higher fatality rate at night is the reduced ability of motorists to be informed by visual cues. Therefore, motorists often rely on traffic control devices (TCD) under dark conditions for information, warnings, and guidance. This study focuses on the visibility of traffic signs under dark conditions.

The visibility of traffic signs at night is directly related to a material property called retroreflectivity. Retroreflection is an optical property of an object to return incident light back to its source (Carlson and Lupes, 2007). In the case of traffic signs, retroreflection is achieved by the use of either spherical beads or micro-prisms (Figure 1). However, the retroreflective properties of both of these sheeting materials degrade overtime. While performance curves have been studied, a reliable relation of retroreflection degradation over time has not been established (Figure 2). Nevertheless, it is known that environmental conditions such as exposure to UV radiation, de-icing materials, moisture and pollutants cause traffic signs to lose their retroreflective properties (Carlson and Lupes, 2007). 

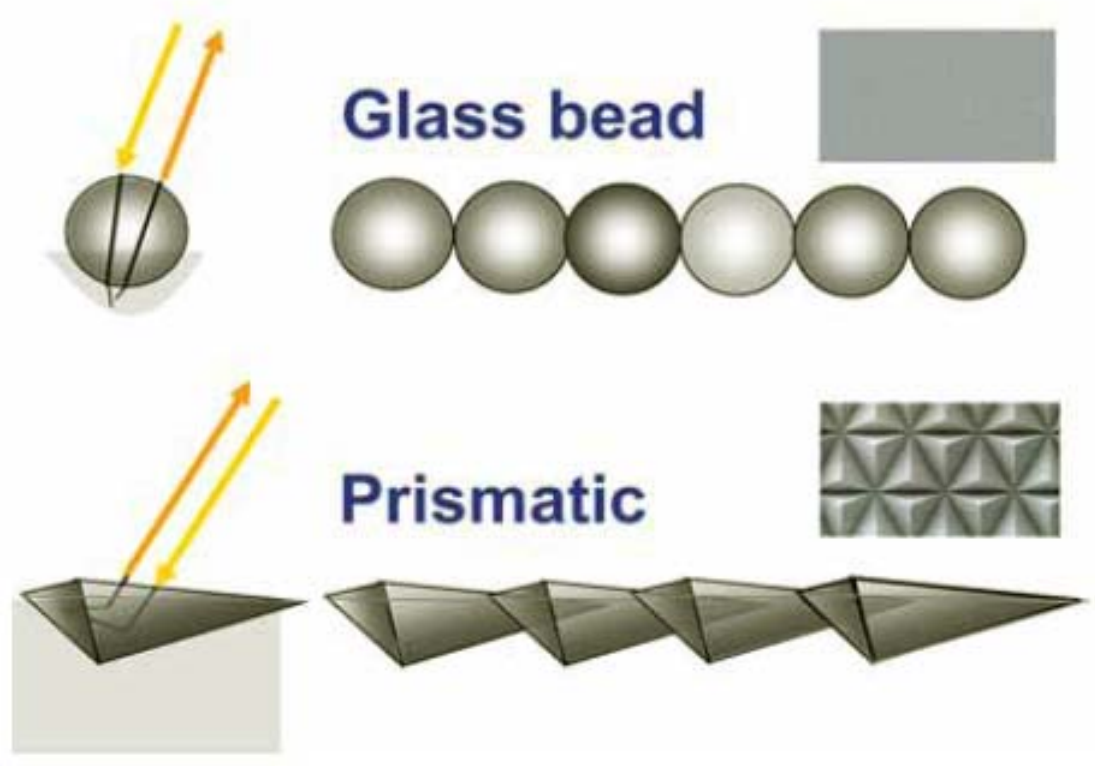

Figure1: Retroreflective Optical Systems

Source: Lloyd, John. Understanding Retroreflectivity: A Brief History of Retroreflective Sign Face Sheeting Materials. Retroreflective Equipment Manufacturers Association. Lancashire, United Kingdom, 2008. 


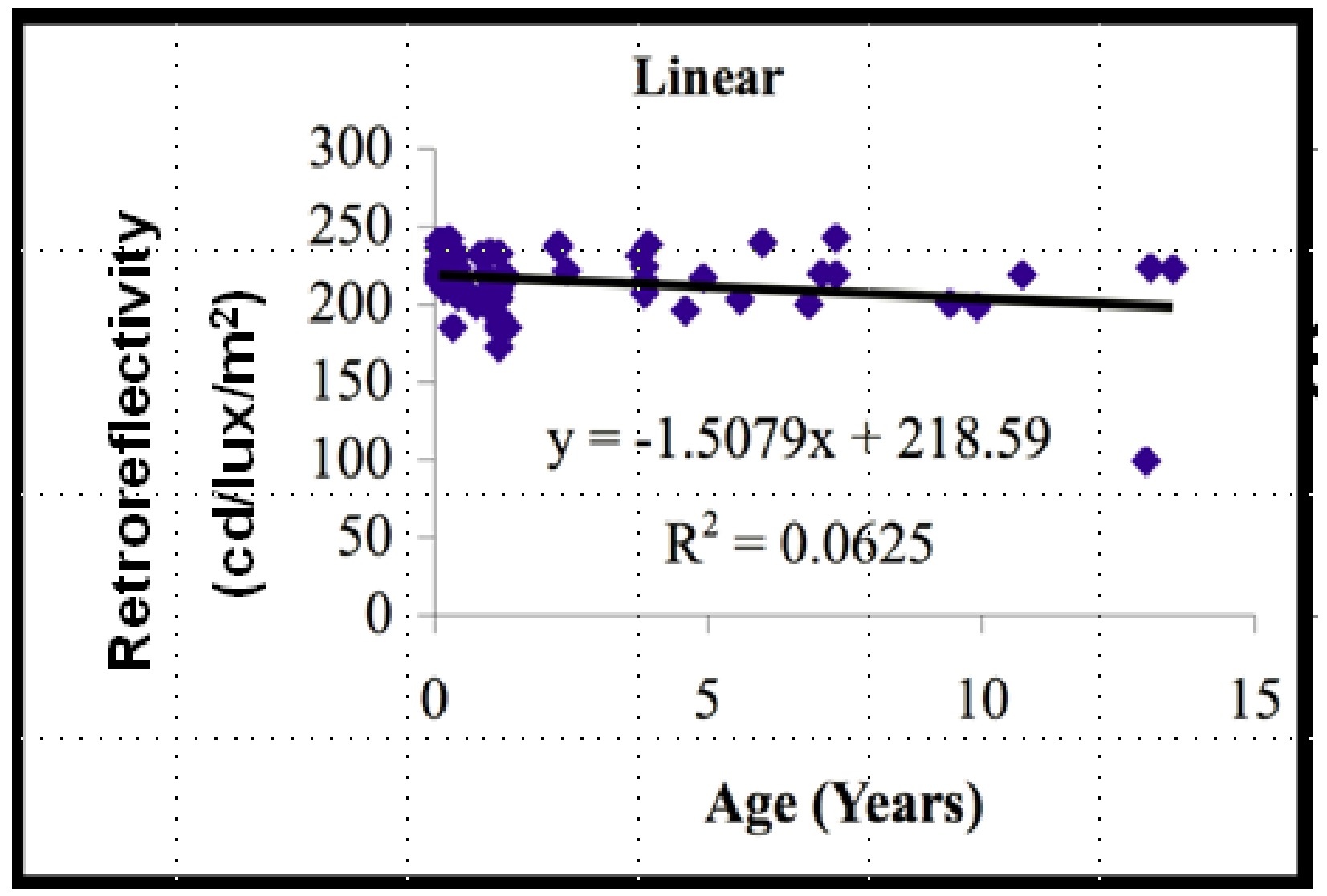

Figure 2: Retroreflective Degradation Over Time (Type III Yellow Signs)

Source: Modified Version from: Rasdorf, William J., Joseph Hummer, Elizabeth A. Harris, Venkata Pavan K Immaneni, and Chunho Yeom. Designing an Efficient Nighttime Sign Inspection Procedure to Ensure Motorist Safety. Report No. FHWA/NC/2006-08, North Carolina Department of Transportation, Raleigh, NC, 2006

Congress directed the secretary of transportation to address the issue of traffic sign visibility and pavement markings under dark conditions in the Department of Transportation Appropriations Act of 1993. The legislation required the secretary of transportation to develop minimum levels of retroreflectivity for traffic signs and pavement markings for all roads open to public travel (MUTCD Rulemaking - Signs, 2008). Research performed by the FHWA, the American Association of State Highway and Transportation Officials (AASHTO) Special Task force on Retroreflectivity, and other groups led to revisions of the Manual on Uniform Traffic 
Control Devices (MUTCD, 2003) to include allowable sign sheeting materials, minimum levels of traffic sign retroreflectivity, and recommended methods for maintaining the minimum levels. (MUTCD, revised 2007).

The revisions to the MUTCD also set milestones for road agencies to come into compliance with the new sign retroreflectivity standards. These milestones include (FHWA-SA07-020, 2007):

1. January, 2012: Deadline to implement a sign management or assessment method.

2. January, 2015: Deadline to replace regulatory, warning and ground mounted guide signs (excluding street name and parking signs) identified by the management or assessment method as not meeting the minimum levels.

3. January, 2018: Deadline to replace street name signs and overhead guide signs identified by the management or assessment method as not meeting the minimum levels.

While the MUTCD describes strategies for maintaining minimum traffic sign retroreflectivity, it does not require these strategies to be part of a total sign management system (SMS). However, a SMS provides a means for organizing information that can be used to make decisions on when a traffic sign has reached the end of its useful life, i.e., has retroreflectivity below the minimum (Improving Traffic Sign Management Process, 2008).

\section{PROBLEM STATEMENT}

The new MUTCD standards on traffic sign retroreflectivity have been promulgated to improve nighttime driving safety on all roads open to public travel. This includes roads under the jurisdiction of local road agencies which may lack the resources such as management systems, money, and personnel to comply with these new standards. While a SMS is not a requirement 
included in the MUTCD retroreflectivity standards, the FHWA promotes the opportunity for road agencies to upgrade their sign management methods as a tool for complying with the new standards. Other studies on the fiscal impact, as well as the impact on sign maintenance practices on the local agency level have shown varying results. This thesis evaluated the impact of the new MUTCD traffic sign retroreflectivity standards on a local road agency without an existing SMS in West Virginia. Also, the development and results of a basic theoretical model for predicting observed light intensity from traffic signs was developed.

\section{OBJECTIVE}

The first goal of this thesis was to assess the impact of the new MUTCD sign retroreflectivity requirements on a local road agency in the state of West Virginia. An assessment was performed via a case study of a local road agency and included the effort to build a basic traffic sign inventory using Microsoft Excel, as well as measuring and recording traffic sign retroreflectivity.

Additionally, this thesis presents a theoretical model for predicting observed light intensity from traffic signs. Ultimately, the model could be used to determine traffic sign size, sheeting material and location to maximize retroreflectivity at critical distances at which motorists are safely and effectively informed. The observed luminance model is a function of the target traffic sign size and sheeting material, the vehicle headlamp intensity pattern, and the horizontal, vertical, and lateral offsets between the motorist's eye, each respective vehicle headlamp, and the target traffic sign. 


\section{SCOPE AND LIMITATION}

The current state of West Virginia's local road agencies sign management was evaluated with a survey (included in Appendix). The survey was sent to all 232 of West Virginia’s incorporated municipalities. Next, the effort to build a SMS from the ground up, including retroreflectivity measurements, using Microsoft Excel was evaluated by a case study in the town of Shinnston, WV.

The effort to build the SMS included creating a basic traffic sign inventory with the following fields: sign location, sign type, sign size, vertical and horizontal offset from the edge of the road surface, installation date if available and retroreflectivity measurement and date of measurement of non-overhead traffic signs, not including street name signs or parking signs, following the American Society for Testing and Materials (ASTM) standard E1709- Standard Test Method for Measurement of Retroreflective Signs Using a Portable Retroreflectometer at a 0.2 Degree Observation Angle. The inventory case study did not investigate the traffic sign sheeting type.

The model of theoretical observed light intensity from traffic signs considers a flat, straight road with no environmental lighting. The data presented in this paper analyzed a Type III, 36 X 36 inch warning sign using the same headlamp intensity pattern for 3 design vehicles: a passenger car, a SUV and a heavy truck (interstate semi trailer).

\section{ORGANIZATION OF THESIS}

The thesis includes six chapters. Chapter one is the introduction to the thesis. Chapter two contains the literature review. Chapter three describes the research methods. Chapter four presents the results and analysis of the traffic sign inventory survey and case study. Chapter five 
is the development and results of a theoretical model of observed light intensity from traffic signs. Finally, Chapter six is the conclusions and recommendations. 


\section{CHAPTER 2:}

\section{LITERATURE REVIEW}

\section{BACKGROUND OF NIGHT DRIVING}

The 2003 Edition of the MUTCD defines the purpose of TCDs to, “...promote highway safety and efficiency by providing for the orderly movement of all road users on streets and highways throughout the Nation. Traffic control devices notify road users of regulations and provide warning and guidance needed for the reasonably safe, uniform, and efficient operation of all elements of the traffic stream.” Therefore, traffic signs are a primary means of communicating information to motorists under both day and night conditions. Visibility of traffic signs under dark conditions is enhanced by retroreflection.

Requirements for sign visibility under dark conditions have been included in MUTCD since the first edition in 1935 (Carlson and Hawkins, 2003). Despite the early recognition of the potential hazards of night driving, night fatalities have been over-represented since such statistics have been recorded by the National Highway Traffic Safety Administration (NHTSA) Fatality Analysis Reporting System (FARS). It was not until the 2000 edition of the MUTCD that a section (2A.09) was reserved for future guidelines on traffic sign retroreflectivity. Revision two of the 2003 edition of the MUTCD, dated December 2007 established minimum levels for traffic sign retroreflectivity (Table 1), suggested sheeting materials, as well as guidelines on how to comply with the new regulations. The new standards were developed to ensure that traffic signs are detectable, legible, and comprehensible at distances to allow motorists to safely respond under night driving conditions (Opiela and Anderson, 2007). 
Table 1: Minimum Maintained Retroreflectivity Levels

Table 2A-3. Minimum Maintained Retroreflectivity Levels ${ }^{(1}$

\begin{tabular}{|c|c|c|c|c|c|c|}
\hline \multirow{3}{*}{ Sign Color } & \multicolumn{5}{|c|}{ Sheeting Type (ASTM D4956-04) } & \multirow{3}{*}{$\begin{array}{l}\text { Additional } \\
\text { Criteria }\end{array}$} \\
\hline & \multicolumn{3}{|c|}{ Beaded Sheeting } & \multicolumn{2}{|c|}{ Prismatic Sheeting } & \\
\hline & I & II & III & \multicolumn{2}{|c|}{ III, IV, VI, VII, VIII, IX, X } & \\
\hline \multirow{2}{*}{ White on Green } & $\mathrm{W}^{*} ; \mathrm{G} \geq 7$ & $\mathrm{~W}^{\star} ; \mathrm{G} \geq 15$ & $\mathrm{~W}^{*} ; \mathrm{G} \geq 25$ & $W \geq 2$ & $\geq 25$ & Overhead \\
\hline & $W^{*} ; G \geq 7$ & \multicolumn{4}{|c|}{$\mathrm{W} \geq 120 ; \mathrm{G} \geq 15$} & Ground-mounted \\
\hline \multirow{2}{*}{$\begin{array}{c}\text { Black on Yellow } \\
\text { or } \\
\text { Black on Orange }\end{array}$} & $\mathrm{Y}^{*} ; \mathrm{O}^{*}$ & \multicolumn{4}{|c|}{$Y \geq 50 ; O \geq 50$} & (2) \\
\hline & $\mathrm{Y}^{\star} ; \mathrm{O}^{\star}$ & \multicolumn{4}{|c|}{$Y \geq 75 ; O \geq 75$} & (3) \\
\hline White on Red & \multicolumn{5}{|c|}{$W \geq 35 ; R \geq 7$} & (4) \\
\hline Black on White & \multicolumn{5}{|c|}{$W \geq 50$} & - \\
\hline \multicolumn{7}{|c|}{$\begin{array}{l}\text { (1) The minimum maintained retroreflectivity levels shown in this table are in units } 0 \\
\text { observation angle of } 0.2^{\circ} \text { and an entrance angle of }-4.0^{\circ} \text {. } \\
\text { (2) For text and fine symbol signs measuring at least } 1200 \mathrm{~mm} \text { ( } 48 \mathrm{in} \text { ) and for all siz } \\
\text { (3) For text and fine symbol signs measuring less than } 1200 \mathrm{~mm} \text { ( } 48 \text { in) } \\
\text { (4) Minimum Sign Contrast Ratio } \geq 3: 1 \text { (white retroreflectivity } \div \text { red retroreflectivity) } \\
\text { * This sheeting type should not be used for this color for this application. }\end{array}$} \\
\hline \multicolumn{7}{|c|}{ Bold Symbol Signs } \\
\hline \multicolumn{2}{|c|}{$\begin{array}{l}\text { - W1-1, -2 - Turn and Curve } \\
\text { - W1-3, -4 - Reverse Turn and } \\
\text { Curve } \\
\text { - W1-5 - Winding Road } \\
\text { - W1-6, -7 - Large Arrow } \\
\text { - W1-8 - Chevron } \\
\text { - W1-10 - Intersection in Curve } \\
\text { - W1-11 - Hairpin Curve } \\
\text { - W1-15-270 Degree Loop } \\
\text { - W2-1- Cross Road } \\
\text { - W2-2, -3 - Side Road } \\
\text { - W2-4, -5 - T and Y Intersection } \\
\text { - W2-6 - Circular Intersection } \\
\text { - W3-1 - Stop Ahead }\end{array}$} & \multicolumn{3}{|c|}{\begin{tabular}{|l} 
- W3-2 - Yield Ahead \\
- W3-3 - Signal Ahead \\
- W4-1 - Merge \\
- W4-2 - Lane Ends \\
- W4-3 - Added Lane \\
- W4-5 - Entering Roadway \\
Merge \\
- W4-6 - Entering Roadway \\
Added Lane \\
- W6-1, -2 - Divided Highway \\
Begins and Ends \\
- W6-3 - Two-Way Traffic \\
- W10-1, -2, -3, -4, -11, -12 - \\
Highway-Railroad Advance \\
Warning
\end{tabular}} & \multicolumn{2}{|c|}{$\begin{array}{l}\text { - W11-2 - Pedestrian Crossing } \\
\text { - W11-3 - Deer Crossing } \\
\text { - W11-4 - Cattle Crossing } \\
\text { - W11-5 - Farm Equipment } \\
\text { - W11-6 - Snowmobile Crossing } \\
\text { - W11-7 - Equestrian Crossing } \\
\text { - W11-8 - Fire Station } \\
\text { - W11-10 - Truck Crossing } \\
\text { - W12-1 - Double Arrow } \\
\text { - W16-5p, -6p, -7p - Pointing } \\
\quad \text { Arrow Plaques } \\
\text { - W20-7a - Flagger } \\
\text { - W21-1a - Worker }\end{array}$} \\
\hline \multicolumn{7}{|c|}{ Fine Symbol Signs - Symbol signs not listed as Bold Symbol Signs. } \\
\hline \multicolumn{7}{|c|}{ Special Cases } \\
\hline \multicolumn{7}{|c|}{$\begin{array}{l}\text { - W3-1 - Stop Ahead: Red retroreflectivity } \geq 7 \\
\text { - W3-2 - Yield Ahead: Red retroreflectivity } \geq 7 \text {; White retroreflectivity } \geq 35 \\
\text { - W3-3 - Signal Ahead: Red retroreflectivity } \geq 7 ; \text { Green retroreflectivity } \geq 7 \\
\text { - W3-5 - Speed Reduction: White retroreflectivity } \geq 50 \\
\text { - For non-diamond shaped signs such W14-3 (No Passing Zone), W4-4p (Cross Traffic Does Not Stop), or } \\
\text { W13-1, -2, -3, -5 (Speed Advisory Plaques), use largest sign dimension to determine proper minimum } \\
\text { retroreflectivity level. }\end{array}$} \\
\hline
\end{tabular}

Source: Table 2A-3 of MUTCD (2003)

National highway safety statistics have been compiled in FARS since 1975. While the national night driving fatality rate in the FARS data has been decreasing since reaching its peak in 1980 at over eight fatalities per 100 million (100M) VMT, the night rate has remained near three fatalities per 100M VMT since 1998 (Figure 3). Night as defined in FHWA-HRT-08-026, 
is the hours from 7pm until 6am, during these hours it is assumed that 25 percent of the total VMT occurs.

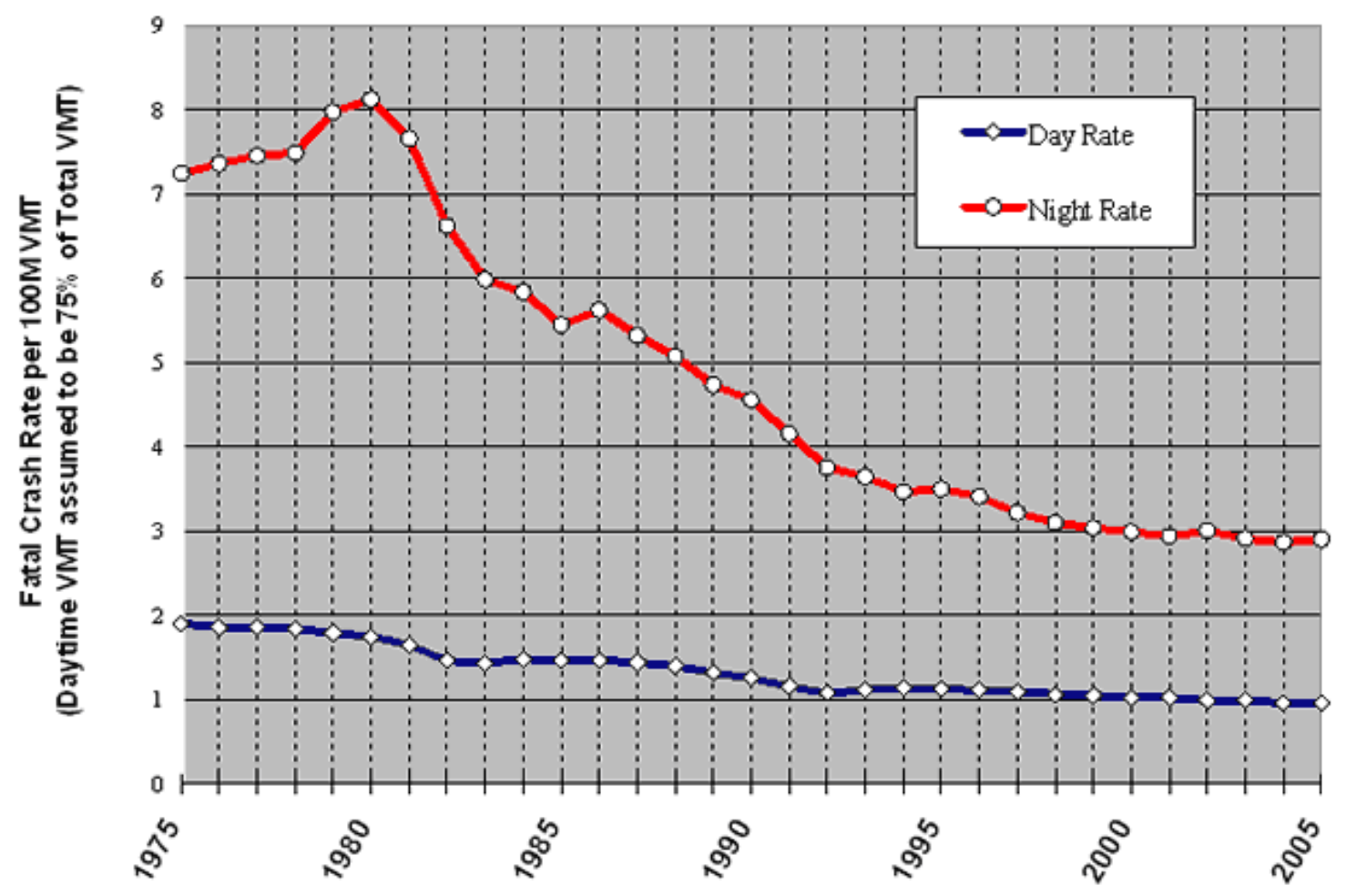

Figure 3: National Day and Night Fatal Crash Rates

Source: FHWA Safety: Driver Night Visibility Needs (2009)

In West Virginia, the percentage of fatalities occurring at night was about 41 percent from 2000-2007, compared to the national percentage of about 45 percent for the same time period. The night fatality rate per 100M VMT within the state of West Virginia from 2000-2007 was about 3.3 as compared to the national rate of 2.6. The ratio of the night fatality rate per 100M VMT to the day fatality rate from 2000-2007 in the state of West Virginia is 2.1, compared to national ratio of about 2.4. Both the night fatality rate per 100M VMT and the percentage of total fatalities occurring at night within the state of West Virginia have been on the 
rise since 2005; this after a general decrease in both statistics from 2000 until 2004 (Figures 4 and 5).

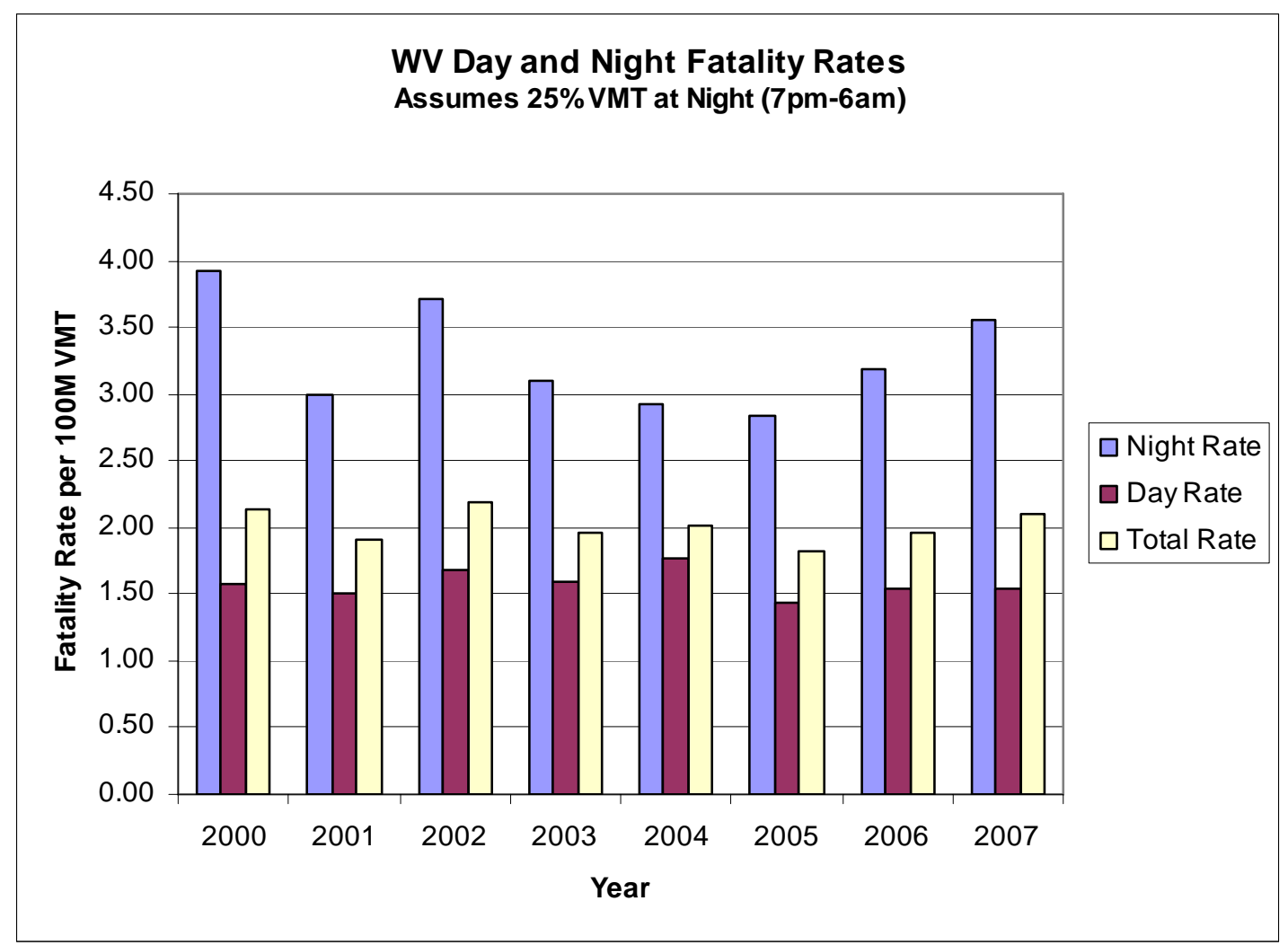

Figure 4: West Virginia Fatality Rates

Data Source: FARS (2009), night defined as 7pm - 6am 


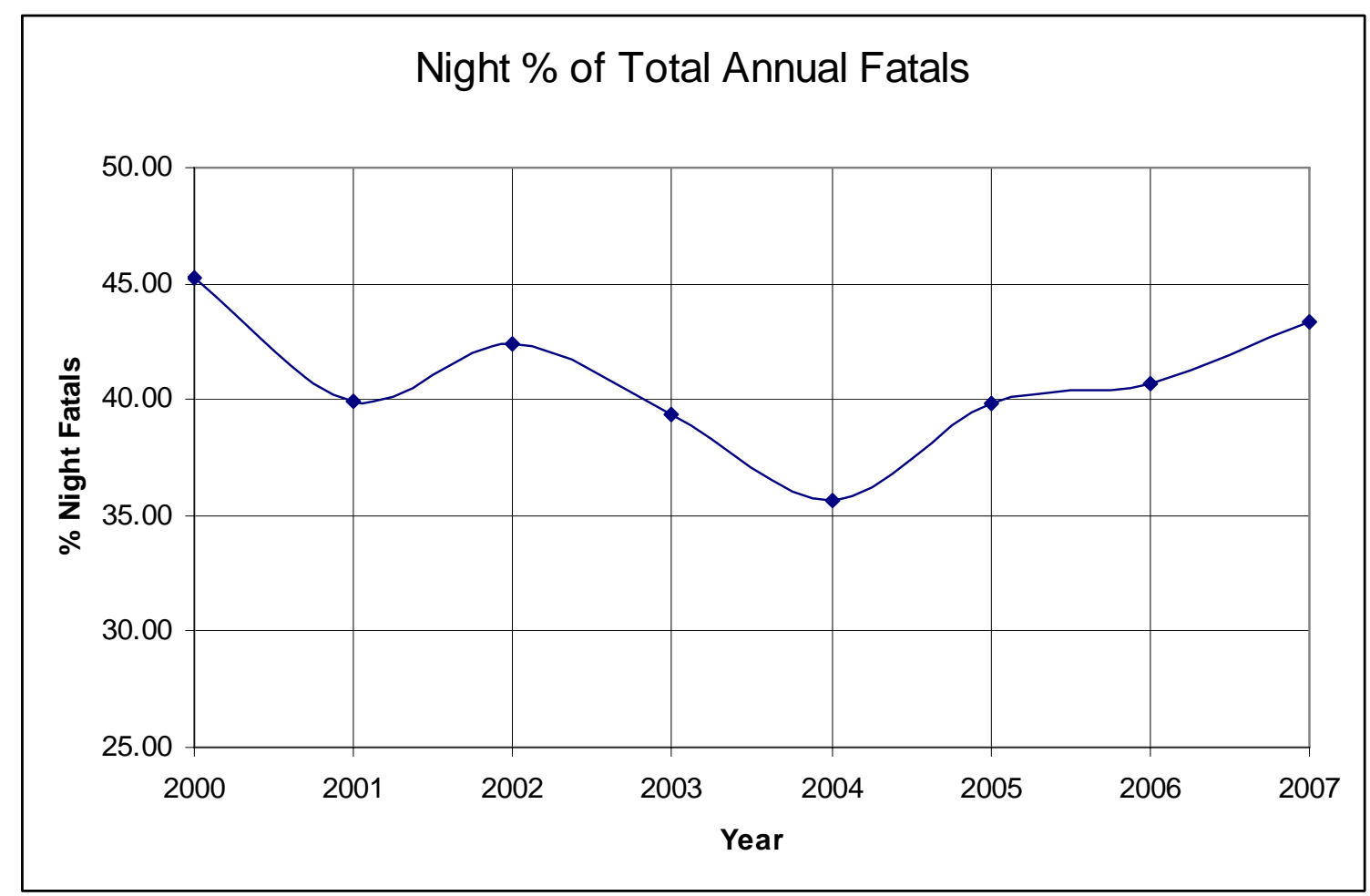

Figure 5: West Virginia Motor Vehicle Night Fatality Percentage of State Total Fatality Data Source: FARS (2009), night defined as 7pm - 6am

\section{RETROREFLECTIVITY BASICS}

Retroreflectivity is the property of an object to return light back to its source.

Retroreflection can be achieved using three optical characteristics. First, light can be sent back to its source via specular reflection, i.e. a polished surface such as a mirror. Next, light can be refracted, changing the direction of light as it passes through different mediums. Finally, light can be sent back to its source by total internal reflection; light hitting transparent material at a certain angle is reflected rather than passed through it. (Lloyd, 2008)

Glass spherical beads use refraction to send incident light back to its source. However, most of the incident light bounces off the bead, thus not passing though. For the light that does pass through, it is refracted to the rear surface of the bead. At this point more light is lost as some 
of the refracted light passes through the rear surface of the bead. Nevertheless, this problem can be solved by coating the rear surface with a thin metallic layer to reflect the light. (Lloyd, 2008) The light is then returned to the surface of the bead where it is refracted back to the original light source.

Micro-prismatic sheeting uses small three-sided pyramid shaped prisms with the base orthogonal to the incident light. Light passes through the surface and is reflected at the base and then internally reflected off the sides of the prism to return the light to its source.

Whether beads or prisms, as reflected light leaves the retroreflective sheeting material, the light is returned in a narrow cone along the illumination axis (Figure 6). In the case of the roadway environment, the light source is the vehicle headlamps. For the sign to be visible to the driver, some of the reflected light must be returned to the driver's eye, i.e., the receptor. This implies that the driver's eye must be in the "cone of retroreflection" for a traffic sign to be visible under dark conditions (What is Retroreflectivity? - THE BASICS, 2009). It is worth noting that the geometry of the cone of retroreflection is a function of both the longitudinal and the lateral distance between the light source and the target, in this case the vehicle headlamp and the traffic sign, respectively. These distances are related by the entrance angle ( $\beta$ ) (Figure 7). Specifically:

$\operatorname{Tan} \beta=\mathrm{x} / \mathrm{d}$

Therefore:

$\mathrm{d}=\mathrm{x} /(\operatorname{Tan} \beta)$ 


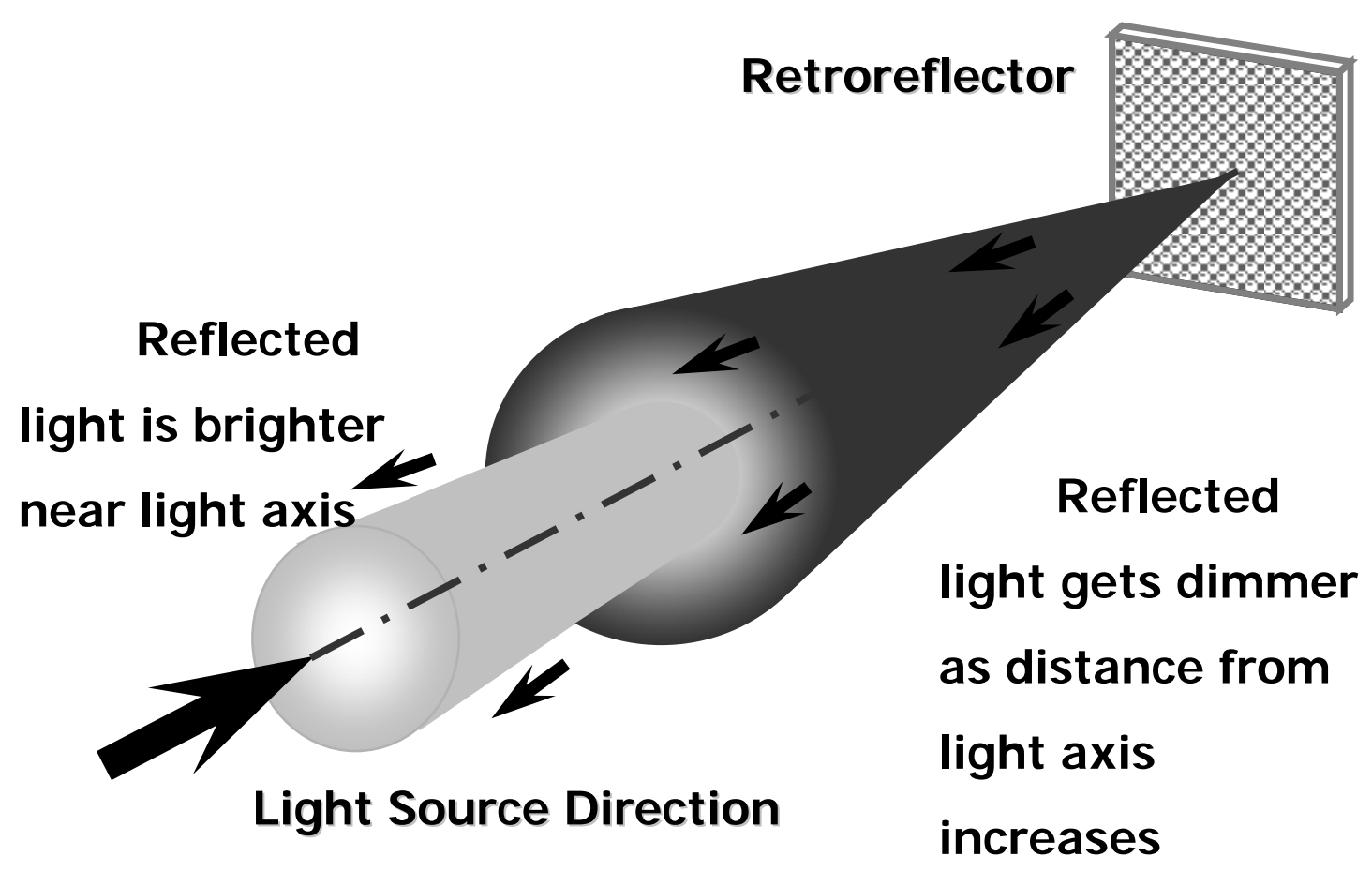

Figure 6: Cone of Reflection

Source: ATSSA Retroreflectivity Clearinghouse, 2009.

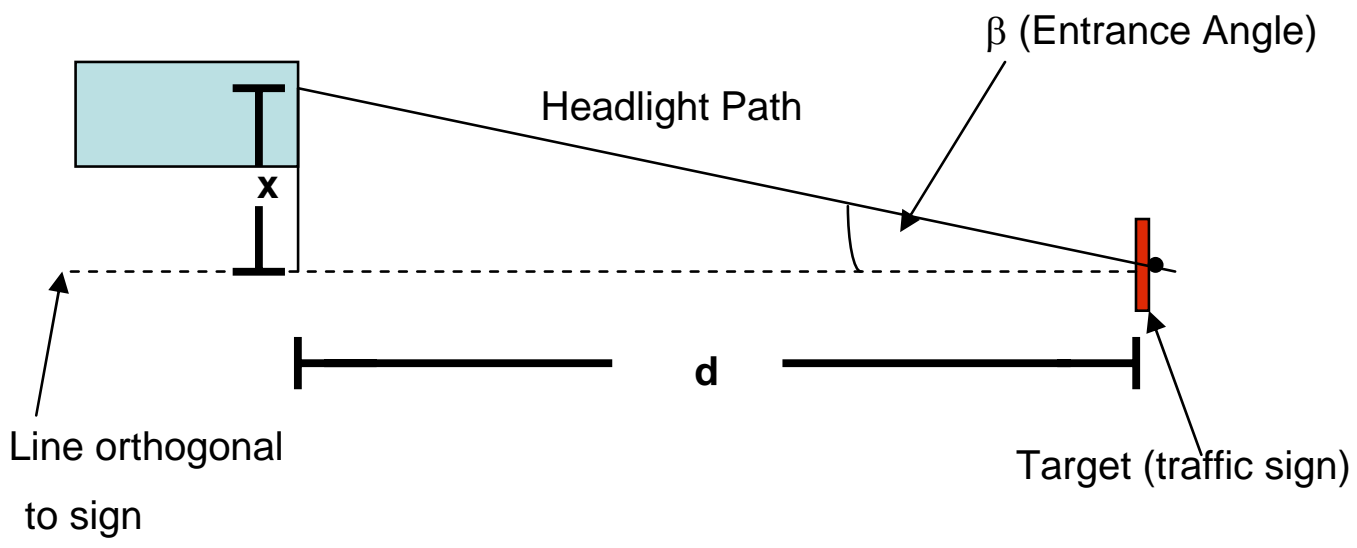

Figure 7: Entrance Angle

Source: Modified version of 3M Traffic Safety Systems Division 
It is important to note that while light is most efficiently retroreflected when $\beta$ is zero, thus resulting in a theoretical distance of infinity; this is obviously not the distance of optimum retroreflectivity. The illuminance of a light source decreases in proportion with the square of the distance from the source (Figure 8). This topic will be further discussed in the theoretical model chapter. This distance must provide enough time for the motorist, operating at the posted speed limit, to comprehend the information contained on the sign and then safely use that information. These distances, often called the minimum required visibility distance (MRVD) are based on a five step human factors process (Paniati and Mace, 1993):

1. Detect the Sign

2. Recognize/Read its message

3. Decide on appropriate course of action

4. Initiate a control response

5. Complete the required maneuver

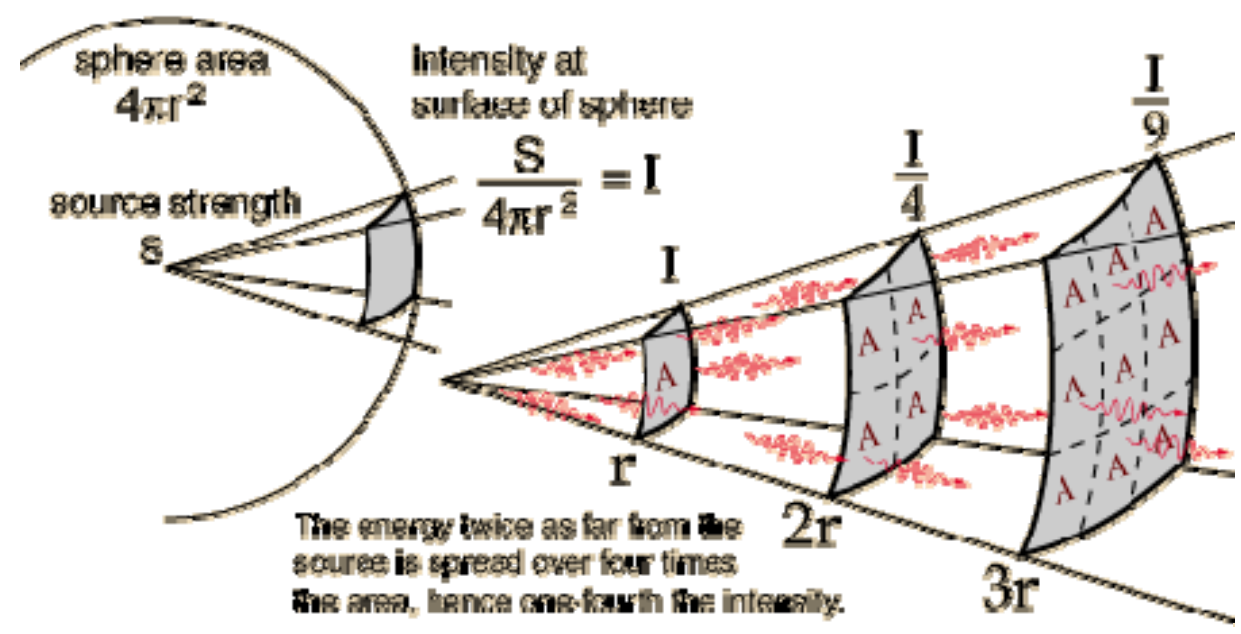

Figure 8: Inverse Square Law of Light

Source: Inverse Square Law for Light. HyperPhysics. 2000. 
Also, the distance between the headlamps and the motorist's eye affects the visibility of sign under dark conditions; this distance is related by the observation angle (Figure 9). While retroreflective sheeting materials return light to its source, this property is limited by the geometry of the retroreflective mechanisms, either the spheres or prisms. Keeping the distance between the vehicle and the traffic sign constant, light is most efficiently reflected when the incident light enters at an angle orthogonal to the reflective surface, an entrance angle of zero degrees (Figure 10), and the receptor is at the same location of the light source, an observation angle of zero degrees (Figure 11) (Carlson, 2001).

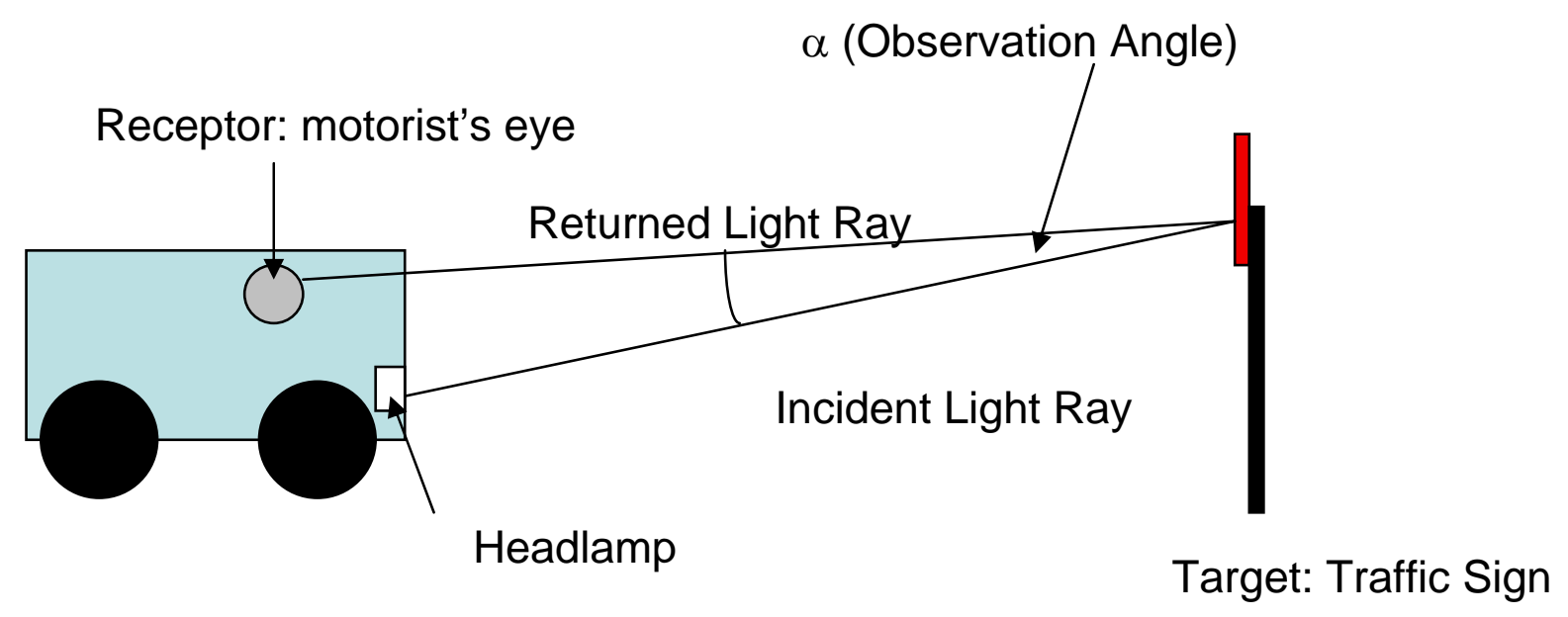

Figure 9: Observation Angel

Source: Modified version of 3M Traffic Safety Systems Division 


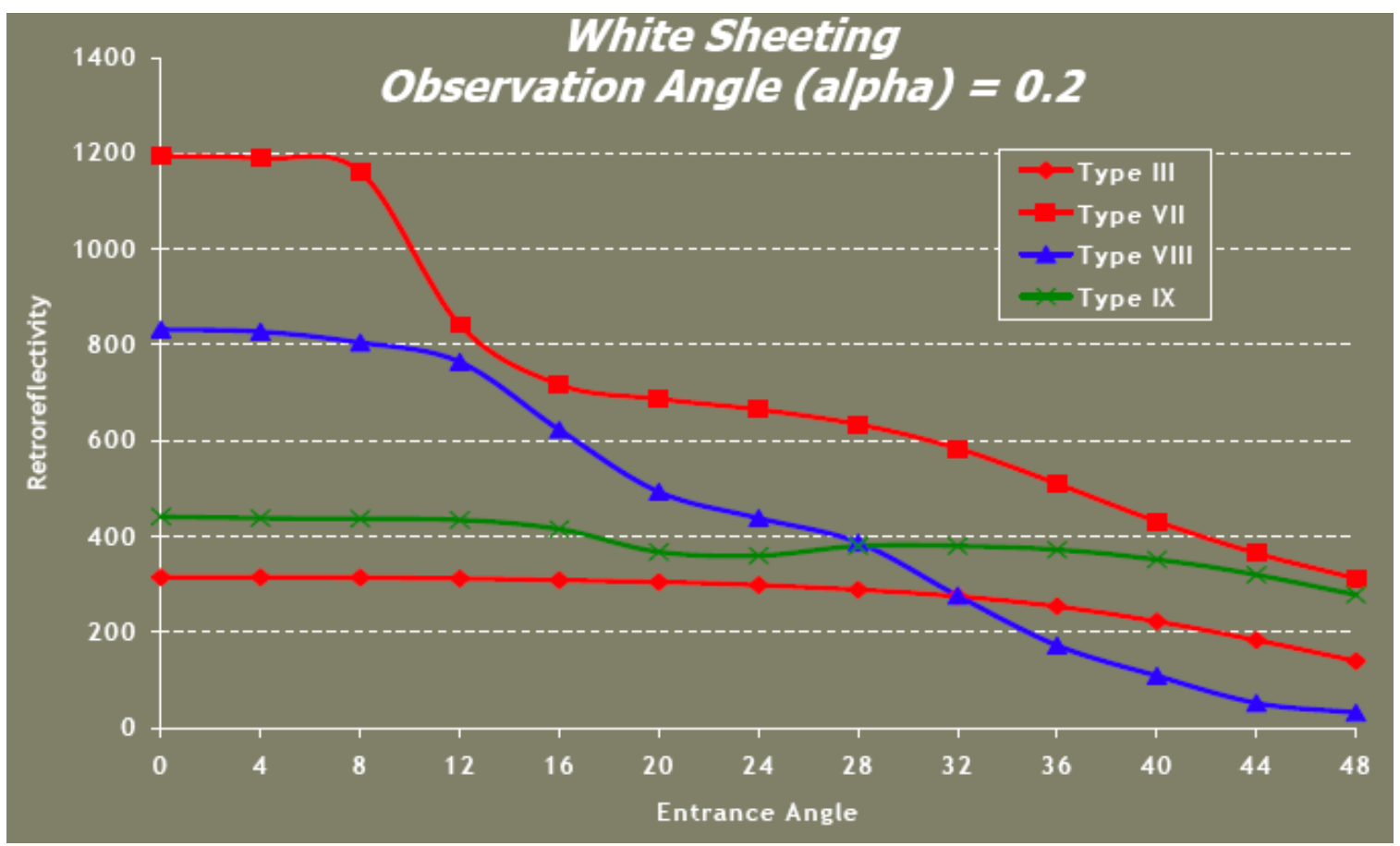

Figure 10: Retroreflectivity Dependence on Entrance Angle

Source: Schertz, Greg, et al. Traffic Sign Retroreflectivity “Sign Retro 101”. U.S. Department of Transportation Federal Highway Administration. Accessed March 19, 2009. 


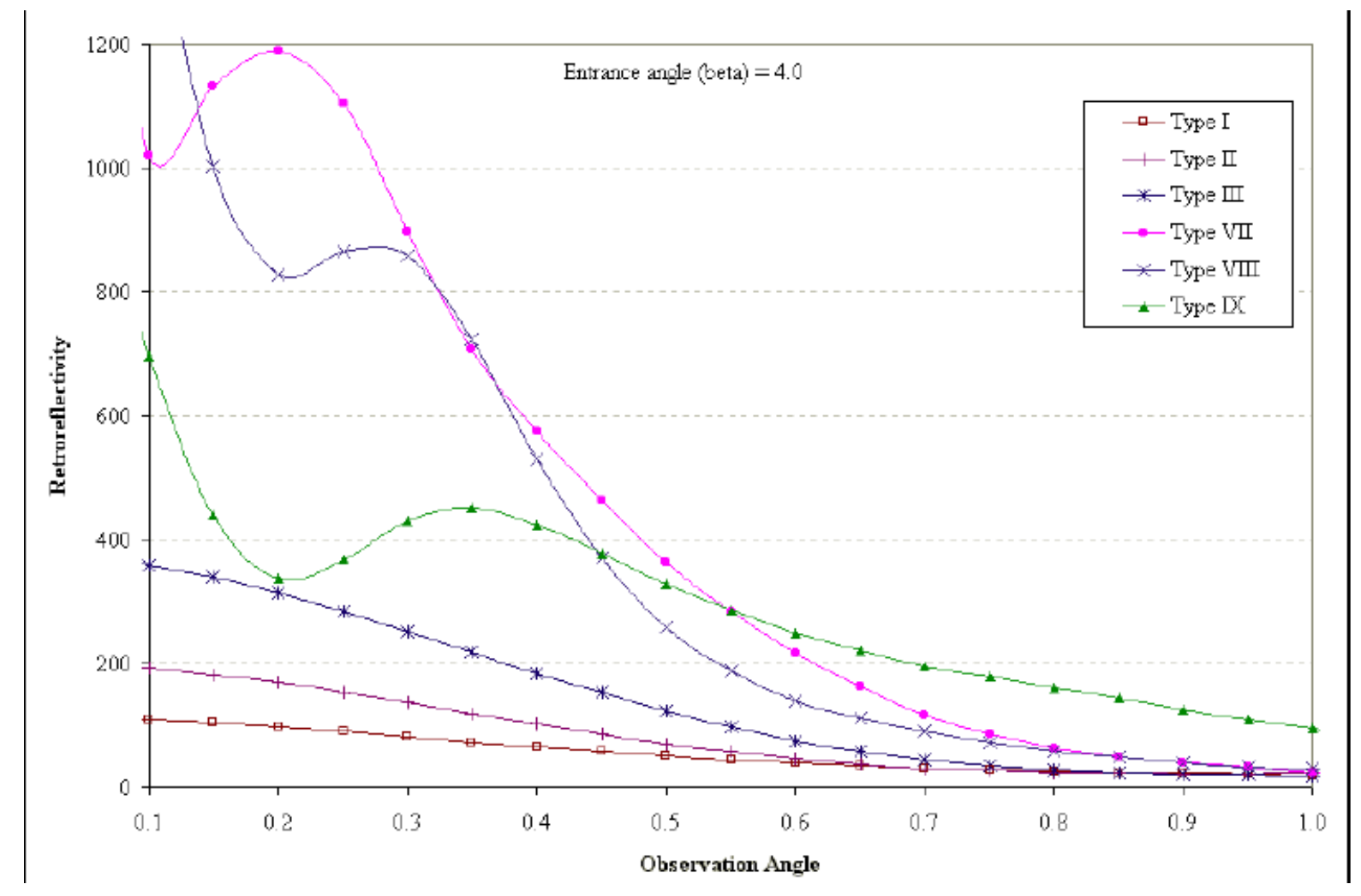

Figure 11: Retroreflectivity Dependence on Observation Angle

Source: Carlson, Paul J. Evaluation of Clearview Alphabet with Microprismatic Retroreflective Sheetings. Report No. FHWA/TX-02/4049-1, Texas Department of Transportation, Austin, Texas, 2001

\section{RETROREFLECTIVE SHEETING TYPES}

In addition to minimum traffic sign retroreflectivity levels, table 2A-3 of MUTCD (2003) also defines acceptable sheeting types for each sign color. These sheeting types are defined by the ASTM D4956-04, Standard Specification for Retroreflective Sheeting for Traffic Control. With the exception of Type XI, typical applications for all other types include permanent highway signing, construction zone devices, and delineators.

The recognized sheeting types are: 
Type I: An enclosed lens glass bead retroreflective surface referred to as "engineering grade” having medium intensity.

Type II: An enclosed lens glass bead, medium-high intensity retroreflective sheeting material called “super engineering grade.”

Type III: Typically an encapsulated glass bead retroreflective sheeting material having high intensity.

Type IV: A high intensity, micro-prismatic retroreflective sheeting material, typically made of un-metalized micro-prisms

Type V: Typically a metalized microprismatic retroreflective sheeting material having super high intensity.

Type VI: A high intensity elastomeric vinyl microprismatic retroreflective material without adhesive. Typical applications include advanced warning signs for temporary traffic control and traffic cone collars.

Type VII: A super high intensity retroreflective sheeting material typically made of unmetalized microprisms. This type of sheeting has highest retroreflective characteristics at long and medium distances.

Type VIII: A super high intensity retroreflective sheeting material typically made of unmetalized microprisms. This type of sheeting has highest retroreflective characteristics at long and medium distances.

Type IX: A very high intensity retroreflective sheeting material typically made of unmetalized microprisms. This type of sheeting has highest retroreflective characteristics at short distances. 
Type X: A super high intensity retroreflective sheeting material. This type of sheeting has highest retroreflective characteristics at medium distances.

\section{OTHER FACTORS AFFECTING RETROREFLECTIVITY}

In addition to sign sheeting material, there are several other factors that affect a traffic sign’s visibility under dark conditions. (Schertz et al., 2009) First, sign location must be considered. The lateral distance from the motorists eye as well the height of the traffic sign play a role in determining the overall visibility of the traffic sign. Second, observation angle is directly related to vehicle size and thus determines how far the motorist's eye is from the headlamps. In general, the larger the vehicle is, the larger the observation angle becomes and increasing the observation angle results in a reduction of traffic sign night visibility (Figure 11). Third, traffic sign night visibility is a function of luminous intensity, the amount of light leaving the headlamps, illuminance, the amount of light hitting the target, and the luminance, the amount of light reflected from the target. Illuminance is a function of the vehicle headlamps, which can come in one of two patterns, sealed beam and modern cutoff. While the modern cutoff pattern reduces glare for oncoming vehicles, it also reduces illuminance of traffic signs (Figure 12). In fact, supply luminance (L) of a retroreflective sign is estimated with (Carlson and Hawkins, 2003):

$\mathrm{L}=\left(\mathrm{R}_{\mathrm{A}} * \mathrm{E}\right)_{\text {left }}+\left(\left(\mathrm{R}_{\mathrm{A}} * \mathrm{E}\right)_{\mathrm{right}} / \cos \mathrm{v}\right.$

Where, $\mathrm{R}_{\mathrm{A} \text {, left }}$ and $\mathrm{R}_{\mathrm{A} \text {, right }}$ are the coefficients of retroreflection of the sign for relating to the left and right headlamps, respectively. $\mathrm{E}_{\text {left }}$ and $\mathrm{E}_{\text {right }}$ are the individual headlamp illuminance values reaching the sign. $\mathrm{Nu}(\mathrm{v})$ is the viewing angle of the sign, using the driver as the observation point, as described in ASTM E808-99. 

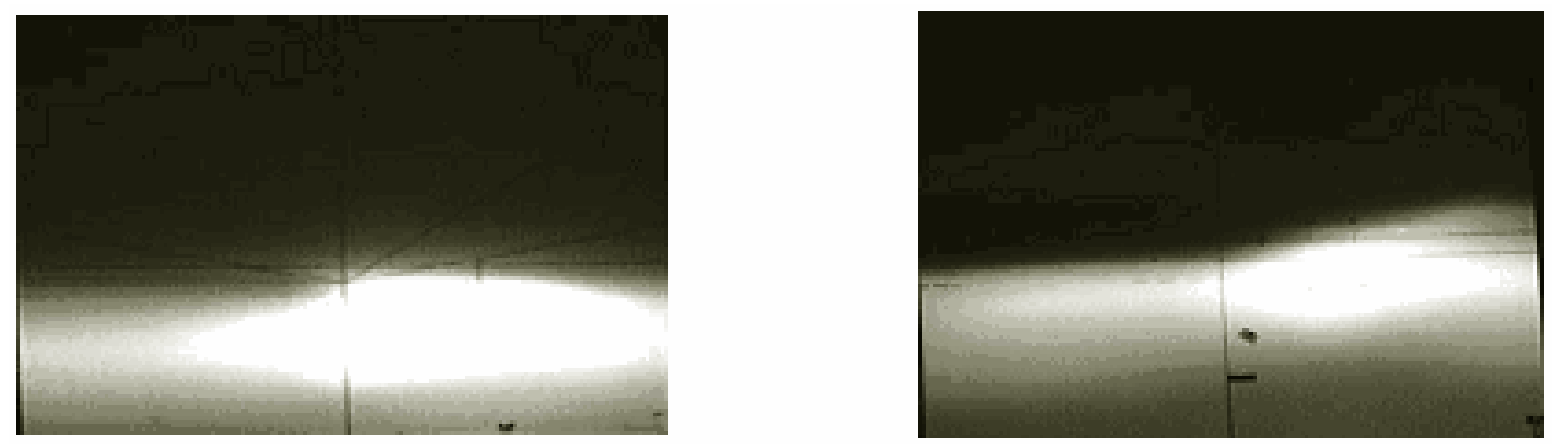

Figure 12: Sealed Beam (Left) and Modern Cutoff Headlamp (Right) Patterns

Source: How Retro is Your Reflectivity. Texas Transportation Researcher. Vol. 40, No.1, 2004.

Finally, the amount of luminance needed for the sign to be visible is affected by the motorist's visual abilities, which is strongly correlated with age. In fact, starting at age 20, the amount of light needed to see doubles every 13 years (Schertz et al.., 2009).

\section{RETROREFLECTIVITY DEGRADATION}

Overtime, traffic sign sheeting materials degrade and lose their retroreflective properties, thus reducing their ability to communicate information to motorists. While there are limited data on how sign sheeting materials deteriorate over time in a given climate, it is known that deterioration is caused by several factors, including UV-radiation, moisture, and pollutants. Additionally, a study conducted by Bischoff and Bullock (2002) found that the color of the retroreflective material also affected the degradation rate, with red signs having the quickest degradation rates in terms of retroreflectivity. With these factors in mind, several studies have been conducted to derive a relationship between deterioration and sign orientation. However, these studies (Kirk, et al. 2001, Anderson 1993, Hawkins et al. 1996, Black et al. 1991) produced different conclusions with respect to such a relationship. Nevertheless, it is evident that higher quality sheeting materials, e.g., ASTM Type VII, tend to remain above minimum retroreflective requirements longer than lower quality materials, e.g., ASTM Type I, when exposed to the same 
environment (Carlson and Lupes, 2007). Another study by Wolshon, et al. (2002), concluded Type III sheeting out performed Type I sheeting both during and after the manufacturer's warranty period.

\section{RETROREFLECTIVITY MAINTENANCE METHODS}

Revision two of the 2003 edition of the MUTCD indentifies five recommended compliance methods for keeping traffic sign retroreflectivity above minimum levels. Each method falls under one of two general descriptions, assessment method or management method.

Assessment methods require the evaluation of each individual sign. The two MUTCD recommended assessment methods are visual nighttime inspection and measured traffic sign retroreflectivity. Visual nighttime inspection requires an in-field evaluation of existing traffic signs by a trained sign inspector, conducted from a moving vehicle under night conditions. Signs indentified by the inspector to be below the minimum requirements should be replaced. On the other hand, measured traffic sign retroreflectivity calls for the use of a retroreflectometer. Field retroreflectometers come in two varieties, handheld and vehicle mounted (Schertz et al., 2009). Retroreflectometers work by illuminating the target with an internal lamp and measuring the amount of light that is returned, the luminance. The ratio of the luminance to the illuminance is called the coefficient of retroreflection $\left(\mathrm{R}_{\mathrm{A}}\right)$. Essentially (ATSSA, 2009):

$\mathrm{R}_{\mathrm{A}}=$ Light OUT (retro)/ Light IN $\left[\mathrm{cd} / \mathrm{lux} / \mathrm{m}^{2}\right]$

The ASTM E1709 standard requires a minimum four measurements of each color on the sign. These four measurements are then averaged and compared to minimum levels. Again, signs below the minimum should be replaced. 
Traffic sign retroreflectivity management methods do not require a physical evaluation of the traffic sign but rather use performance histories of a given sheeting material to predict when a traffic sign has reached the end of its service life, i.e. its measured retroreflectivity is below the minimum (Carlson and Lupes, 2007). The MUTCD describes three recommended management methods:

1. Expected sign life

2. Blanket replacement

\section{Control signs}

The expected sign life method replaces based on the anticipated performance life of the sheeting material. The performance life may be based on manufacturer's warranties or other information on retroreflectivity degradation for a given location. This method requires tracking the installation date of each sign.

The next management method is the blanket replacement method. Similar to the expected sign life method, the blanket method specifies replacing traffic signs based on expected performance life. However, the blanket replacement method does not require tracking the service life of individual signs. Instead, all signs in a given area or corridor are replaced using a schedule based on expected sign life.

Finally, the MUTCD describes the control sign method. This management method replaces signs based on the performance of a representative sample of the total sign population. The sample signs may be randomly selected in-field signs or signs in a maintenance yard. In either case, the control signs must be regularly monitored to determine the end of the service life 
for all field signs represented by the control sample. Once the control signs’ measured retroreflectivity is below the minimum, all associated in-field signs should be replaced.

Additionally, the MUTCD allows agencies to combine any of the above mentioned methods to meet their individual needs. Alternative methods may be developed based on engineering studies (MUTCD, 2003).

\section{IMPACT CASE STUDIES OF RETROREFLECTIVITY STANDARDS}

Assessing the cost impact of the new traffic sign retroreflectivity standards on a large scale basis is difficult for many reasons. The costs to comply with the new standards are a function of the condition of existing signs, current sign management practices, and agency practices on sign usage (Opiela and Anderson, 2007). However, several studies have been conducted at the state level and a few at the local level to quantify the impact of the new traffic sign retroreflectivity regulations (Bischoff and Bullock 2002, McGee and Taori 1998b, Kilgour et al. 2006, Rasdorf et al. 2006). On a national basis, county agencies own $45 \%$ of the total road length open to public travel in the United States. Towns, townships and municipalities own 31\%, followed by state agencies with 19\%, and the remaining five percent being owned by federal or other agencies (Figure 13) (USDOT, 2008). Therefore, 76\% of America’s public roads are maintained by local agencies, counties and municipalities, which often have fewer resources and weaker maintenance practices than state and federal agencies (McGee and Taori 1998a, quoted in Kilgour et al. 2006).

McGee and Taori (1998b), collected data on in field traffic sign retroreflectivity from nine local and 16 state agencies. The study estimated that five percent of signs under state agency jurisdiction and eight percent of signs under local agency jurisdiction would not meet the proposed minimum levels. Yet, it is recognized that there may be significant variations in the 


\section{U.S. Public Road Milage by Agency Ownership}

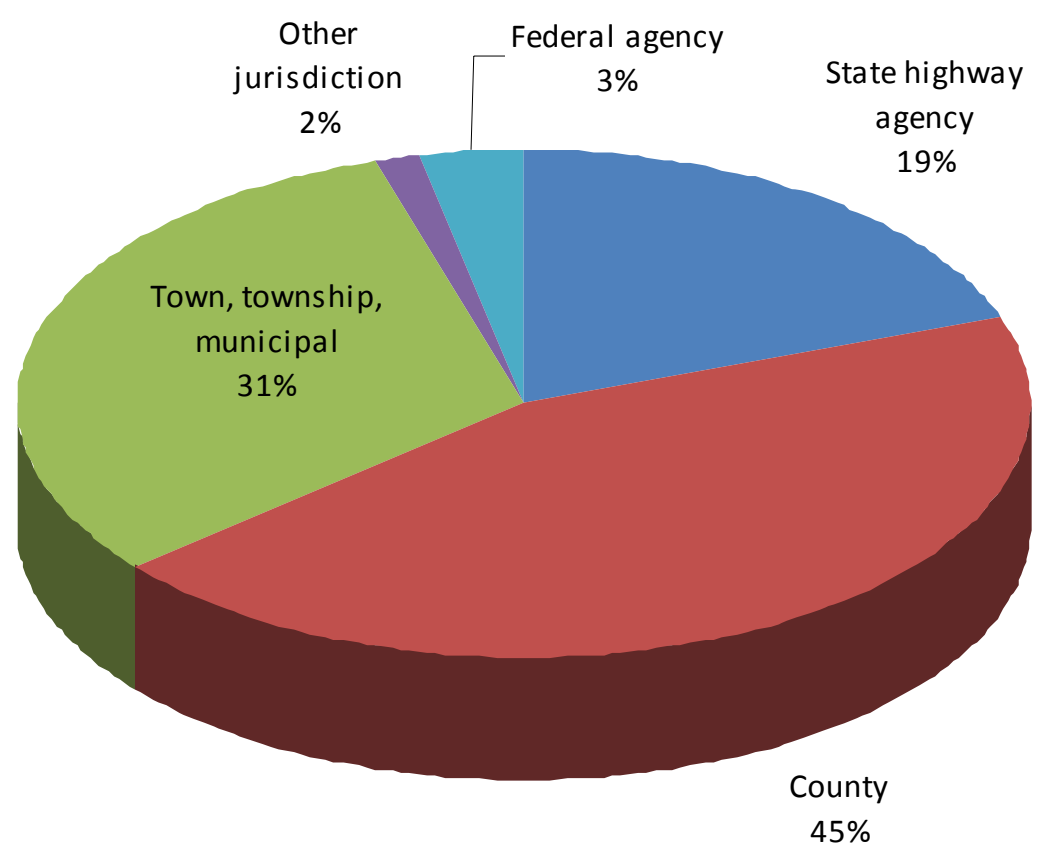

Figure 13: U.S. Road Ownership by Agency

Source: U.S. Department of Transportation, Federal Highway Administration, Highway Statistics 2006, Washington, DC: 2008, table HM-10.

percentage of signs under the minimum values at the local agency level due to differing sign management practices. For instance, before the new traffic sign retroreflectivity requirements were passed, local agencies may have used Type I sheeting, engineering grade, with less frequent replacement schedule than state agencies that may use a higher quality sheeting material such as Type III sheeting, high intensity grade. The study estimated the total cost to replace non- 
compliant signs nationwide to be \$32 million for state agencies combined and \$144 million for local agencies.

\section{LOCAL AGENCY IMPACTS}

Kilgour et al. (2006) examined the impact of the new MUTCD traffic sign retroreflectivity standards on local agencies in Indiana. The study included 182.8 miles of county roads, 29.9 miles of city roads, and 12.1 miles of town roads, there were a significant number of non-compliant traffic signs in all three jurisdictions. Counties had 33.9 percent non-compliant signs, similarly cities had 33.9 percent non-compliant signs, and towns had 39.6 percent noncompliant signs. The authors estimated non-compliant sign replacement for cities, counties, and towns in Indiana would cost $\$ 14.2$ million.

In 2007, Opiela and Anderson analyzed the national impact of the new traffic sign retroreflectivity requirements and addressed the concerns expressed by local and state agencies at workshops hosted by FHWA in 2002. The workshops generated a comprehensive list of concerns in terms of administrative, fiscal, implementation, and tort impacts. While the workshop participants suggested Federal funding assistance, the report FHWA-RD-97-053 (McGee and Taori, 1998b) stated that in terms of sign replacement costs, agencies "will not likely feel any additional impact of implementing the minimum retroreflectivity guidelines.” However, McGee and Taori did recognize the measurement of traffic sign retroreflectivity and the implementation of a sign inventory to record traffic sign retroreflectivity will impact an agency's budget. Opeila and Anderson (2007) estimated that the national sign replacement cost would be about $\$ 37.5$ million, excluding labor, equipment, and travel cost. The study used a seven year implementation period for regulatory, warning and non-overhead guide signs and a ten year implementation period for street name and overhead guide signs. Of the $\$ 37.5$ million to 
replace traffic signs, local agencies are expected to expend $\$ 25.7$ million or about 69 percent of the national total, with years one through seven of the implementation period costing \$3.1 million annually and years eight through ten costing \$1.4 million annually.

Finally, a study by Black et al. (1992) measured about 8,000 traffic signs across the county to evaluate the general condition of the nation’s traffic signs. Estimates of sign management practices including inventories, maintenance and replacement were gathered via a survey with 48 responses from state, county and city jurisdictions. The study estimated the national population of traffic signs in 1992 to be approximately 60 million, excluding street name and parking signs. The minimum retroreflectivity standards were defined using units of specific intensity per unit area (SIA). The upper and lower minimum SIA value was evaluated for each traffic sign sheeting color. The upper and lower minimum SIA values for each color were based on several factors such as driver needs and FHWA recommendations. The upper and lower values are summarized in Table 2. If a higher traffic sign retroreflectivity minimum were to be established, the study estimated that nearly 17 million or about 28 percent of the nation's traffic signs would need to be replaced.

To assess the impact on a given agency, the total number of signs under that agency’s jurisdiction needs to be known or at least estimated. The total sign population was estimated using a relationship of signs per roadway mile to jurisdiction type (city or county) based on survey responses. The survey concluded that cities have 29 signs per mile and counties have 11 signs per mile. It was assumed that sign densities for state roads were similar to sign densities for county roads and sign densities for town roads similar to sign densities for city roads. Annual sign maintenance cost included establishing a traffic sign inventory, sign inspection and replacement of non-compliant traffic signs. The estimated annual sign maintenance cost was 
Table 2: Minimum SIA Values

\begin{tabular}{|c|c|c|}
\hline \multirow{2}{*}{$\begin{array}{c}\text { Sheeting } \\
\text { Color }\end{array}$} & \multicolumn{2}{|c|}{ Minimum Retroreflectivity Values (SIA) } \\
\cline { 2 - 3 } & Lower Value & Upper Value \\
\hline Red & 8 & 21 \\
\hline Yellow & 20 & 60 \\
\hline Green & 8 & 10 \\
\hline White & 35 & 70 \\
\hline
\end{tabular}

Source: Black, K.L., H.W. McGee, and S.F. Hussain, Implementation Strategies for Sign

Retroreflectivity Standard. NCHRP Report 346, Transportation Research Board, Washington, D.C. 1992.

found to be $\$ 135$ per mile for city roads, $\$ 120$ per mile for urban county roads, and $\$ 80$ per mile for rural county areas before imposing traffic sign retroreflectivity standards. A projection of costs to comply with traffic sign retroreflectivity standards for a one, three, five and ten year implementation period was estimated on a per mile basis for state, county, city, and town jurisdictions. The projection for each implementation period evaluated both a lower and upper traffic sign retroreflectivity standard. For local agencies, the annual cost to comply with the lower standards for the five-year implementation period was $\$ 85, \$ 130$, and $\$ 99$ per mile for counties, cities, and towns, respectively. The annual cost to comply with the upper standards for the five-year period were found to be $\$ 197$, $\$ 254$, and $\$ 206$ per mile for counties, cities, and towns, respectively. The annual cost to comply with the lower standards for the ten-year implementation period was $\$ 76, \$ 101$, and $\$ 81$ per mile for counties, cities, and towns, respectively. The annual costs to comply with the upper standards for the same period were found to be $\$ 139, \$ 159$, and $\$ 137$ per mile for counties, cities, and towns, respectively. 
The study concluded the lower retroreflectivity standards to have a minor economic impact on annual per mile sign maintenance costs for the three, five, and ten year implementation periods. The cost to comply with the upper retroreflectivity standards were found to be as much as six times the pre-standard annual per mile sign maintenance cost. It was recognized that there may be significant variation in these cost estimates due to varying sign management practices for a given roadway agency (Black et al. 1992).

\section{STATE AGENCY IMPACTS}

A study of the Indiana DOT (INDOT) in-field traffic signs, predominantly Type III sheeting, conducted by Bischoff and Bullock (2001 through 2002) found that 98 percent of the traffic signs met or exceeded the minimum retroreflectivity levels proposed by FHWA-RD-97052. At that time, INDOT used a ten-year replacement cycle for traffic signs on interstate and state highways. The annual cost to replace and maintain traffic signs was based on the INDOT averages from fiscal year 2001. The average annual sign maintenance cost, defined as signs needing cleaned or replaced due to vandalism or knockdown, was \$63 per sign and the average annual sign replacement costs was $\$ 72$ per sign using the ten-year sign replacement cycle. The study found that signs with yellow or white backgrounds had retroreflectivity levels above the minimum levels for longer than ten years and thus recommended the implementation of the expected sign life for signs with yellow or white backgrounds be changed from ten years to 12 years. The estimated annual savings from this change in life expectancy of signs with white or yellow backgrounds would be at least $\$ 27,000$ per year in material costs. The study concluded that new traffic sign retroreflectivity standards would have little impact on INDOT’s traffic sign management practices. 
A study done for the North Carolina DOT (NCDOT) by Veeren et al., (2002) estimated that there were three million total traffic signs in the state, of which approximately one million signs were under state jurisdiction. The authors estimated less than three percent of the signs in the state were below the minimum traffic sign retroreflectivity standards proposed by the AASHTO Retroreflectivity Task Force. Given a seven-year implementation period, the impacts on the NCDOT would be minimal. While not required in the MUTCD traffic sign retroreflectivity standards, the authors recognize the importance of a SMS and recommend incorporating a tort claim tracking system in such a system. The cost of implementing these recommendations depends on the amount of data to be included in the SMS, but could add $\$ 80,000$ - $\$ 100,000$, not including training, rollout, or operation costs, to the statewide estimate (Vereen et al., 2002).

\section{SIGN MANAGEMENT SYSTEMS AND SIGN INVENTORIES}

“A management system can be defined as an integrated and coordinated set of policies, procedures, methods, and tools that assist decision makers in providing a product in a serviceable condition in the most cost-effective manner" (McGee and Paniati, 1998). In the case of traffic signs, a SMS is, "a coordinated program of policies and procedures which ensure that the highway agency provides a sign system that meets the needs of the user most cost-effectively within available budgets and constraints” (McGee and Paniati, 1998). In order to meet the needs of the motoring public, a SMS should have several goals including, improving quality of signage, improving the ability to manage signage throughout its life cycle, improved budgeting abilities, and providing a tool for making decisions on signage practices (Hawkins et al., 2006). In fact, "a sign management system may be worth the investment solely for its help in budgeting and scheduling” (Hawkins et al., 1996). Additional benefits of a SMS include improved tort 
defense and potential reduction in insurance premiums (Improving Traffic Sign Management Process, 2009). The implementation of such a SMS is illustrated in Figure 14.

\section{INTEGRATION OF SIGNING ACTIVITIES THROUGH THE HIGHWAY SIGNS MANAGEMENT SYSTEM}

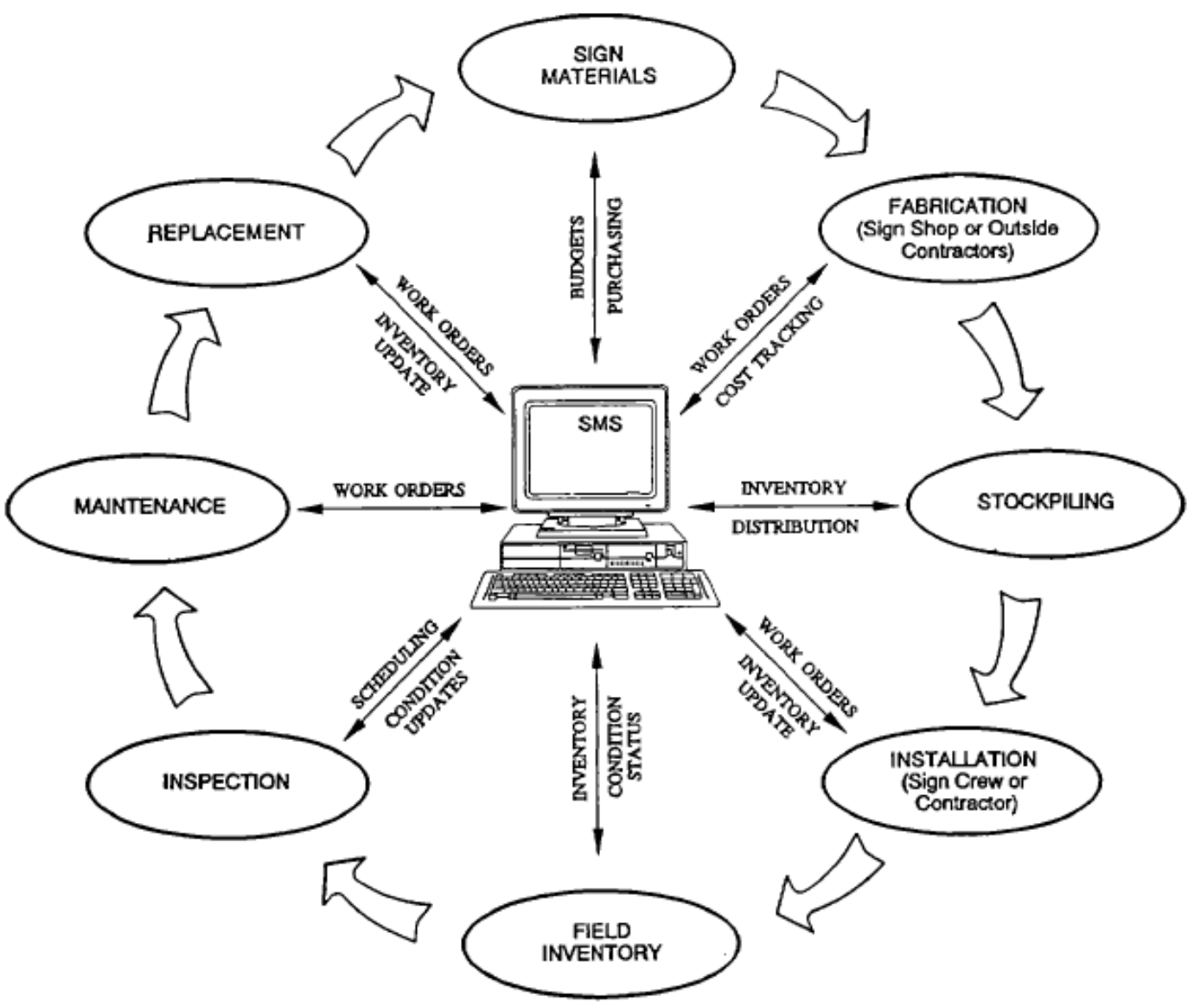

Figure 14: Integrated Traffic Sign Management System

Source: McGee, H.W. and J.F. Paniati. An Implementation Guide for Minimum RetroReflectivity Requirements for Traffic Signs. FHWA-RD-97-052, Department of Transportation, Federal Highway Administration, Washington, D.C., 1998 
The foundation of a SMS is the inventory of signs on the road network (McGee and Paniati, 1998). The traffic sign inventory can serve many functions including, targeting signs for replacement, identifying problems such as high vandalism areas, minimizing tort liability, planning and budgeting for sign replacement, and maximizing productivity of traffic sign maintenance activities (Institute of Transportation Engineers, 1997). The steps to building a successful traffic sign inventory are (Institute of Transportation Engineers, 1997 and McGee and Paniati, 1998):

1. Involving Key Personnel

2. Selecting a Location Reference System

\section{Choosing Data Elements}

\section{Selecting Inventory Software}

5. Preparing for Data Collection

6. Initial Data Collection

7. Maintaining the Inventory

While the benefits of having a sign inventory are well documented, it is also important to recognize that building a sign inventory from the ground up requires considerable costs and effort (Black et al., 1992). This fact is partially due to the amount of information that can be included in the traffic sign inventory. For example, data fields may include sign location, MUTCD sign code, maintenance activity, sheeting type, retroreflectivity, as well as many others. Therefore, each agency must carefully select what data to collect and balance those efforts with the cost to collect and maintain that data (Hawkins et al., 1996). 
With initial costs to establish a traffic sign inventory in mind, it is important to consider what percentage of road agencies has a sign inventory in place. The study conducted by Black et al. (1992) found that 33 percent of state agencies had a sign inventory. A study conducted for the Texas DOT found that 61.5 percent of agencies in the state of Texas had some form of a traffic sign inventory sign (Hawkins et al., 1996). It should be noted that a non-electronic inventory (i.e., a pen and paper system) would likely need to be updated to an electronic system, thus resulting in a presumably high cost and effort in building the new inventory system.

Electronic SMS software, which includes a traffic sign inventory package, comes in many forms. Also, stand-alone sign inventory management systems (SIMS) are available. In any case, the software may be customized programs, off-the-shelf software, or turn-key systems (Institute of Transportation Engineers, 1997). Customized programs are created to meet specific user needs. These programs may be developed in-house or contracted to software developers. However, customized programs generally come with an increased cost in development, maintenance, and support. Next, off-the-shelf software includes packages of both public domain and proprietary software. These packages range in sophistication, but generally meet the basic needs of any roadway agency. Lastly, turn-key systems are offered by firms that develop software to supplement their data collection services. This option has the potential to reduce the burden of building a sign inventory from scratch (Institute of Transportation Engineers, 1997).

\section{TRAFFIC SIGN LOCATION DATA ACQUISITION}

With so many options available, road agencies should carefully select the software that best meets their needs and resources. Some functions to consider are user-friendliness, user support, availability of basic features, and availability of desired data elements (Institute of Transportation Engineers, 1997). Another important consideration is the data acquisition format 
(Veeren et al., 2002). Traditionally, many inventories used a route and mile post reference system to track the location of roadway assets such as traffic signs. However, a task force within the Iowa DOT recognized potential downfalls with such a system. These downfalls include potential for human error in data entry, measurement and milepost reference, as well as the fact that mileposts and routes may change over time (Hawkins et al., 2006). Additionally, the limited location reference resolution of the milepost method may lead to confusion in areas of high traffic sign density. For these reasons, the Iowa DOT Task Force compared the capabilities of two sign referencing techniques based in global positioning systems (GPS) with respect to the route and milepost method. When the positions of the route and milepost method were compared to the positions of each GPS method, the average difference in sign location in both cases was found to be about 53 meters. When the sign positions of the two GPS where compared to each other, the average difference in sign location was 4.6 meters. To show the accuracy of the two GPS methods, each was compared to a High Accuracy Reference Network (HARN), a satellitebased positioning system. The accuracy of both GPS systems was near the vendor specifications. Based on these results, the Task Force concluded the GPS technique is preferred over the route and milepost method (Hawkins et al., 2006).

\section{TRAFFIC SIGN RETROREFLECTIVTY MODELS}

Several models predicting traffic sign retroreflectivity have been developed. The Exact Roadway Geometry Output (ERGO) model, created by the Avery Dennison Corporation, much like the Target Visibility Predictor (TarVIP) program created at the Operator Performance Laboratory at The University of Iowa, evaluates how well a given material returns light to its source using a single light source (Chrysler et al., 2003). While this information is useful in characterizing the performance of traffic sign sheeting types, it does not necessarily simulate a 
driving environment. The Computer Analysis of Retroreflectance of Traffic Signs (CARTS) model used by the FHWA, used only a single microprismatic sheeting, type VII (Chrysler et al., 2003). Another model created by Aktan and Schnell (2002), calculated legibility thresholds and traffic sign luminance. The program calculated luminance for a single vehicle geometry, based on sheeting type, headlamp pattern by vehicle make and model as well as atmospheric transmitivity and ambient luminance. Chrysler, et al.(2003) at the Texas Transportation Institute developed a model predicting theoretical traffic sign luminance for several retroreflective sheeting types at several longitudinal distances. Sign luminance was calculated for left shoulder, right shoulder and overhead signs, each at a single defined height and lateral offset. Lastly, a study by Hawkins and Gogula (2008) considered the affect of vertical curves on traffic sign illuminance for vehicles equipped with both sealed beam and modern cutoff headlamps. The study concluded that more recent headlamp designs have reduced the amount of light illuminating road signs, especially on vertical curves.

\section{SUMMARY OF LITERATURE REVIEW}

The studies on the impact of the new retroreflectivity standards suggest sign management practices of many state agencies are addressing the issues raised by the new MUCTD requirements and complying with standards will have little if any impact on state highway agencies. For local agencies the literature indicated varying impacts. One study found local agencies may pay up to 6 times the pre-standard sign management cost, while two studies estimated a minimal impact for local agencies. Estimating the cost to comply with the new traffic sign retroreflectivity standards on a large scale basis is difficult due to the varying sign management practices for different road agencies. 
Several theoretical models of traffic sign retroreflectivity have been developed. These studies assessed the sign illumination and retroreflectivity at the sign position. The studies did not consider light availability at the motorist's eye position. 


\section{CHAPTER 3: \\ RESEARCH METHODS}

\section{INTRODUCTION}

To assess the impact of the new MUTCD minimum retroreflectivity levels on local road agencies in West Virginia, the current state of traffic sign management practices at the local agency level was determined via survey. The survey (included in appendix) was sent out to all 232 of West Virginia's incorporated municipalities. The goal of the survey was to compile information at the local agency level on general traffic sign management practices, including awareness and implementation of the new MUTCD retroreflectivity standards.

Knowing the state of traffic sign management practices in the state of West Virginia, it was then possible to design a case study to assess the effort needed to effectively comply with the new MUTCD traffic sign retroreflectivity standards. Effective compliance assumes that retroreflectivity compliance methods be part of an electronic SMS.

\section{LOCAL ROAD AGENCY SURVEY}

The survey consisted of eight questions with subparts regarding awareness of the new traffic sign retroreflectivity requirements before receiving the survey, plans for implementation of a traffic sign retroreflectivity compliance method if not already in place, and existence and sophistication of a traffic sign inventory. The survey was supplemented with FHWA-SA-07-020, a brochure summarizing the new MUTCD traffic sign retroreflectivity standards. The survey was sent to all 232 of West Virginia's incorporated municipalities, via email, fax or mail, depending on the contact information provided in the 2008-2009 West Virginia Municipal League Directory. 


\section{CASE STUDY}

The selection of the Shinnston, WV (Figure 15) for the case study was based on the agency's representation of typical sign management practices for local agencies in the state of West Virginia (based on the survey results) and the potential benefit of participating in the study. Shinnston is located in north central West Virginia and has about 2,240 residents (City of Shinnston, 2009). The city street department has 6 crew members that are responsible for about 17.4 miles of roadway centerline.

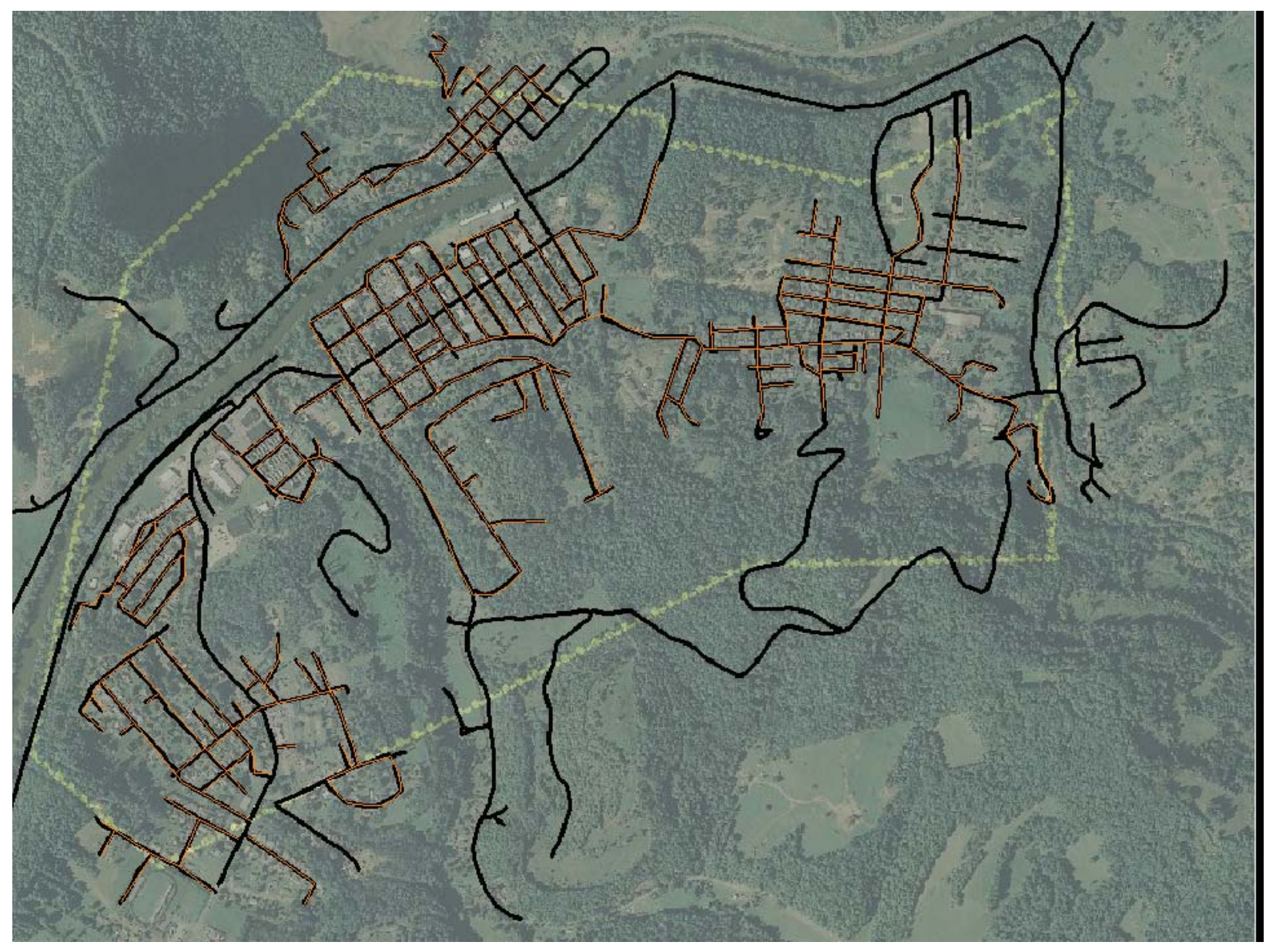

Figure 15: Shinnston, WV Road Network

Source: Modified Version of WV GIS Technical Center Map, 2009. 
Based on the results of the survey, most local agencies would have to build a traffic sign inventory from the ground up as part of a total SMS. For this study, the inventory included data collection of sign location, sign type, sign size, vertical and horizontal offset from the edge of the road surface, installation date if available and retroreflectivity measurement and date of measurement. To comply with the new MUTCD traffic sign standards, this study uses the measured retroreflectivity method, ASTM E1709- Standard Test Method for Measurement of Retroreflective Signs Using a Portable Retroreflectometer at a 0.2 Degree Observation Angle (2008). The measured retroreflectivity value and date will also be included in the inventory data. Assuming most local agencies do not have over-head signs in their jurisdiction, such signs were not included in this study. The effort to build such an inventory with an electronic SMS was assessed by measuring the time to be trained on the electronic SMS, as well as the time to gather and record inventory data, including the time to measure and average the retroreflectivity measurements for each color on each sign, as described in ASTM E1709. This study uses Microsoft Excel to build the traffic sign inventory and establish the foundation of a total SMS. Though this particular study uses the measured traffic sign retroreflectivity method, the Excel inventory spreadsheet could be used as a template for any traffic sign retroreflectivity compliance method.

\section{DATA COLLECTION}

Traffic sign data was collected on sign latitude and longitude position, sign type, sign size, lateral and horizontal offsets as defined in the MUTCD section 2A.16, name of street or intersection where the sign was located and the direction of travel the sign faced. Also included was the measured retroreflectivity following ASTM standard E1709. The sign latitude and 
longitude position was found using the Garmin eTrex handheld GPS unit. Sign size, lateral and vertical offsets were measured using a tape measure.

\section{TRAFFIC SIGN RETROREFLECTIVITY ASSESSMENT}

Assessment of traffic sign retroreflectivity was performed using the measured sign retroreflectivity method. Four measurements of the coefficient of retroreflection for each color on each sign were taken using the Delta RetroSign Type 4500 retroreflectometer. The type 4500 is a handheld point aperture retroreflectometer with an observation angle of 0.2 degrees and an entrance angle of -4 degrees (Figure 16). The individual coefficient of retroreflectivity measurements as well as the average for each color was recorded for each sign. For measurements of retroreflective text, a lens reducer was used. Using the lens reducer changes measured sign luminance. The adjustment can be made by taking measurements of the calibration cap both with and without the lens reducer. The Delta calibration cap has a $\mathrm{R}_{\mathrm{A}}=321$, which is the measurement without the lens reducer. The measurement of the calibration cap using the lens reducer is $R_{A}=86$. Therefore, the lens reducer results in a reduction of $R_{A}$ by 3.73 . The reported $\mathrm{R}_{\mathrm{A}}$ values for text are the measured values multiplied by 3.73 .

\section{MICROSOFT EXCEL SPREADSHEET INVENTORY}

While more sophisticated GIS based Roadway Asset Management Systems are available, the initial cost of such a system may be beyond the financial means of local road agencies. Microsoft Excel was chosen to build the traffic sign inventory based on its presumably low cost of implementation and ease of use. The spreadsheet provides a convenient way to electronically record traffic sign data. 


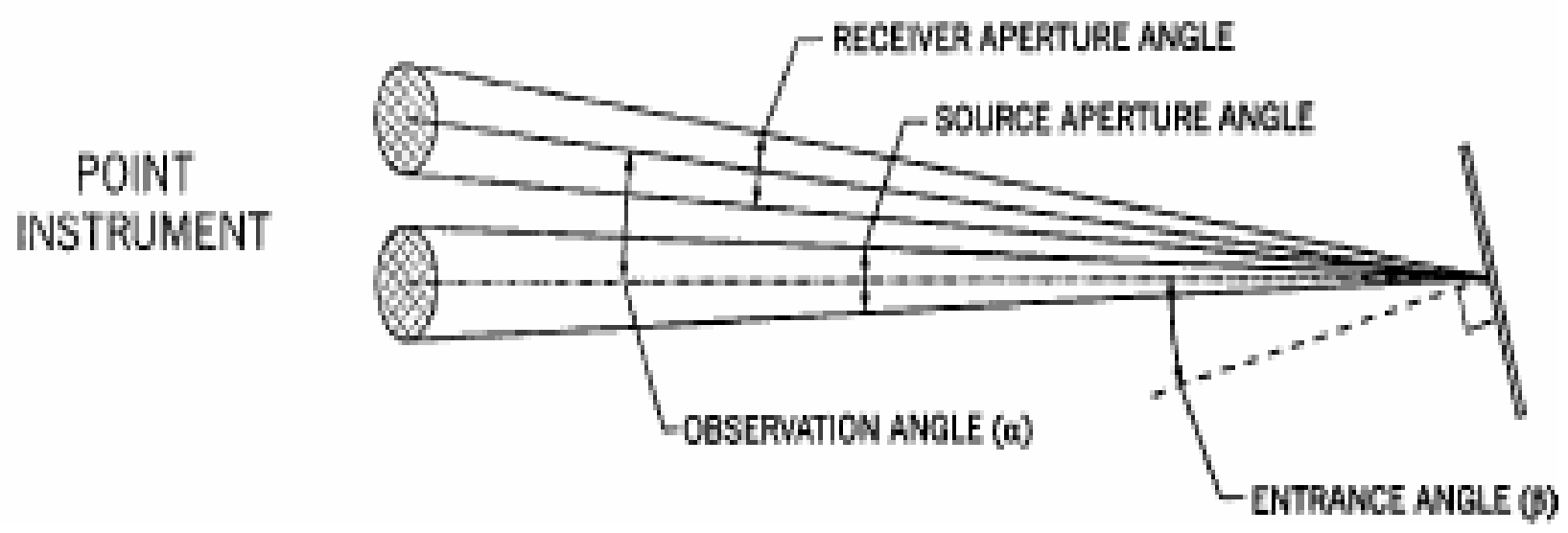

Figure 16: Point Aperture Instrument Angles

Source: Reprinted, with permission, from ASTM E1709-00e1 Standard Test Method for Measurement of Retroreflective Signs Using a Portable Retroreflectometer, copyright ASTM International, 100 Barr Harbor Drive, West Conshohocken, PA 19428

In-field data collection was done by hand and later entered into Excel, the assessment will include the man hours used to collect and then digitize the data. 


\section{CHAPTER 4:}

\section{RESULTS AND ANALYSIS OF TRAFFIC SIGN INVENTORY SURVEY AND CASE STUDY}

\section{SURVEY RESULTS AND COMMENTS}

Of the 232 surveys sent to each incorporated municipality in the state of West Virginia, 27 responses were received, resulting in a response rate of $11.6 \%$. Ten of the respondents, 37 percent, were aware of the new MUTCD regulations on minimum traffic sign retroreflectivity requirements before receiving the survey. These agencies were made aware of the new regulations by traffic sign vendors or by the West Virginia Local Technical Assistance Program (WV LTAP), housed at the West Virginia University Department of Civil and Environmental Engineering. Six of the respondents, 22 percent, had some type of a traffic sign inventory in place. None of the respondents had a traffic sign retroreflectivity compliance method in place, though 20, 74 percent, had specific plans on the implementation of some compliance method. Of the maintenance methods suggested in the MUTCD, the night time visual inspection method was the predominant method planned to be implemented, representing 19 percent of the respondents. Lastly, 10 agencies provided both total agency and traffic sign funding data. The average percentage of the total annual agency budget used for traffic sign maintenance was 1.1 percent, with four agencies having no allocated annual budget for traffic signs. Two of these agencies acquire money for traffic sign maintenance on an "as needed” basis. The summarized statistics of the survey are presented Tables 3, 4 and 5. 
Table 3: West Virginia Incorporated Municipality Survey: Traffic Sign Inventory Statistics

\begin{tabular}{|c|c|c|}
\hline Inventory Item & $\begin{array}{l}\text { Affirmative } \\
\text { Responses }\end{array}$ & Rate \\
\hline Inventory & 6 & 22 \\
\hline sign type & 4 & 67 \\
\hline sign sheeting & 3 & 50 \\
\hline sign location & 6 & 100 \\
\hline dist from road & 3 & 50 \\
\hline sign size & 3 & 50 \\
\hline date installed/replaced & 4 & 67 \\
\hline maintenance activity & 4 & 67 \\
\hline electronic inventory & 1 & 17 \\
\hline
\end{tabular}

Table 4: West Virginia Incorporated Municipality Survey: Traffic Sign Retroreflectivity Compliance Method Statistics

\begin{tabular}{|l|c|c|}
\hline \multicolumn{1}{|c|}{ Retroreflectivity Item } & Affirmative & Responses \\
\hline Retro Compliance Method in Place & 0 & 0 \\
\hline Plan to Implement Nighttime Visual Inspection & 5 & 19 \\
\hline Plan to Implement Measured RA & 2 & 7 \\
\hline Plan to Implement Expected Life & 3 & 11 \\
\hline Plan to implement Blanket Replace & 0 & 0 \\
\hline Plan to Implement Control Signs & 0 & 0 \\
\hline Plan to Implement Combo & 7 & 26 \\
\hline Plan to Implement Other & 3 & 11 \\
\hline No Response or No Plan & 7 & 26 \\
\hline
\end{tabular}


Table 5: West Virginia Incorporated Road Agency Survey: Traffic Sign Maintenance Annual Budget Statistics

\begin{tabular}{|c|c|c|}
\hline \multirow{2}{*}{ Sign \$ } & Total \$ & \multicolumn{2}{|l|}{ Fund \% of Total } \\
\hline 1950 & 131300 & 1.5 \\
\hline 30000 & 815401 & 3.7 \\
\hline 0 & 230000 & 0.0 \\
\hline 5500 & 847117 & 0.6 \\
\hline 5000 & 979400 & 0.5 \\
\hline 4600 & 159000 & 2.9 \\
\hline 0 & 10000 & 0.0 \\
\hline 21500 & 1088328 & 2.0 \\
\hline 0 & 18000 & 0.0 \\
\hline 0 & 500000 & 0.0 \\
\hline & AVERAGE & 1.1 \\
\hline
\end{tabular}

The survey results showed that many local road agencies in West Virginia were not aware of the MUTCD traffic sign retroreflectivity standards before receiving the survey. Many local agencies expressed concerns for the cost and effort to come into compliance with the traffic sign retroreflectivity standards. The survey showed several local agencies in West Virginia allocate little, if any of the agency’s total annual funding toward traffic sign management/maintenance. Also, some local agencies in West Virginia have no full time employees in the agency’s street department, making regular traffic sign management difficult. 


\section{CASE STUDY RESULTS}

The city of Shinnston, WV has approximately 17.4 miles of road centerline under city jurisdiction (highlighted in orange in Figure 16). The inventory gathered data on 144 signs, not including parking or street name signs. This results in a traffic sign density of 8.3 signs per mile. All traffic sign data for the city of Shinnston, WV was collected over a two day period. The data collection required a total of 24.5 man hours and was completed with 2 workers. Entering the data into the Excel spreadsheet required an additional 4 man hours. Using the developed spreadsheet as a template for any traffic sign retroreflectivity compliance method, little time would need to be spent modifying the template. Also, it is assumed the data entry into Excel would require little if any training. However, training with the data collection tools such as the GPS unit may add a few hours to data collection time estimate. An estimate for spreadsheet modification and personnel training of 4 hours per person was used, bringing the total man hours to build a basic sign inventory with retroreflective assessment for a town with similar road network size and sign size density as Shinnston, WV, to 36.5 man hours.

\section{CASE STUDY TRAFFIC SIGN POPULATIONS AND RETROREFLECTIVITY ASSESSMENT}

Of the 144 traffic signs in Shinnston, WV, 89.6 percent were regulatory signs, 7.6 percent were warning signs, and 2.8 guide signs. A STOP sign was the most used of any sign, used 89 times, comprising nearly 62 percent of the total inventory, followed by SPEED LIMIT signs, used 15 times, composing about 10 percent of the inventory.

The average retroreflective coefficient measurement for STOP signs was 34 for the red background and 178 for the white text. The average $\mathrm{R}_{\mathrm{A}}$ measurement for the white background of SPEED LIMIT signs was 133. 
Table 6 summarizes the evaluation of each sign using the MUTCD minimum retroreflectivity levels. Using the assumed average sign replacement cost of \$150 in a study done by Opiela and Anderson (2007), which includes labor, hardware, and administrative expenses, the cost to replace the 24 traffic signs in the inventory that do not met the MUTCD minimum $R_{A}$ values was $\$ 3600$. The MUTCD minimum $R_{A}$ for white on red traffic signs is $R_{A} \geq 35$ and red $\mathrm{R}_{\mathrm{A}} \geq 7$, with the additional requirement of contrast ration of 3:1 (white: red). The requirement for black on white traffic signs is white $\mathrm{R}_{\mathrm{A}} \geq 50$, and the requirement for black on yellow signs is yellow $R_{A} \geq 75$, for signs less than $48 X 48$ inches. For the special case of the one stop ahead warning sign in the inventory, there is an additional requirement of red $\mathrm{R}_{\mathrm{A}} \geq 7$. 
Table 6: Summary of Shinnston’s in-field Traffic Sign Retroreflectivity

\begin{tabular}{|l|c|c|c|}
\hline \multicolumn{1}{|c|}{ Sign Type } & $\begin{array}{c}\text { \# Signs in } \\
\text { Compliance }\end{array}$ & \# Sign Type in Inventory & $\begin{array}{c}\text { \% of Sign Type in } \\
\text { Compliance }\end{array}$ \\
\hline $\begin{array}{l}\text { Warning (not } \\
\text { including Stop } \\
\text { Ahead) }\end{array}$ & 7 & 10 & 70.0 \\
\hline $\begin{array}{l}\text { White } \\
\text { Background (not } \\
\text { including Speed } \\
\text { limit) }\end{array}$ & 11 & 26 & 42.3 \\
\hline Speed limit & 12 & 15 & 80.0 \\
\hline Stop & 87 & 89 & 100.0 \\
\hline Yield & 2 & 2 & 0.0 \\
\hline Stop Ahead & 0 & 1 & 83.2 \\
\hline TOTAL & 119 & $143^{1}$ & $\$ 3600$ \\
\hline $\begin{array}{l}\text { Assume \$150 sign replacement cost } \\
\text { that are below MUTCD retroreflective minimums }\end{array}$ & & & \\
\hline
\end{tabular}

${ }^{1}$ Since there is no retroreflectivity requirement for signs with blue backgrounds, the retroreflectivity of the single interstate sign was not included, thus resulting in one less sign than in the inventory.

${ }^{2}$ Source: Opiela, Kenneth S. and Carl K. Anderson. Maintaining Traffic Sign Retroreflectivity: Impacts on State and Local Agencies. Publication no. FHWA-HRDS05. Washington, DC: Federal Highway Administration, 2007 


\section{CHAPTER 5:}

THEORETICAL MODEL OF OBSERVED LIGHT INTENSITY FROM TRAFFIC SIGNS

\section{CONSTRUCTING THE CONE OF RETROREFLECTION}

Retroreflectivity enhances the visibility of traffic signs at night. The detection of the traffic sign at night is essentially accomplished by retroreflecting incident light towards a receptor near the incident light source. Retroreflectivity is a function of luminance intensity, illuminance and luminance (Figure 17).

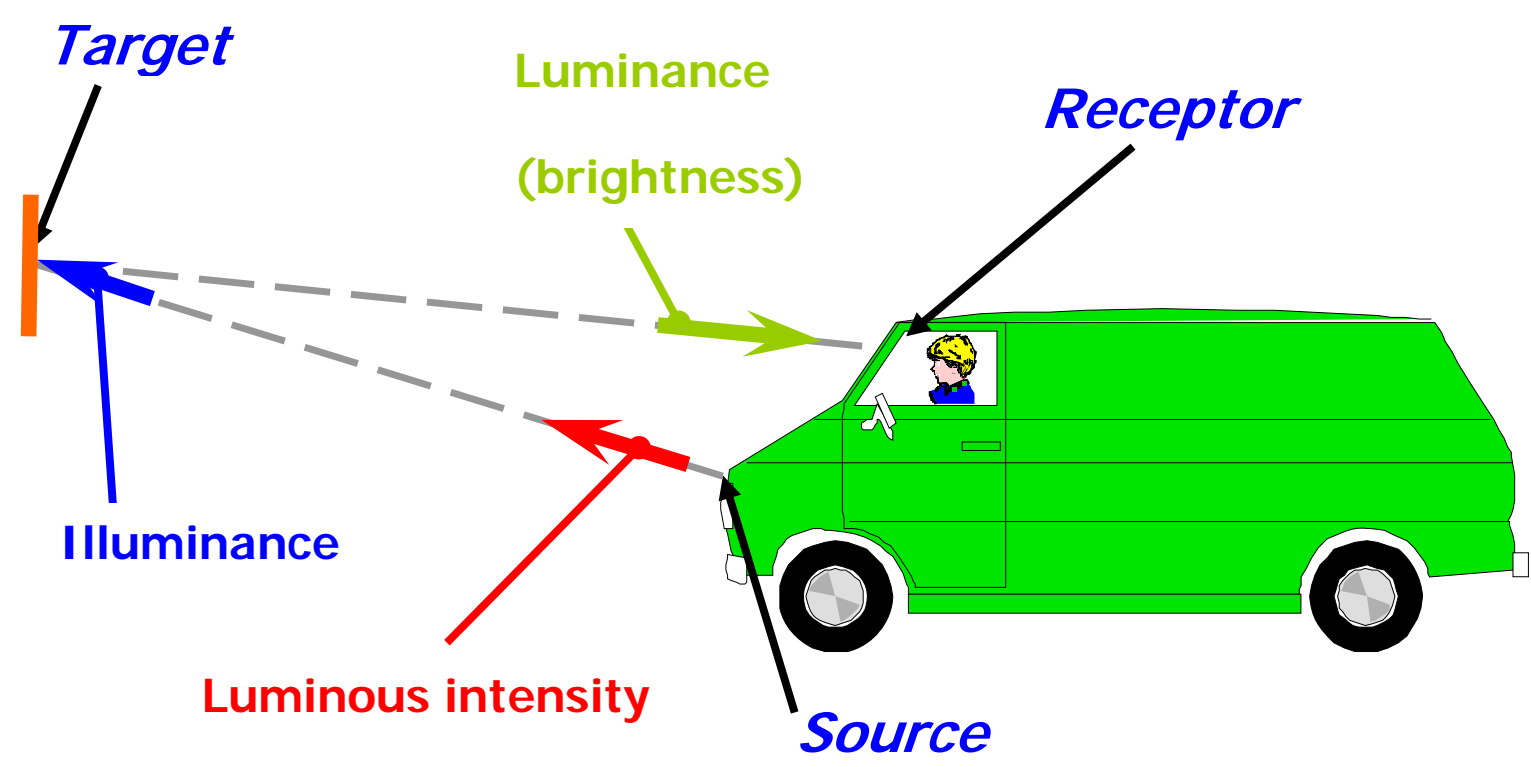

Figure 17: Lighting and Reflective Parameters

Source: Schertz, Greg, et al. Traffic Sign Retroreflectivity “Sign Retro 101”. U.S. Department of Transportation Federal Highway Administration. Accessed March 19, 2009. 
For retroreflection to occur, light must hit a retroreflective surface. In the case of motor vehicles, light from the vehicle headlamps strikes the retroreflective sheeting of a traffic sign. The amount of light that hits the traffic sign is a function of the size of the traffic sign, intensity of the headlamp, the headlamp pattern and the lateral, longitudinal and vertical distance between the headlamp and the traffic sign. Once the light hits the traffic sign, some of it will be retroreflected. The amount of incident light that is retroreflected depends on the sheeting type of the traffic sign as well as the entrance angle of the incident light. Assuming a favorable entrance angle, beaded sheeting typically retroreflects 7 to 14 percent of incident light, while microprismatic sheeting retroreflects about 32 to 58 percent of incident light (Science of Retroreflectivity, 2009).

Light retroreflected from the entire traffic sign can be represented by a cone of retroreflection originating at a single point from the center of the sign via superposition (Figures 18 and 19). The traffic sign will appear to be brightest when the maximum amount of light retroreflected by the traffic sign is detected by the motorist's eyes. For most sheeting types, the cone of retroreflection is brightest when the receptor is within 3 degrees of the illumination axis (3M Reflectivity, 2009). However, the distance from the illumination axis is not the only variable controlling traffic sign brightness. Obviously, the longitudinal distance plays a role in traffic sign brightness. This phenomenon can be explained using the geometry of the cone of retroreflection and the inverse square law of light. The cross-section of the cone at a significant distance from the traffic sign is much larger than the cross section close to the traffic sign. Since the amount of light in the cone must be conserved, the amount of light in any given cross-section of the cone of retroreflection is the same. Thus, the density of light per unit area is less at distances farther from the traffic sign. Holding all other variables constant, such as the entrance 
angle, observation angle and detector size, the amount of light hitting the detector is greater at shorter distances. This principle can be proven mathematically, using parameters defined in Figure 20:

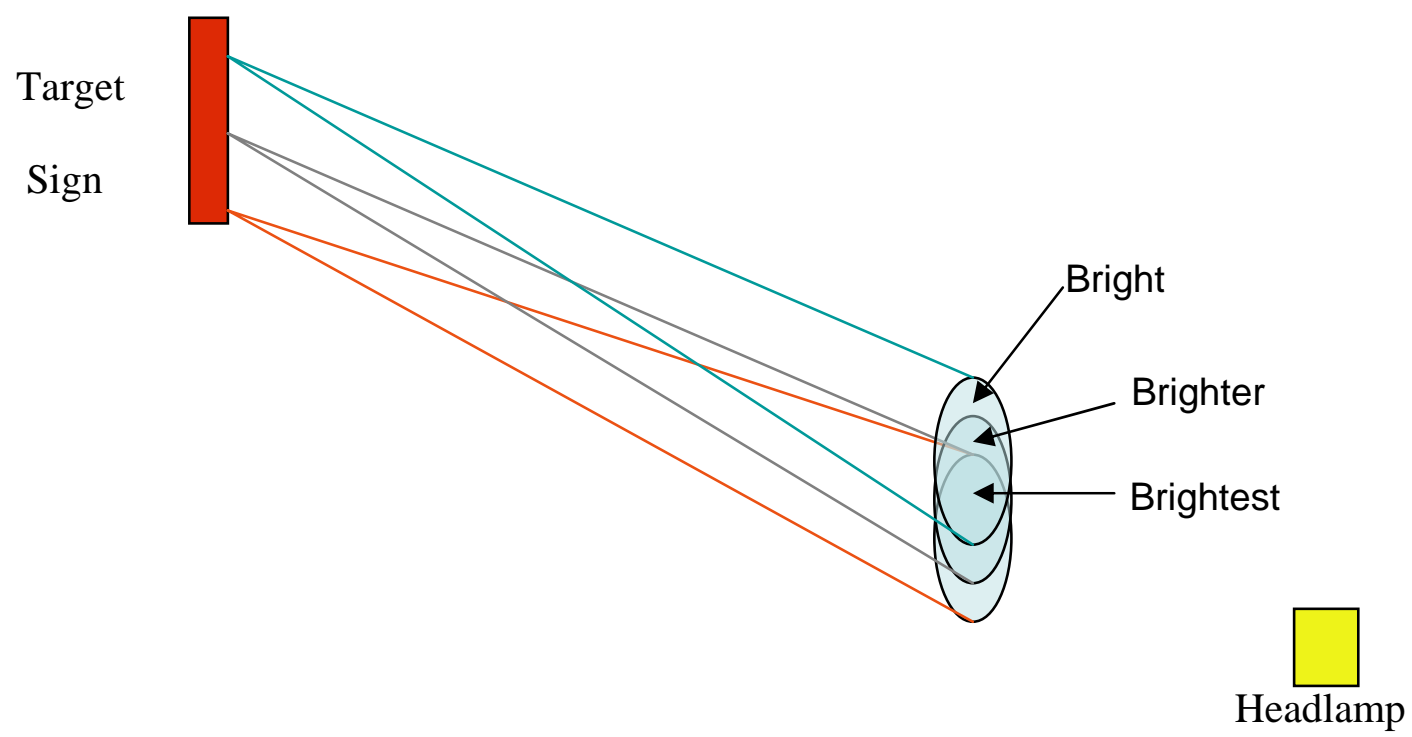

Figure 18: Visualization of Superposition of Cone of Retroreflection 


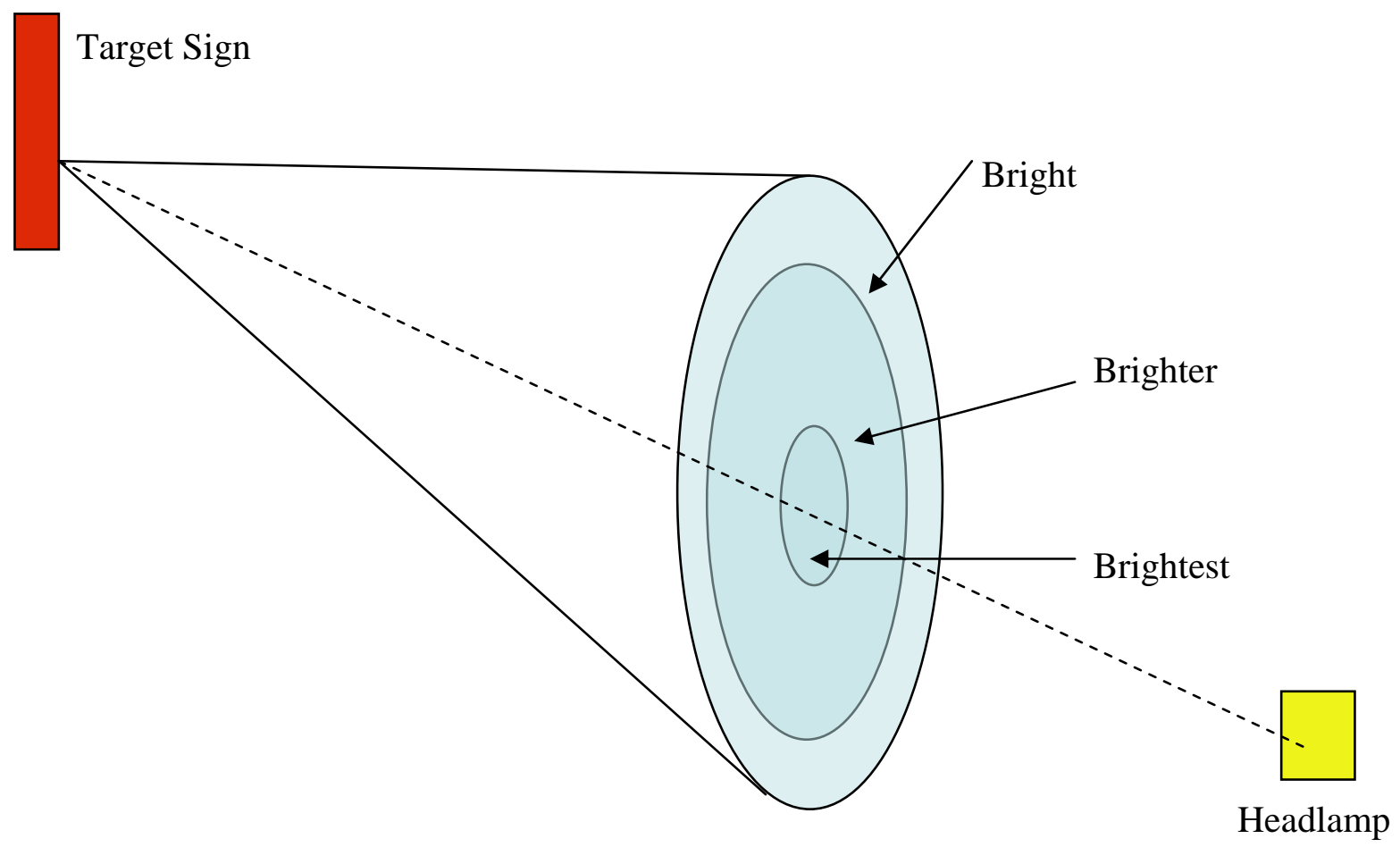

Figure 19: Superposition Resultant Cone

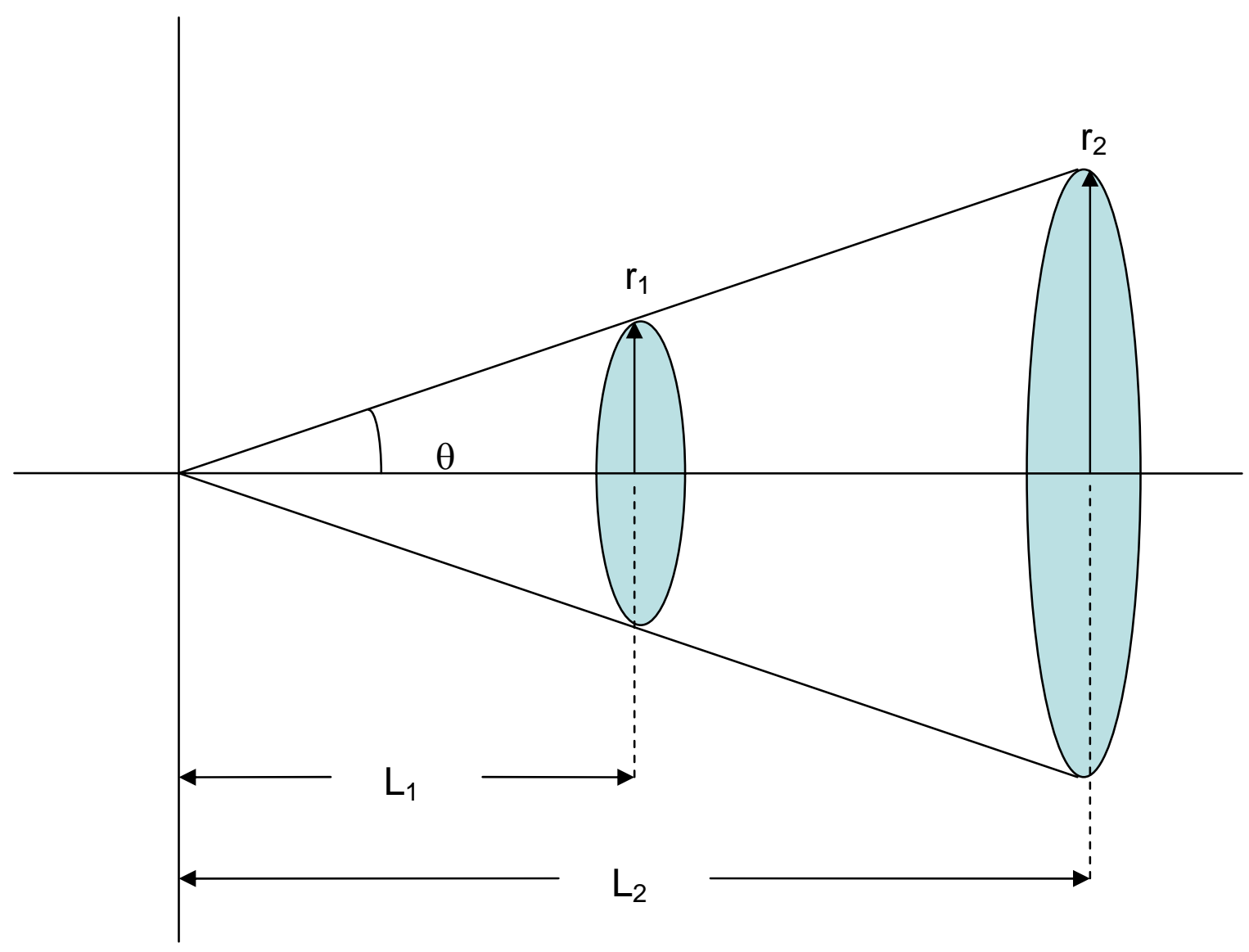


Figure 20: Geometry of Cone of Retroreflection

Using the tangent, derive a relationship between $r_{1}$ and $r_{2}$ :

$\operatorname{Tan} \theta=\mathrm{r}_{1} / \mathrm{L}_{1}=\mathrm{r}_{2} / \mathrm{L}_{2}$

Therefore:

$\mathrm{r}_{1}=\mathrm{r}_{2}\left(\mathrm{~L}_{1} / \mathrm{L}_{2}\right)$ where, $\left(\mathrm{L}_{1} / \mathrm{L}_{2}\right)<1$

Now define the cross sectional areas of the cone at $\mathrm{L}_{1}$ and $\mathrm{L}_{2}$ :

$\mathrm{A}_{2}=\pi \mathrm{r}_{2}^{2}$

$\mathrm{A}_{1}=\pi \mathrm{r}_{1}^{2}$

Finally, assume that the amount of light, $\mathrm{n}$, in the cone is constant at any L. The brightness or luminance, $\mathrm{B}$, is then the amount of light per unit area:

$\mathrm{B}_{1}=\mathrm{n} / \mathrm{A}_{1}=\mathrm{n} /\left[\pi \mathrm{r}_{1}^{2}\right]$

$\mathrm{B}_{2}=\mathrm{n} / \mathrm{A}_{2}=\mathrm{n} /\left[\pi \mathrm{r}_{2}{ }^{2}\right]$, then

$\mathrm{B}_{1} / \mathrm{B}_{2}=\mathrm{r}_{2}{ }^{2} / \mathrm{r}_{1}{ }^{2}$

Thus showing the inverse square law also applies for cones.

\section{DEVELOPING THE MODEL}

A model of theoretical traffic sign luminance has been developed as a function of vertical, lateral, and longitudinal offsets as well as headlamp pattern and intensity, sign size and sheeting type properties $\left(\mathrm{R}_{\mathrm{A}}\right)$. The headlamp pattern and intensity are defined by the isocandela plot for the Computer Analysis of Retroreflectance of Traffic Signs (CARTS) median headlamp (Figure 21) (Chrysler et al., 2003). While the model is capable of analyzing any sign size and 
sheeting type, only a 36 X 36 inch warning sign with Type III sheeting is presented. The model uses the vertical offset between the motorist's eye $\left(h_{m}\right)$, the vehicle headlamps $\left(h_{h}\right)$ and the center of the target traffic sign $\left(h_{s}\right)$ with respect to the road surface, as well as the distance from the illumination axis to the motorist's eye. The lateral offsets considered are the offsets from a line orthogonal to the target traffic sign surface to each of the headlamps $\left(\mathrm{x}_{\mathrm{i}}\right)$, defining the entrance angle and similarly, the offsets from the center of the headlamps to the center of the target traffic sign, used to find the horizontal angle on the isocandela plot. Lastly, the longitudinal offsets used are the distance between the headlamp and target traffic sign (d) and the longitudinal distance between the motorist's eye and the headlamps $\left(\mathrm{L}_{0}\right)$.

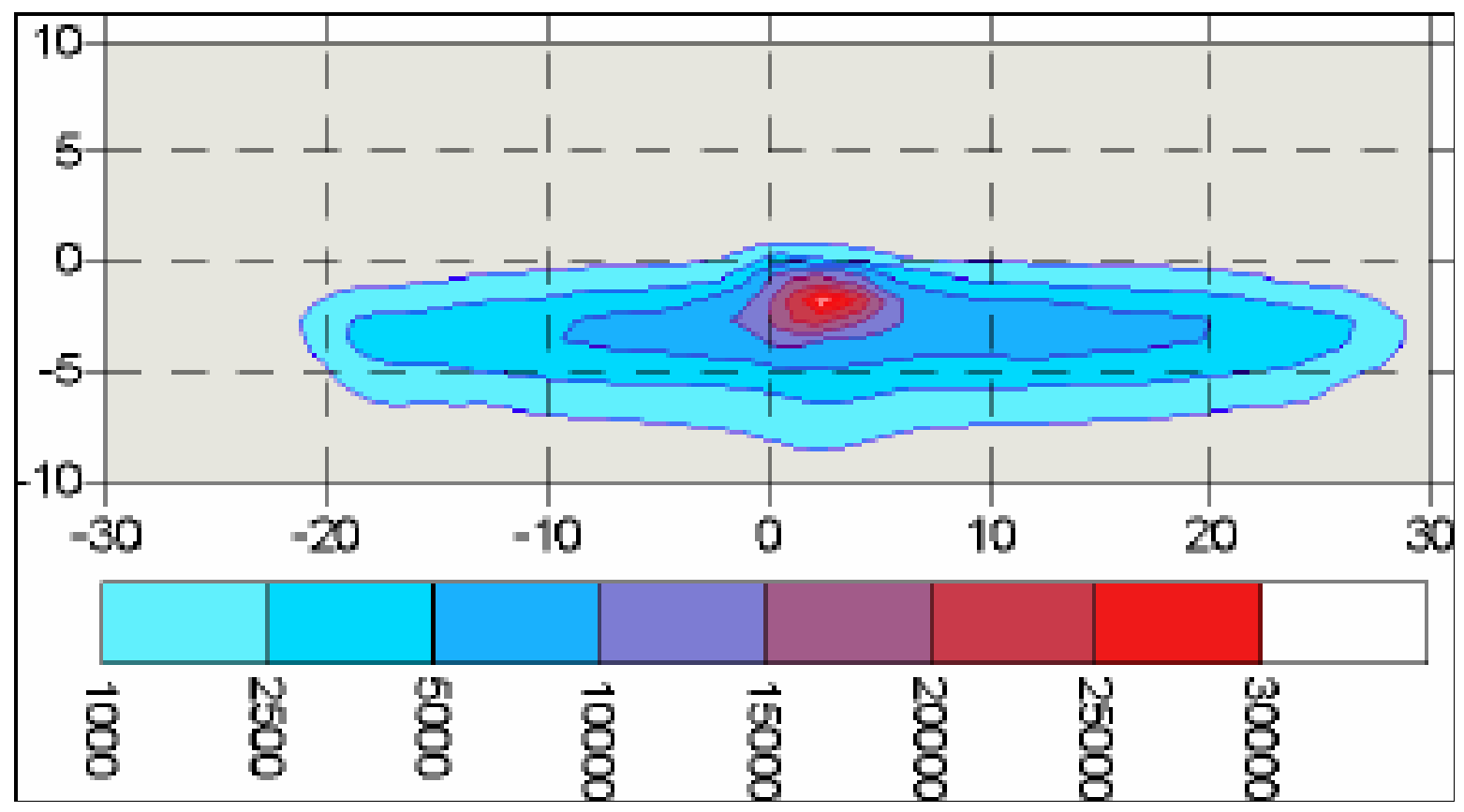

Figure 21: Isocandela Plot for the CARTS Median Headlamp.

Source: Chrysler, Susan T., Carlson, Paul J. and Hawkins, H. Gene. Headlamp Illumination Provided to Sign Positions by Passenger Vehicles. Report No. FHWA/TX-03/0-1796-3, Texas Department of Transportation, Austin, Texas, 2003 


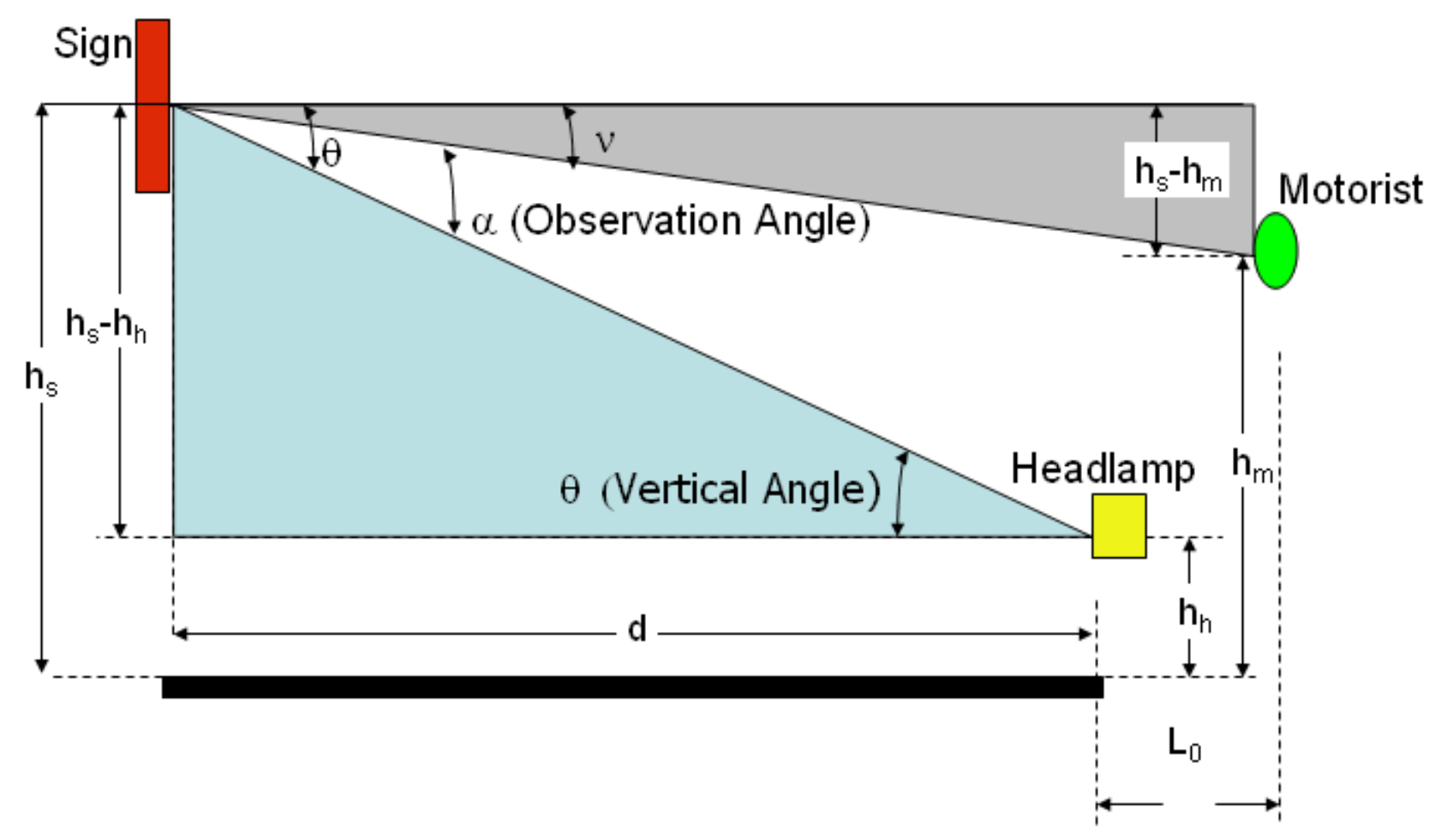

Figure 22: Observation Angle as a Function of Vertical and Longitudinal Offsets

The observation angle $(\alpha)$ can be defined using offsets and angles defined in Figure 22 Using alternate interior angles of parallel lines, $\alpha=\theta-v$, where:

$\theta=\operatorname{Tan}^{-1}\left[\left(\mathrm{~h}_{\mathrm{s}}-\mathrm{h}_{\mathrm{h}}\right) / \mathrm{d}\right]$

$v=\operatorname{Tan}^{-1}\left[\left(\mathrm{~h}_{\mathrm{s}}-\mathrm{h}_{\mathrm{m}}\right) /\left(\mathrm{d}+\mathrm{L}_{0}\right)\right]$

Therefore:

$\alpha=\operatorname{Tan}^{-1}\left[\left(\mathrm{~h}_{\mathrm{s}}-\mathrm{h}_{\mathrm{h}}\right) / \mathrm{d}\right]-\operatorname{Tan}^{-1}\left[\left(\mathrm{~h}_{\mathrm{s}}-\mathrm{h}_{\mathrm{m}}\right) /\left(\mathrm{d}+\mathrm{L}_{0}\right)\right]$ 
As explained in the literature review, the entrance angle is defined as, $\beta=\operatorname{Tan}^{-1}\left(x_{i} / d\right)$, where $x_{i}$ is the lateral offset from the respective headlamp to a line orthogonal to the target traffic sign.

\section{HEADLAMP INTENSITY}

The headlamp intensity hitting the target traffic sign was found using the headlamp isocandela plot for the CARTS median headlamp. The plot defines headlamp intensity based on vertical and horizontal angles from the center of the headlamp. Therefore, the intensity of light falling on the target traffic sign can be found using offsets with respect to the center of the headlamp. In fact, the vertical offset angle $(\theta)$ is defined in Figure 22 as $\theta=\operatorname{Tan}^{-1}\left[\left(\mathrm{~h}_{\mathrm{s}}-\mathrm{h}_{\mathrm{h}}\right) / \mathrm{d}\right]$, and using the alternate interior angles of parallel lines, the horizontal angle is the same as the entrance angle, $\beta=\operatorname{Tan}^{-1}\left(x_{i} / d\right)$.

Knowing the vertical and horizontal offset angles from the center of the headlamp, a three-dimensional interpolation of the headlamp intensity was simulated using AutoCAD Civil 3D software. The isocandela plot for the CARTS median headlamp was first scaled and centered using the absolute coordinate system. Next, the contour lines were digitized by tracing polylines over the contours and defining the $\mathrm{z}$ coordinate as the light intensity. The original isocandela plot terminates at a contour of 1000 candela; however, it can be observed that the light from the headlamp does not have an abrupt cut-off; it gradually falls off to zero. With this in mind, a zero candela contour line was constructed using cross-sections of a triangulated irregular network (TIN) surface terminating at 1000 candela. The TIN was created using the defined polyline contours of light intensity (Figure 23). Next, straight cross-sections were created at horizontal angles of -20, -10, -5, 0, 5, 10 and 20 (Figure 24) with the first stations for each cross-section on 
the upper curve of the 1000 candela contour. For each cross section, the intensity curve was extended from 1000 candela intensity down to zero candela intensity (Figure 25). Since, the cross-sections are straight lines and the cross-section plots are drawn to scale in the $\mathrm{x}$ direction, the $\mathrm{x}$ axis distances in negative direction are positive vertical distances on the isocandela plot. Therefore, by measuring the $\mathrm{x}$ axis distance from the 1000 candela, $0+00$ station for each crosssection, seven points will be created to model the upper curve of the zero contour line (Figure 26 and 27). To complete the contour, the bottom of the curve was approximated following the shape of the 1000 candela bottom curve. Finally, a second TIN surface was created with the zero contour as the boundary. Data points were plotted on the TIN surface using a grid spacing of 0.1 degrees in both the vertical and horizontal directions. These points where then exported to Microsoft Excel to be used as a lookup table of intensity based on calculated horizontal and vertical angles with respect to the center of each headlamp. The intensity from each headlamp was summed, resulting in the total headlamp intensity striking the target traffic sign.

\section{TRAFFIC SIGN ILLUMINATION AND LUMINANCE}

Knowing the intensity of light striking the sign and the longitudinal distance between the headlamps and the target traffic sign, the illumination or lux can be found using the inverse square law of light, that is the lux $=\mathrm{cd} / \mathrm{d}^{2}$. Since the model uses English units of feet, the distance must be converted to square meters resulting in:

$$
\text { Lux } \text { headlamps }=\mathrm{cd}_{\text {headlamps }} /\left(\mathrm{d}^{2} * 0.0929\right)[\mathrm{lx}]
$$




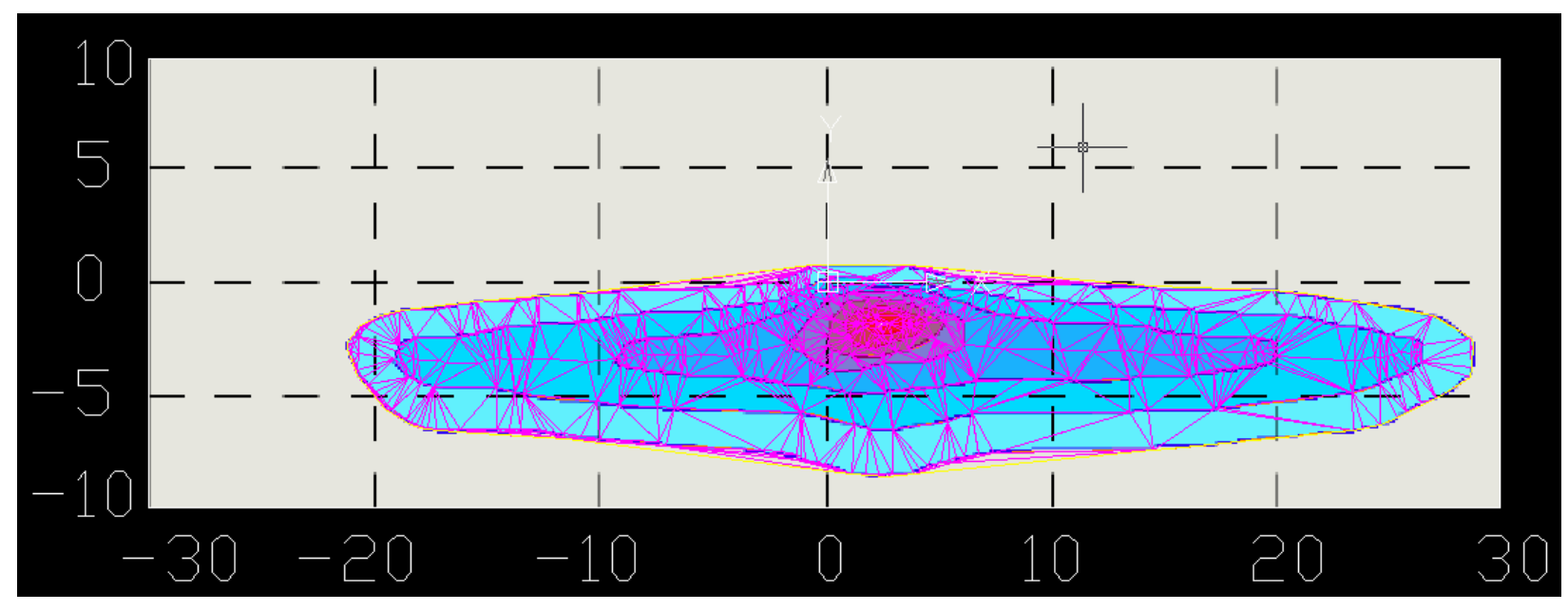

Figure 23: Original TIN Surface of Headlamp Intensity Terminating at 1000 Candela

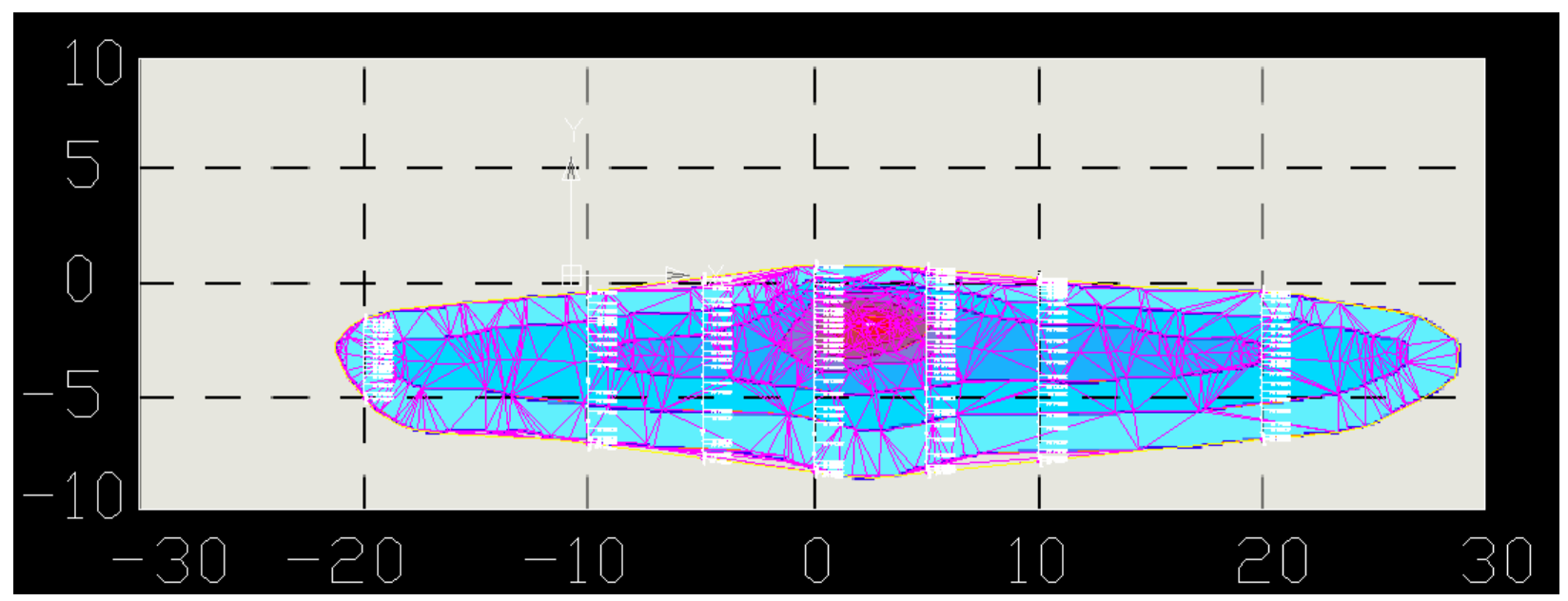

Figure 24: Cross-sections on TIN surface 


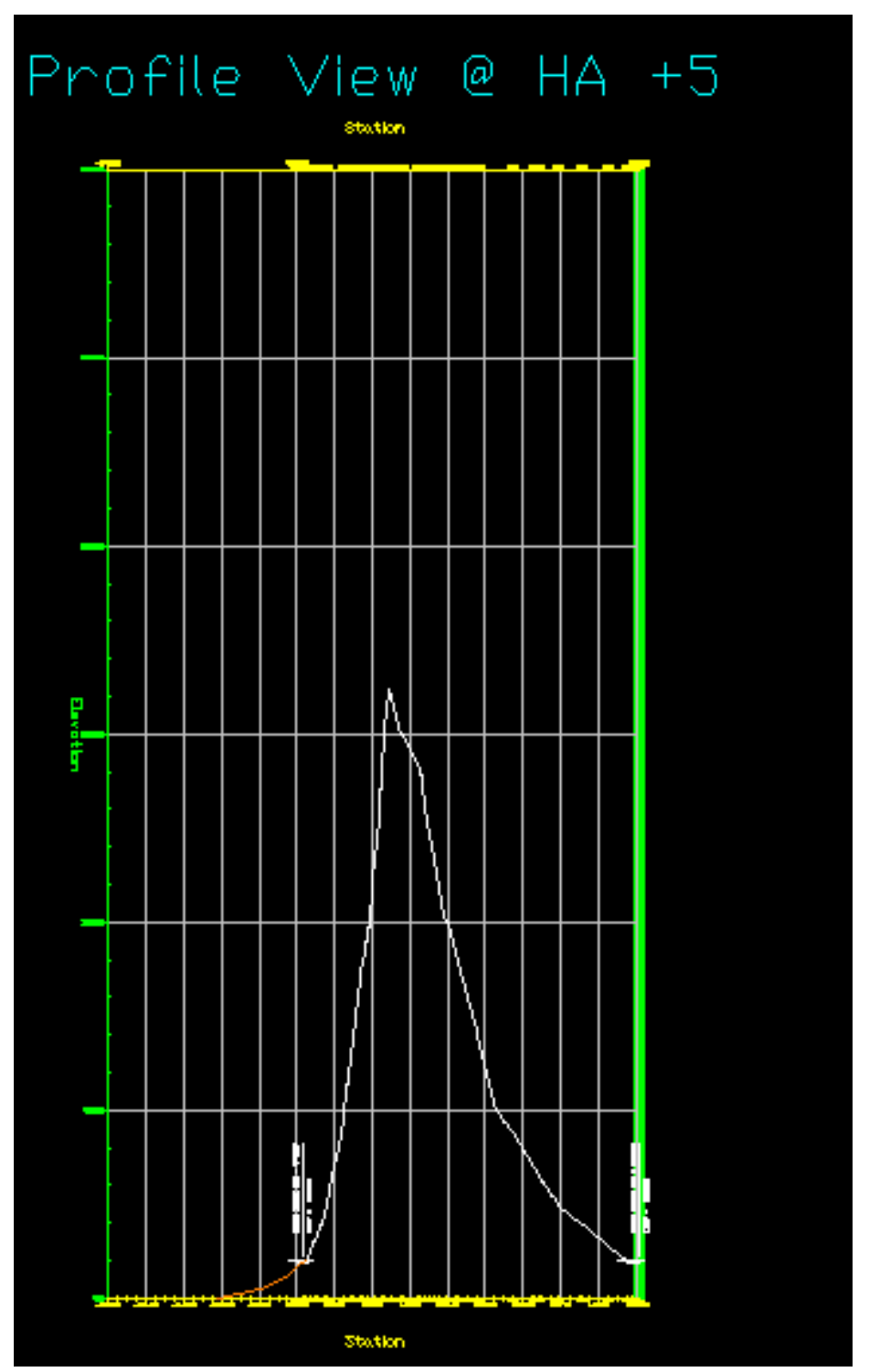

Figure 25: Extending the Intensity Curve to Zero Candela 


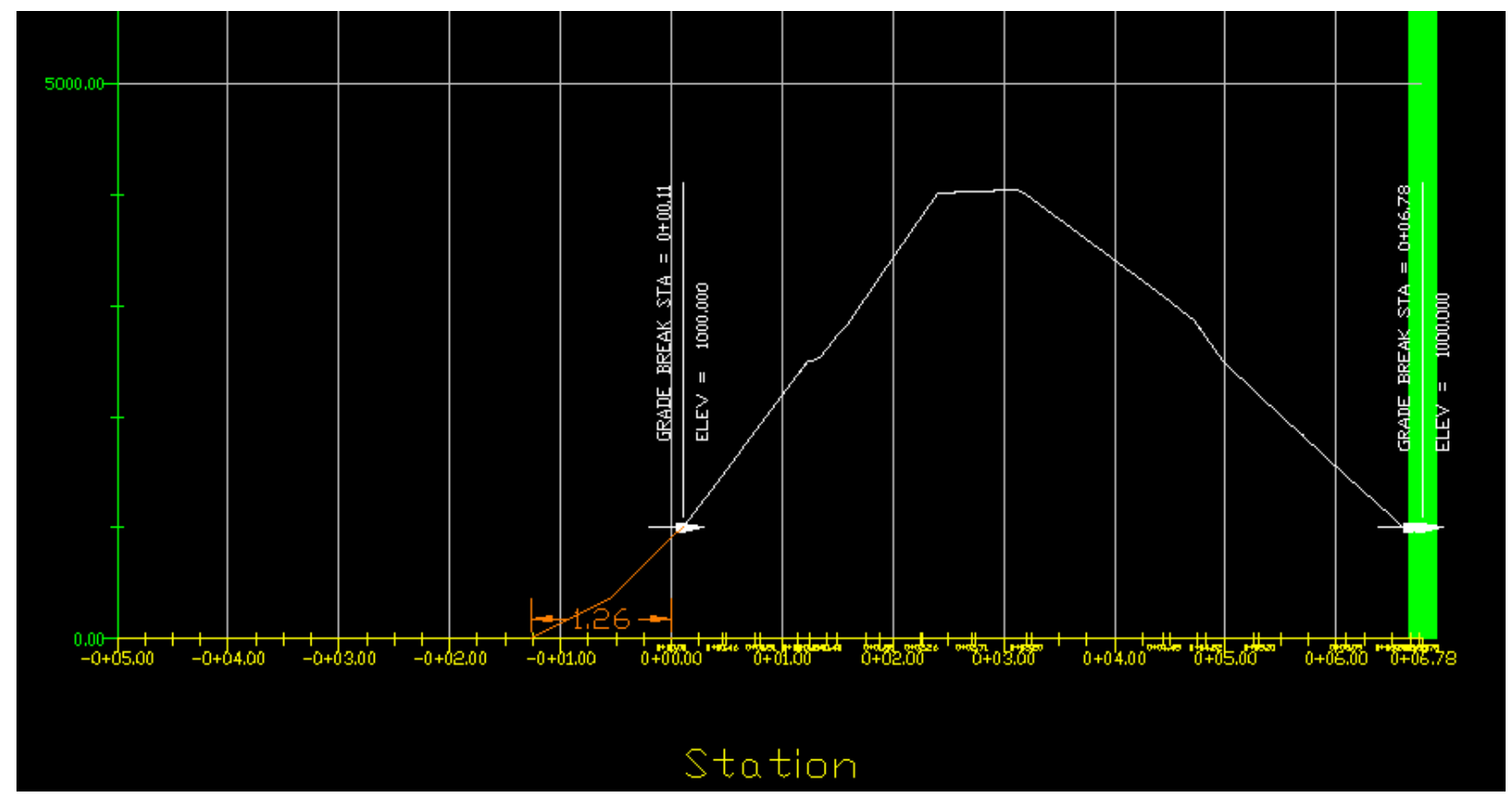

Figure 26: Measuring X Axis Distance Between 1000 and Zero Candela at Horizontal Angle of 10.

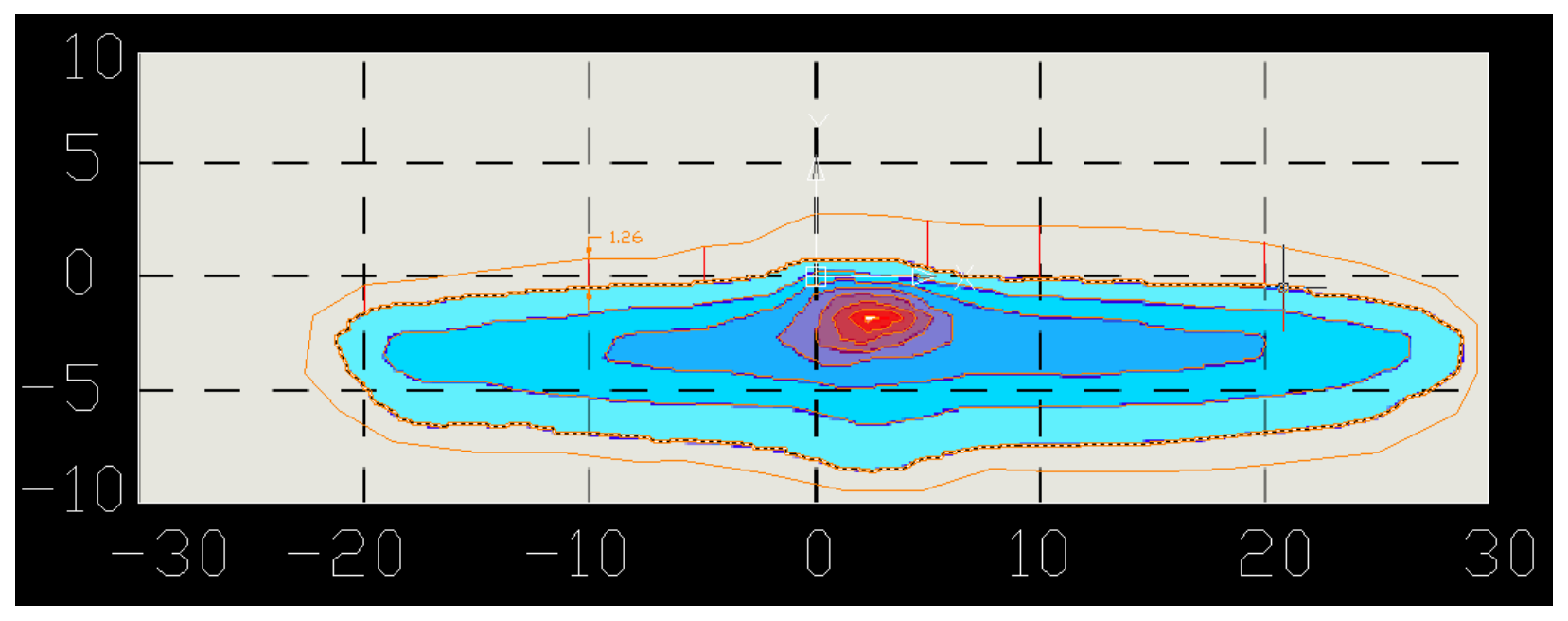

Figure 27: Constructing the Zero Candela Contour

To find the luminance of the traffic sign is a function of the illumination, the size of the traffic sign, and the amount of light that is retroreflected which is defined by its retroreflective coefficient. Using sign size measured in square feet, the amount of light retroreflected is then: 
$\mathrm{L}_{\text {retro }}=$ Lux $* \operatorname{sign} \operatorname{size}^{*} 0.0926 * \mathrm{R}_{\mathrm{A}}[\mathrm{cd}]$

Luminance is then the amount of light leaving the target traffic sign per unit area of the traffic sign, again in square feet:

Lum $=\mathrm{L}_{\text {retro }} /($ sign size $* 0.0926)=\operatorname{Lux} * \mathrm{R}_{\mathrm{A}}\left[\mathrm{cd} / \mathrm{m}^{2}\right]$

\section{LIGHT INTENSITY FROM TRAFFIC SIGNS}

While luminance of a sign is important to in the recognition of traffic signs under dark conditions, it does not consider how much light is detected by the motorist. To calculate the amount of light that is detected by the motorist, the traffic sign can be treated as a light source. Using the amount of light retroreflected by the sign $\left(\mathrm{L}_{\text {retro }}\right)$ as the light intensity at the origin of the cone of retroreflection at the center of the sign face, the lux from the traffic sign is:

$\operatorname{Lux}_{\text {sign }}=\mathrm{L}_{\text {retro }} /\left(\mathrm{d}^{2} * 0.0929\right)[\mathrm{lx}]$.

Next, we have to consider how much light intensity is striking the motorist's eyes. According to the National Eye Institute (2009), the cornea, "controls and focuses the entry of light into the eye.” Therefore, the cornea is used as the receptor of light from the traffic sign surface. A study done by Piñero et al. (2008) found that the mean human corneal diameter was $12.25 \mathrm{~mm}$. This diameter was used to find the area of the motorist's eye used to detect light $\left(\mathrm{A}_{\text {eye }}\right)$ in units of square meters. The amount of light detected by both eyes is then:

$\mathrm{L}_{\text {eyes }}=\operatorname{Lux}_{\text {sign }} * 2\left(\mathrm{~A}_{\text {eye }}\right)=\operatorname{LuX}_{\text {sign }} * 2\left[\pi((12.25 \mathrm{E}-3) / 2)^{2}\right][\mathrm{cd}]$

\section{THEORETICAL OBSERVED LIGHT INTENSITY FROM TRAFFIC SIGNS REDUCED BY DISTANCE FROM ILLUMINATION AXIS}

Lastly, for a traffic sign to be visible at night, the motorist's eye must be in the cone of retroreflection. This requirement can be tested using the observation angle. Both the observation angle and the cone of retroreflection are measured from the illumination axis. Therefore, if the 
observation angle is less than 3 degrees, than the motorist's eye will be the cone of retroreflection. It is also worth noting that even within the cone of retroreflection; light luminance will fall off as distance from the illumination axis increases. Since this model considers only the vertical distance between the illumination axis and the motorist's eye, an approximation of the reduction of theoretical observed light intensity from traffic signs due to distance from illumination angle was calculated using a retroreflectivity versus observation angle plot (Figure 11). For accuracy, the vertical axis was plotted to scale in AutoCAD. Next, straight lines connecting the $\mathrm{x}$ axis to points on the Type III sheeting at $\mathrm{x}$ value intervals of 0.1 degrees, from 0.1 to 1.0 degrees. With these ten data points, a fourth order equation was fit with an $\mathrm{R}^{2}$ value of 1 (Figure 28):

$y=-1499.1 x^{4}+3802.9 x^{3}-2803 x^{2}+151.81 x+366.23$

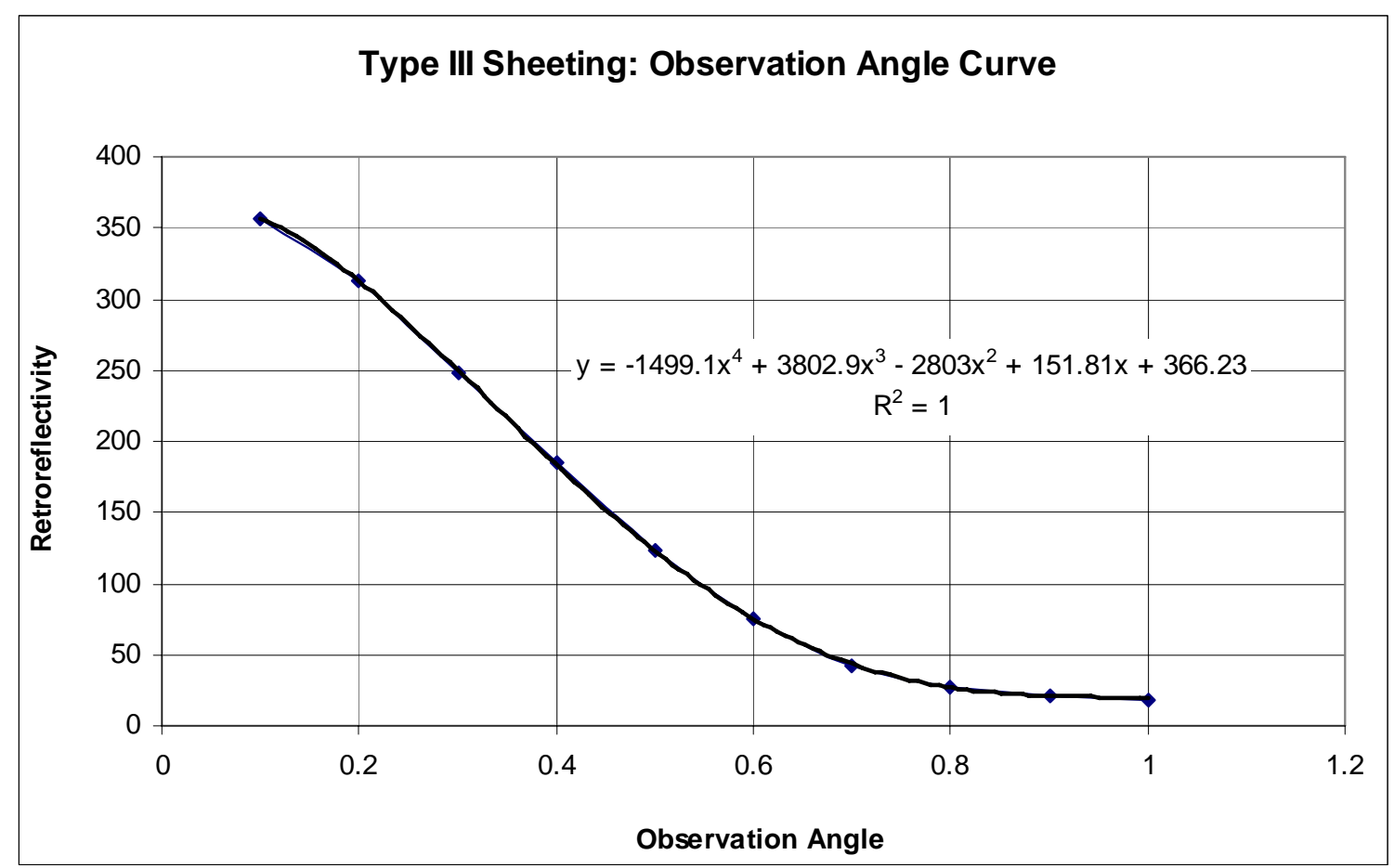

Figure 28: Fitting a Function to the Observation Angle Curve 
Since this plot references specific retroreflectivity coefficient values, which may not correspond to values for the sheeting type being evaluated, the calculated retroreflectivity values were converted to a percentage of total retroreflected light returned to the motorist's eye at a given distance from the illumination axis. The percentage was found by assuming that light is most efficiently returned at an observation angle of 0.1 degrees and $\mathrm{R}_{\mathrm{A}}=357$, the smallest distance from the illumination axis for which there are data (the data presented does not have observation angles smaller than 0.1 degrees). The percent of traffic sign luminance perceived by a motorist was found by dividing the retroreflective coefficient, by 357. The retroreflective coefficient was found using the calculated observation angle in the fourth order equation.

\section{ASSUMPTIONS AND LIMITATIONS OF MODEL}

The model simulates a flat straight roadway with no environmental lighting and assumes the cone of retroreflection is returned to midpoint between the two headlamps of the design vehicle being evaluated. Lateral offset of the motorist with respect to headlamps is not being considered. Thus, the distance from the illumination axis is a purely vertical measurement.

The traffic sign luminance and theoretical observed light intensity from the traffic sign was calculated for three design vehicles, a passenger car, a SUV and a heavy truck, with properties defined in Table 7. For a given lateral offset and design vehicle, traffic sign luminance was calculated at distances at 50 foot intervals from 50 to 750 feet, as well as at 240 and 640 feet to compare luminance thresholds defined by Chrysler, et al. (2003), which is further discussed later in this chapter. The MUTCD defines typical installation heights and lateral offsets of traffic signs in section 2A.16 (2003). The MUTCD defines the lateral off set of a traffic sign as the distance from the edge of the road surface or shoulder to the edge of the sign nearest to the road, 
and the sign height is the vertical distance from the road surface to the bottom of the traffic sign. Since the cone of retroreflection is assumed to be at the center of the sign, half of the signs width must be added to the lateral offset and half of its height to the mounting height. Considering the offset to the center of the 36 X 36 warning sign at $2.1 \mathrm{ft}$, and using the MUTCD minimum lateral offset of 6 feet to the edge of the sign, the model begins analyzing lateral offsets at 8 feet, increasing by 2-foot intervals out to 20 feet. The data presented analyzes the bottom of the Type III warning sign mounted at 7 feet, thus placing the origin of the cone of retroreflection at 9.1 feet. The retroreflective coefficient of the Type III sheeting was found by averaging four retroreflective measurements of a Type III warning sign in new condition, resulting in a retroreflective coefficient of 256 for the yellow background. Note that the MUTCD minimum retroreflective coefficient for black on yellow signs less than $48 \mathrm{X} 48$ inches, is yellow $\mathrm{R}_{\mathrm{A}} \geq 75$.

Table 7: Design Vehicle Dimensions

\begin{tabular}{|l|c|c|c|c|}
\hline Vehicle type & $\begin{array}{l}\text { Driver eye } \\
\text { height (ft) }\end{array}$ & $\begin{array}{l}\text { Headlamp } \\
\text { height (ft) }\end{array}$ & $\begin{array}{l}\text { Longitudinal offset of } \\
\text { headlamp to Driver (ft) }\end{array}$ & $\begin{array}{l}\text { Distance between } \\
\text { headlamps (ft) }\end{array}$ \\
\hline Passenger car & $3.77^{1}$ & $2.13^{1}$ & $7.0^{2}$ & $3.7^{2}$ \\
\hline $\begin{array}{l}\text { Multipurpose } \\
\text { vehicle (SUV) }\end{array}$ & $4.86^{1}$ & $2.76^{1}$ & $6.9^{2}$ & $4.45^{2}$ \\
\hline Heavy Truck & $8.03^{1}$ & $3.68^{1}$ & $7.9^{3}$ & $6.5^{4}$ \\
\hline
\end{tabular}

Source: $\quad{ }^{1}$ Fambro, et al. 1997

${ }^{2}$ Chrysler, et al. 2003

${ }^{3}$ Scaled AASHTO Geometric Design Manual Image of interstate semi trailer wb19 [sb-62]

${ }^{4}$ Estimate of $8 \mathrm{ft}$ wide interstate semi trailer wb-19 [sb-62] 


\section{RESULTS OF THE MODEL}

The theoretical sign luminance from traffic signs is a function of:

1. Headlamp intensity pattern

2. Sign Sheeting Properties $\left(\mathrm{R}_{\mathrm{A}}\right)$

3. Horizontal and vertical angles with respect to the center of each respective headlamp

4. Lateral distances between the target traffic sign with respect to each headlamp

5. Longitudinal distance between the target traffic sign and the headlamps

6. Longitudinal and vertical offsets between the motorist's eye and the headlamps.

Also, for the theoretical observed light intensity, the size of the light-receiving part of the motorist's eyes, the cornea, was considered.

The vertical, horizontal, and observation angle are all functions of the inverse tangent function, these parameters change rapidly at near distances, less than about 250 feet, then begin to become more stable at increasing distances, as shown in Figures 29, 30, and 31. Looking at the headlamp intensity falling on the target traffic sign at a constant lateral offset each design vehicle displays unexpected “jumps” at given distances (Figures 32, 33, and 34). These “jumps” in intensity can be explain by the unexpected increases in the traffic sign illumination (Figure 35) caused by the simulated interpolation performed by the TIN surface. These “jumps" in light 
intensity are ultimately translated to the traffic sign luminance perceived by the motorist, which is the sign luminance reduced by the observation angle, for each design vehicle (Figure 36). Since there is no data for the observation angle curve beyond 1 degree, observation angles greater than 1.0 degree are set to zero.

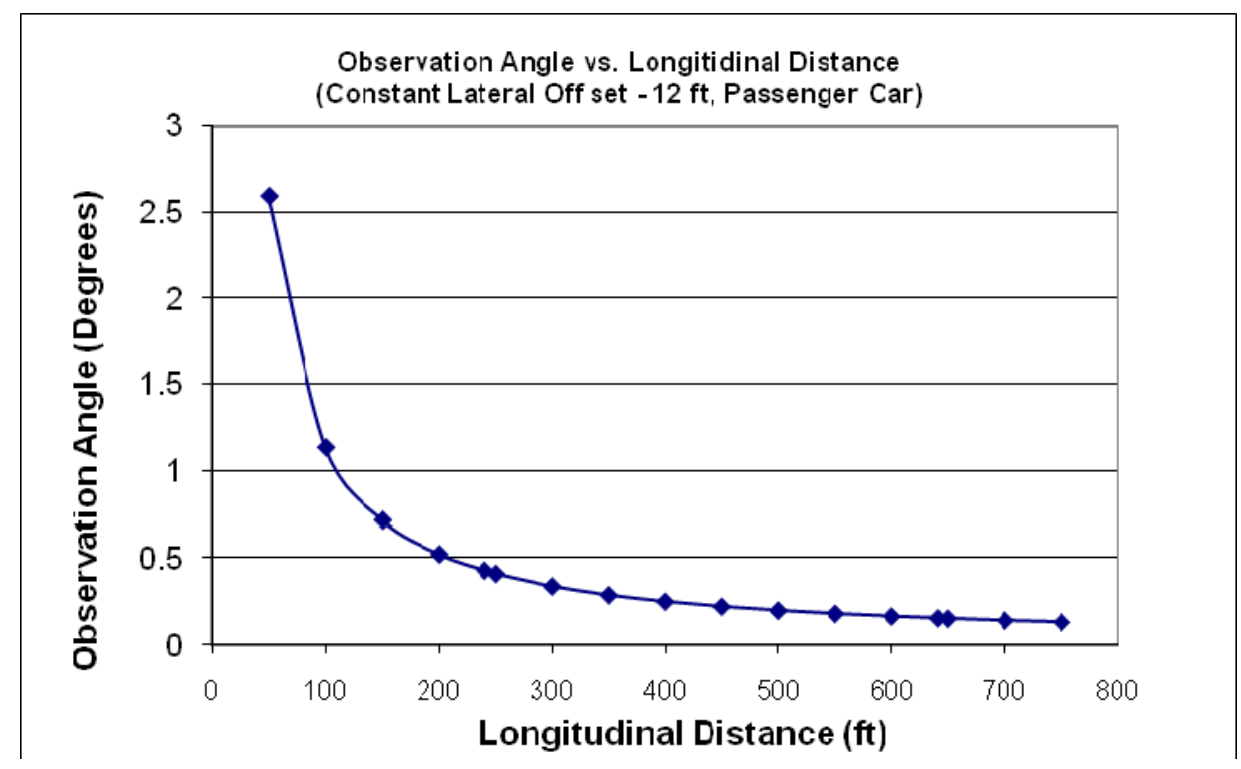

Figure 29: Observation Angle Dependence on Longitudinal Distance 


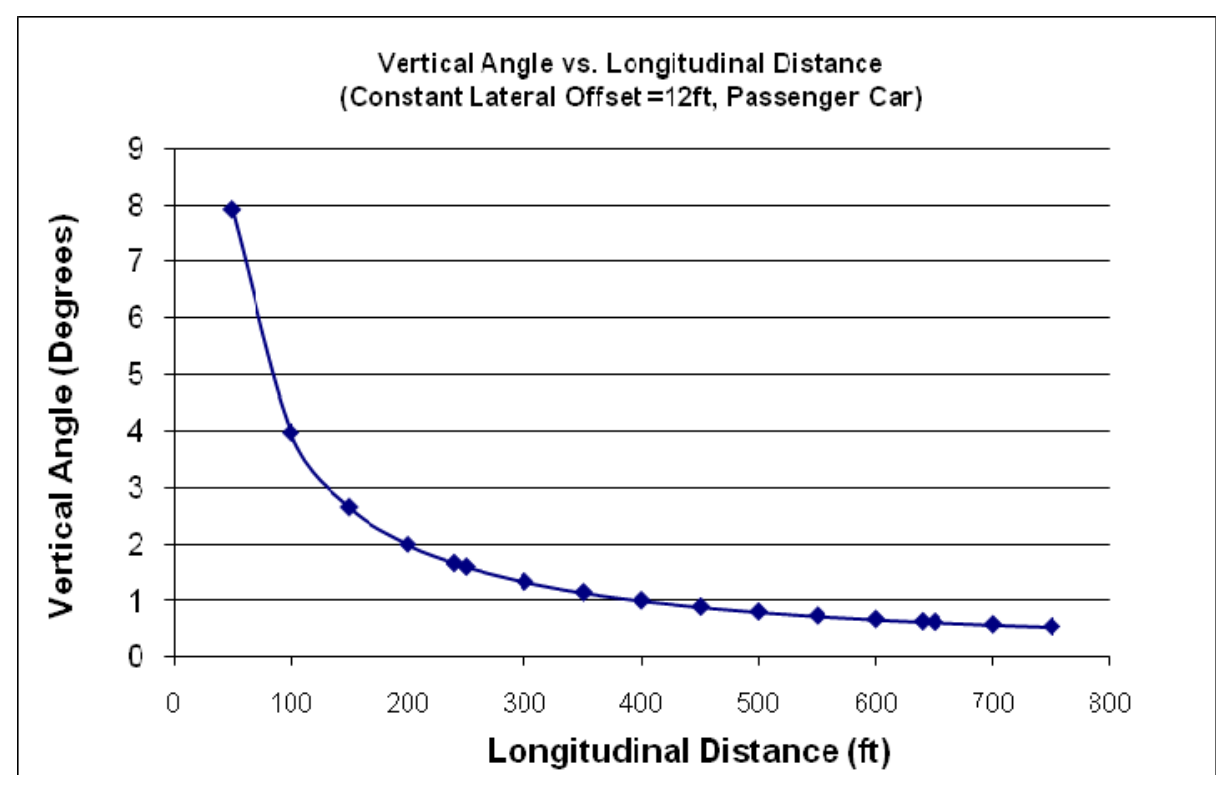

Figure 30: Vertical Angle Dependence of Longitudinal Distance at Lateral Offset $=12$ feet vs. Longitudinal Distance (Passenger Car)

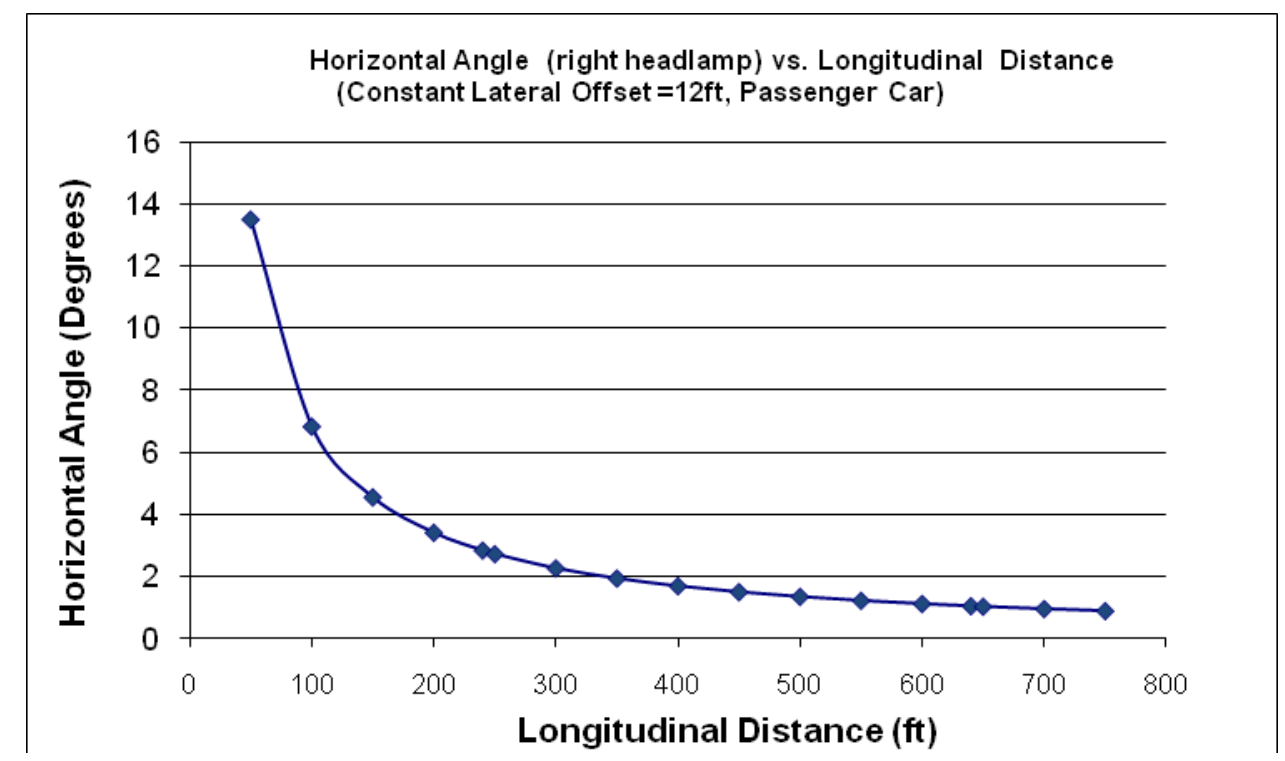

Figure 31: Horizontal Angle Dependence of Longitudinal Distance at Lateral Offset = 12 feet vs. Longitudinal Distance (Passenger Car) 


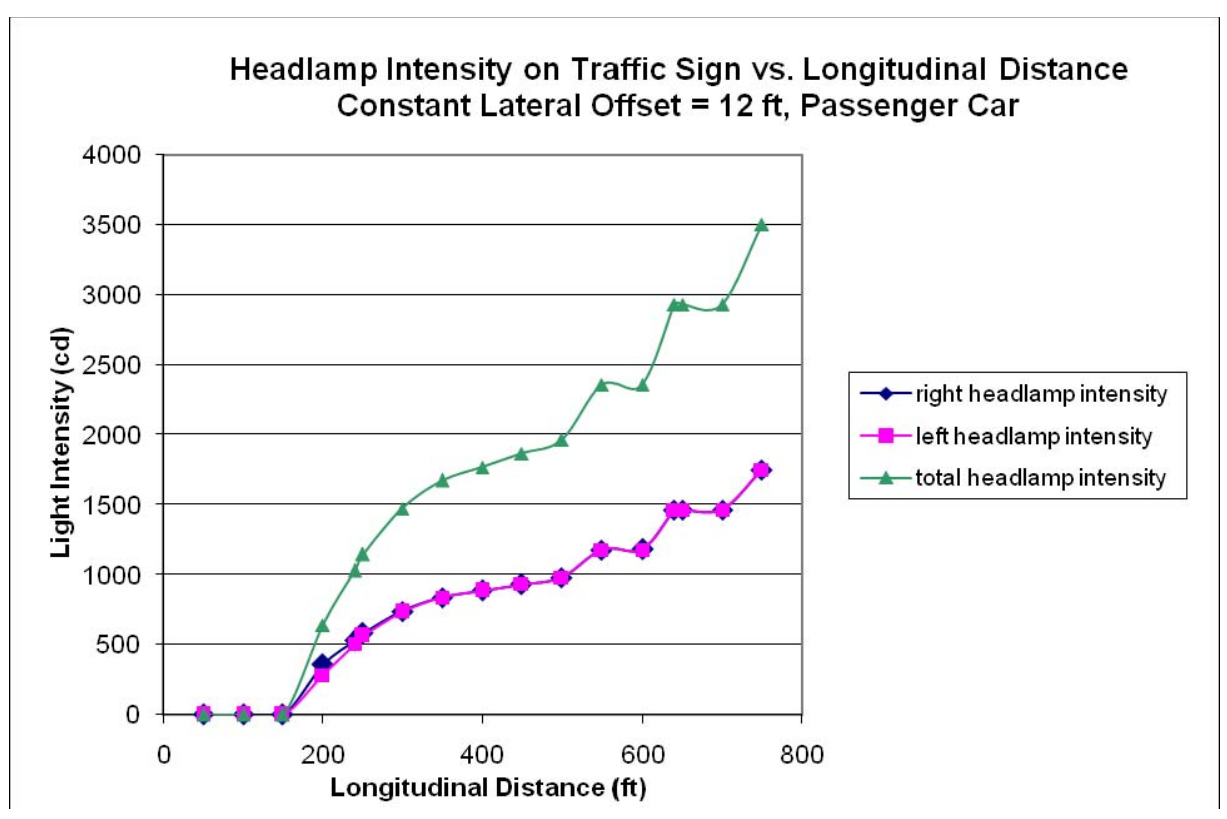

Figure 32: Headlamp Intensity Striking Traffic Sign for Passenger Car at Lateral Offset $=12$ feet vs. Longitudinal Distance

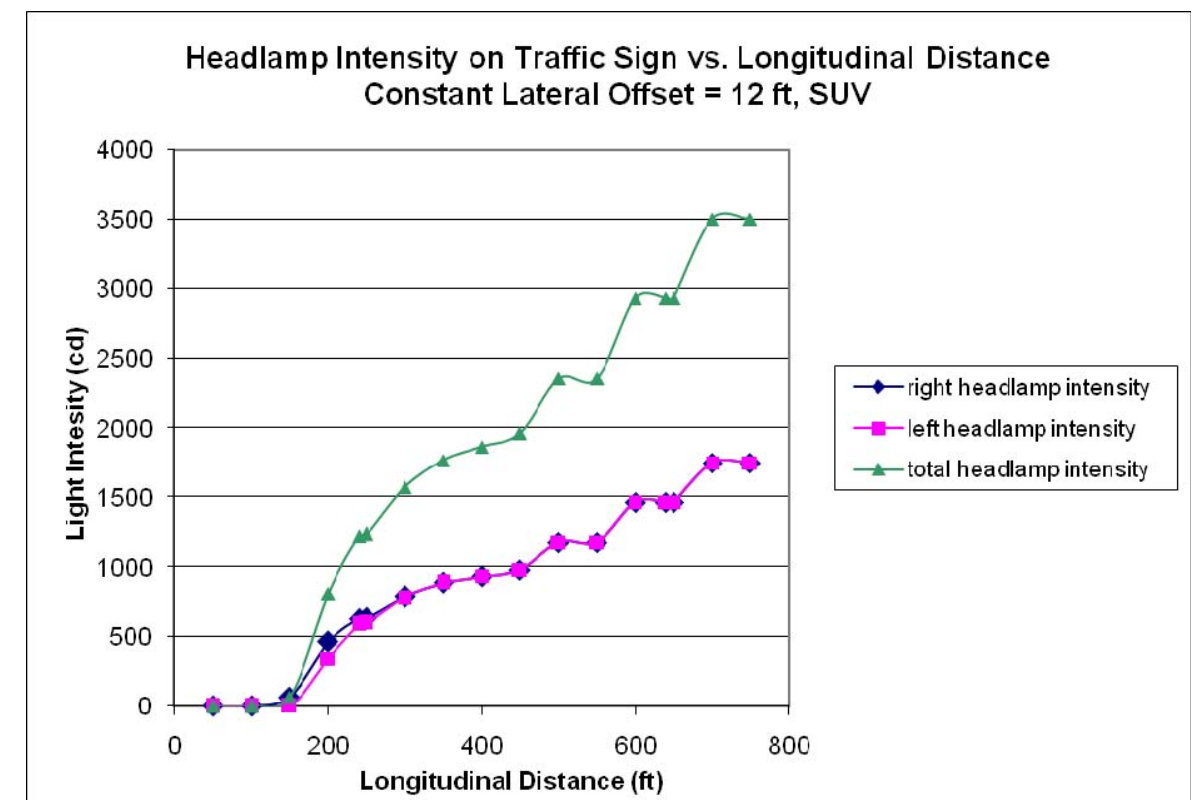

Figure 33: Headlamp Intensity Striking Traffic Sign for SUV at Lateral Offset $=12$ feet vs. Longitudinal Distance 


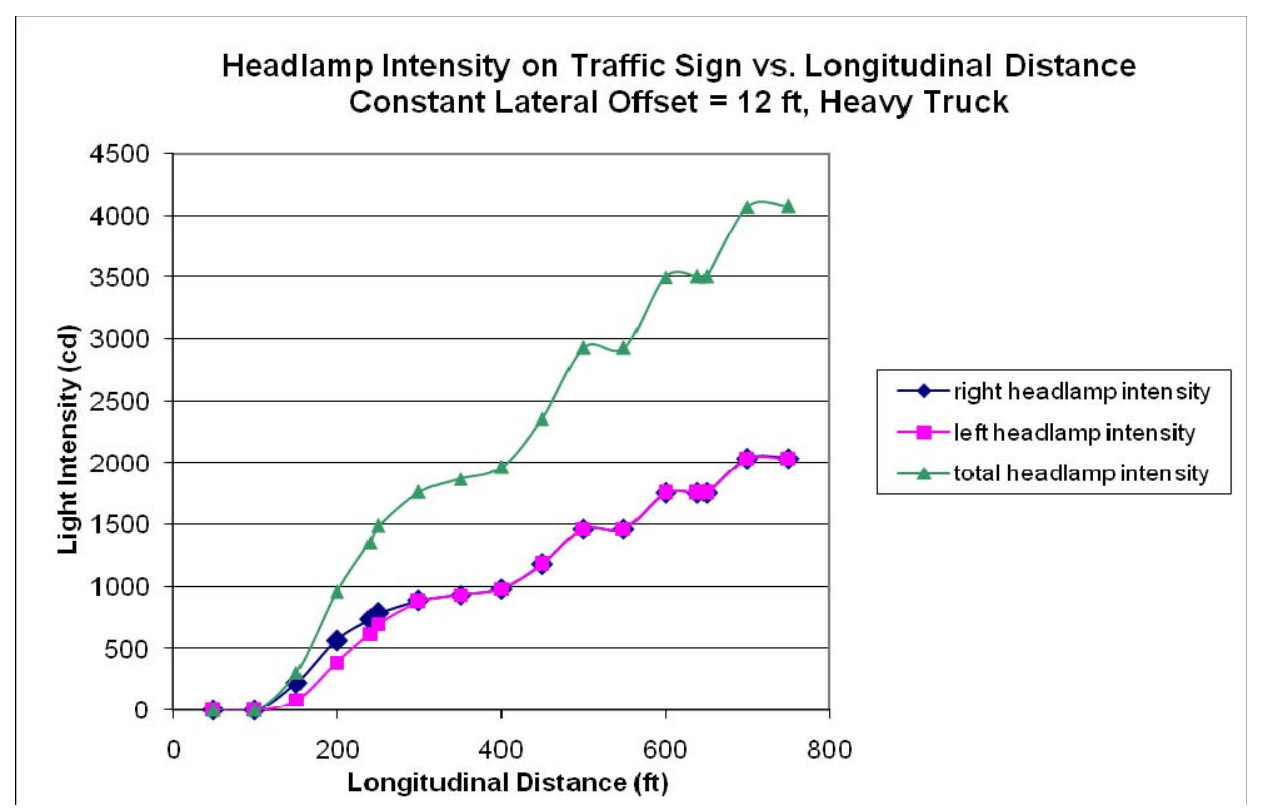

Figure 34: Headlamp Intensity Striking Traffic Sign for Heavy Truck at Lateral Offset $=12$ feet vs. Longitudinal Distance

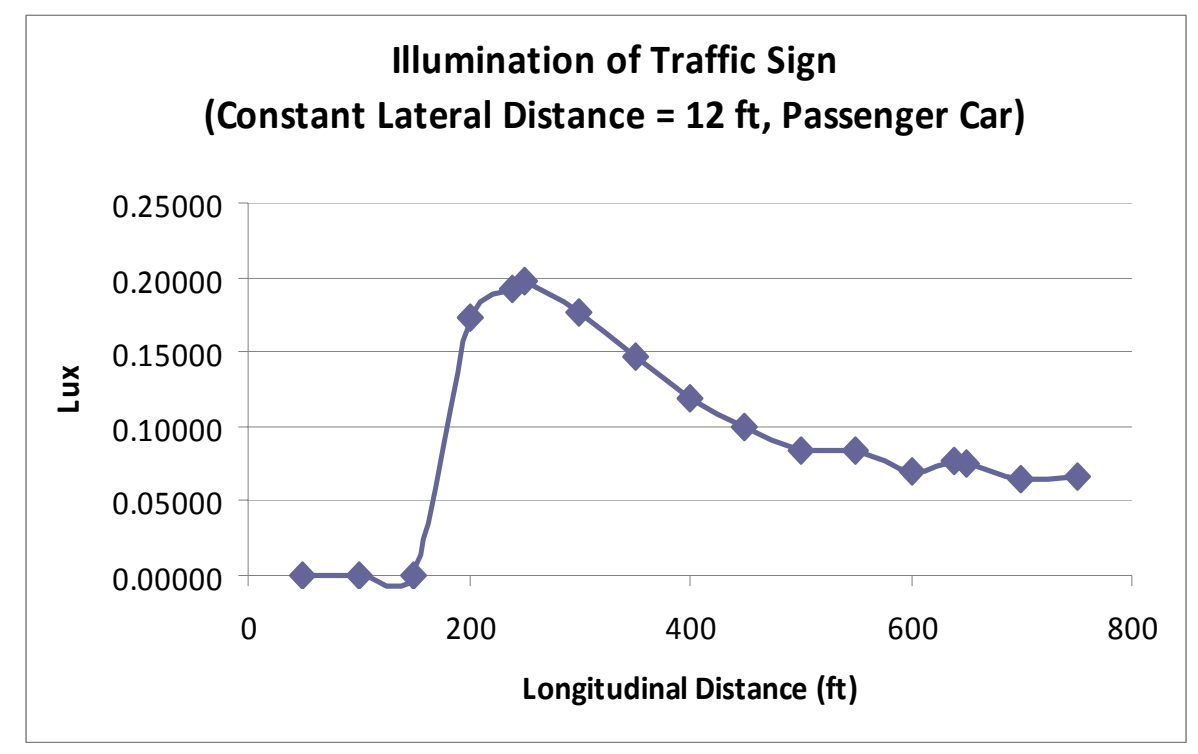

Figure 35: Traffic Sign Illumination for Passenger Car at Lateral Offset $=12$ feet vs. Longitudinal Distance 


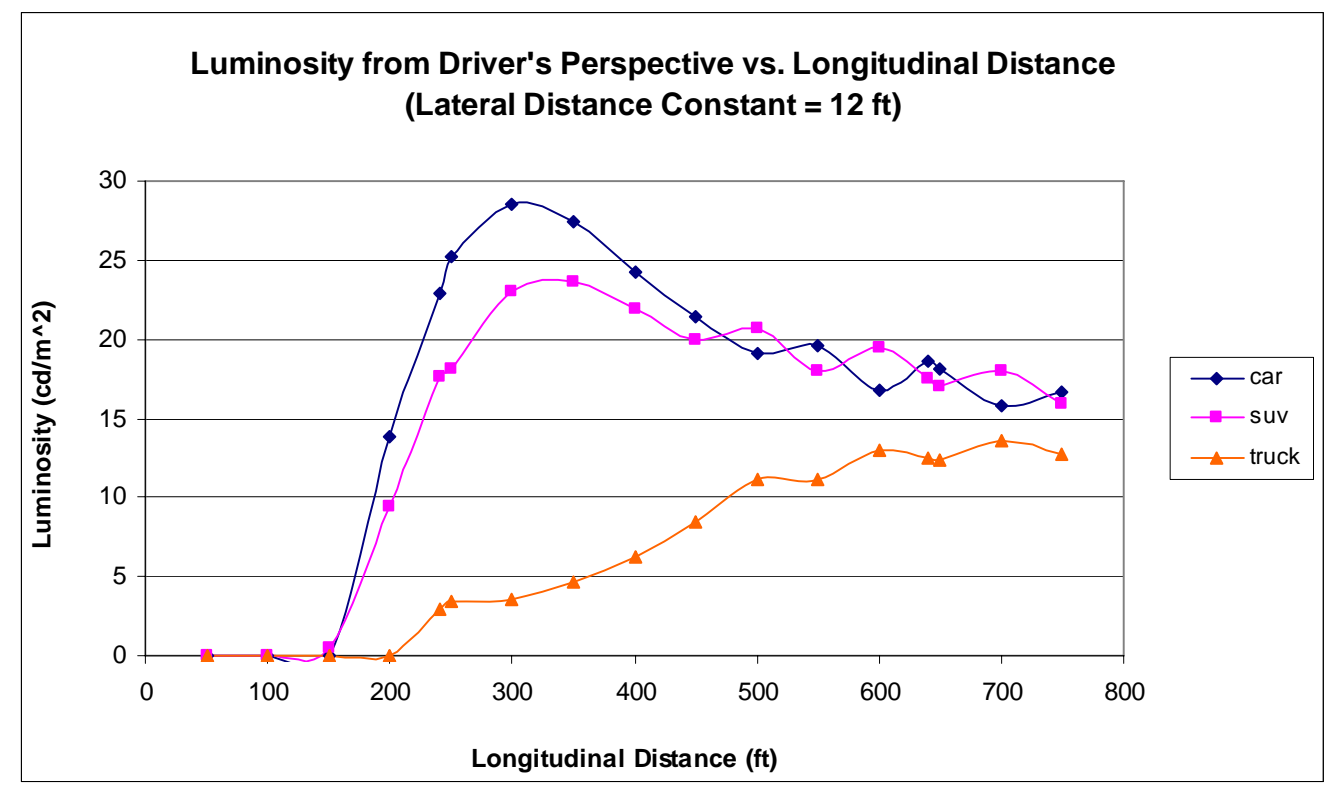

Figure 36: Luminosity from Driver’s Perspective at Lateral Offset $=12 \mathrm{ft}$ vs. Longitudianl Distance

The model was compared to target luminance values of $2.3 \mathrm{~cd} / \mathrm{m}^{2}$ for signs at a distance of 640 feet, and $3.9 \mathrm{~cd} / \mathrm{m}^{2}$ for signs at a distance of 240 feet, as used by Chrysler et al. (2003). Both of target luminance values were based on the $50^{\text {th }}$ percentile older driver, i.e., a driver older than 55 years. At both distances, the theoretical observed luminance was compared to the target luminance at lateral offsets of 8, 10, 12, 14, 16, 18 and 20 feet. For the Type III warning sign with $\mathrm{R}_{\mathrm{A}}=256$ for the yellow background, the target luminance was exceeded at 240 at all lateral offsets by the passenger car and SUV. The heavy truck was below the target luminance at all lateral offsets at longitudinal distance of 240 feet (Figure 37). At 640 feet, the target luminance was met for all design vehicles at all lateral offsets (Figure 38). 


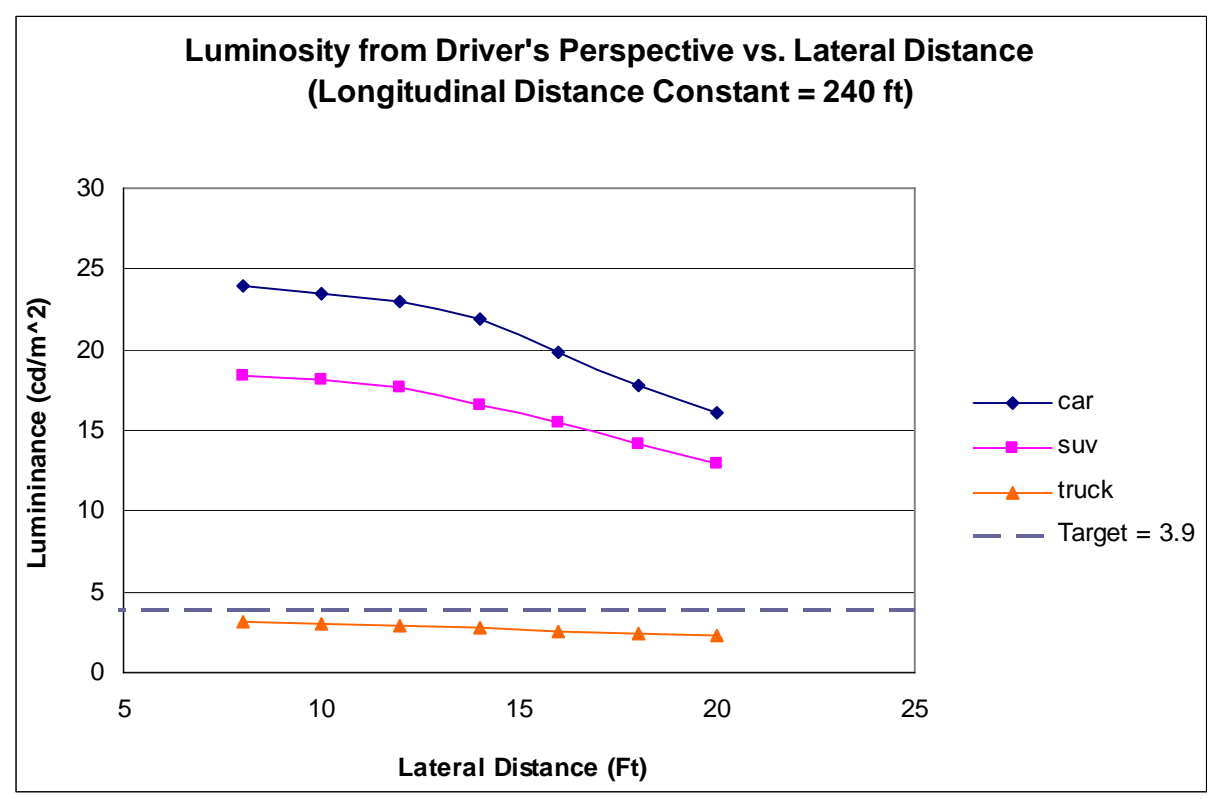

Figure 37: Luminosity from Driver's Perspective at Lateral at Longitudinal Distance $=240$ feet vs. Lateral Distance

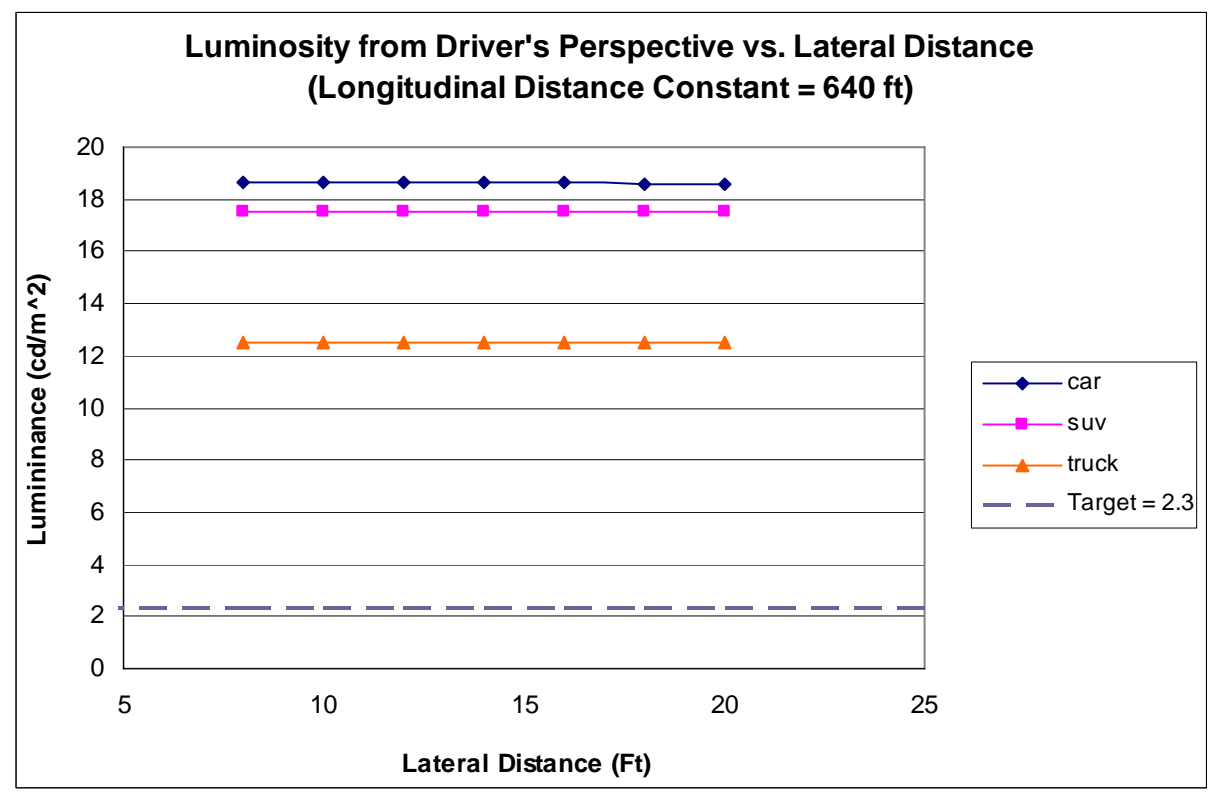

Figure 38: Luminosity from Driver's Perspective at Lateral at Longitudinal Distacne $=640$ feet vs Lateral Distance 
Lastly, the model calculated the theoretical observed light intensity from traffic signs at a constant lateral offset of 12 feet, for longitudinal distances from 50 to 750 feet, using 50 foot intervals. Also included are the theoretical observed light intensity from traffic sign at longitudinal distances of 240m and 640 feet to compare calculated observed light intensity thresholds from luminance thresholds defined by Chrysler, et al. (2003) (Figure 39). The observed light intensity thresholds are calculated by using the defined luminance thresholds of $3.9 \mathrm{~cd} / \mathrm{m}^{2}$ and $2.3 \mathrm{~cd} / \mathrm{m}^{2}$ for 240 and 640 feet, respectively. Each luminance thresholds was divided by the respective square of the longitudinal distance, then are multiplied by the area of the motorist's eyes $\left(\mathrm{A}_{\text {eye }}\right.$, thus defining a threshold light intensity for each longitudinal distance. For a longitudinal distance of 640 feet, this value was found to be 5.96 E-9 candelas and for a longitudinal distance of 240 feet this value was found to be 7.18 E-8 candelas. At each of these longitudinal distances, the theoretical observed light intensity from the traffic sign was compared to the calculated target light intensities at lateral offsets of 8, 10, 12, 14, 16, 18 and 20 feet (Figures 40 and 41). Again, only the heavy truck at all lateral offsets, at the longitudinal distance of 240 feet failed to meet the calculated target light intensity. 


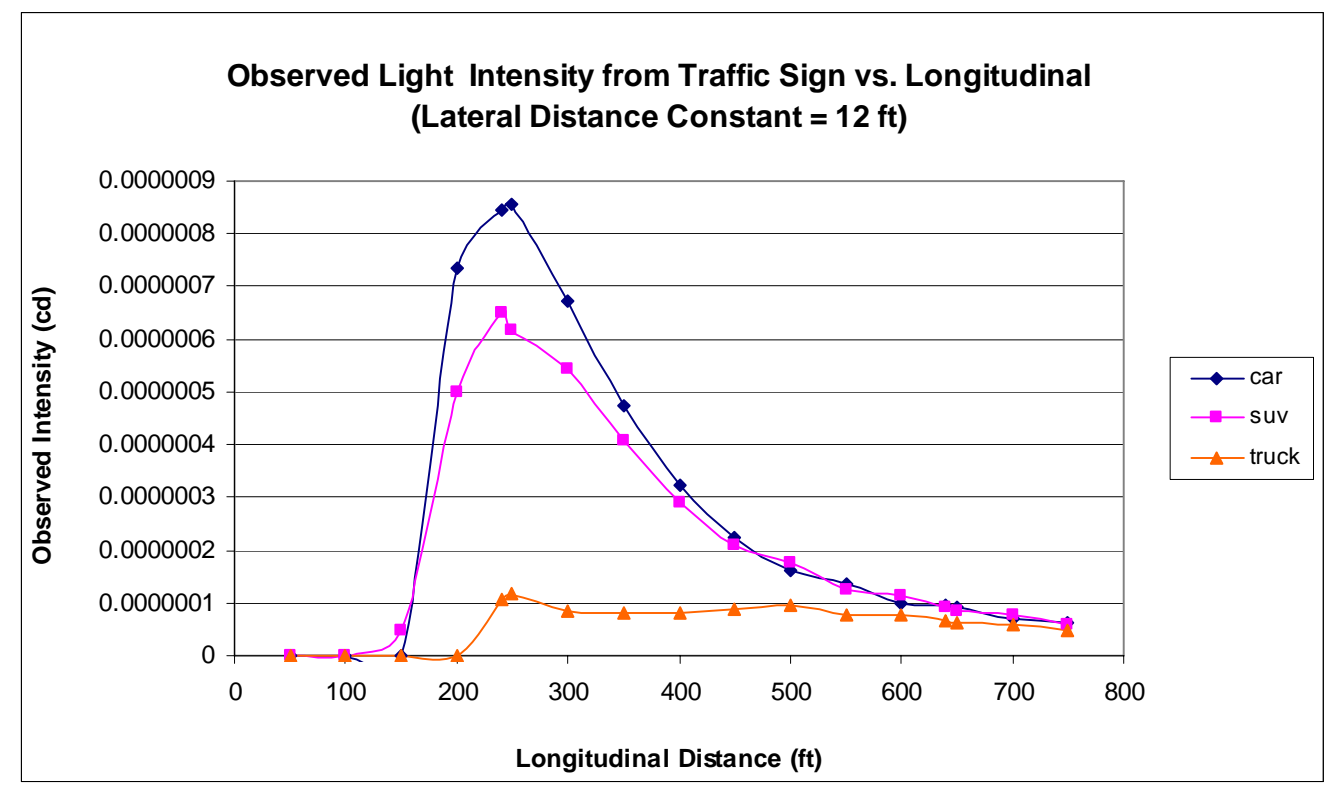

Figure 39: Observed Light Intensity from Traffic Signs at Lateral Offset $=12$ feet vs. Longitudinal Distance

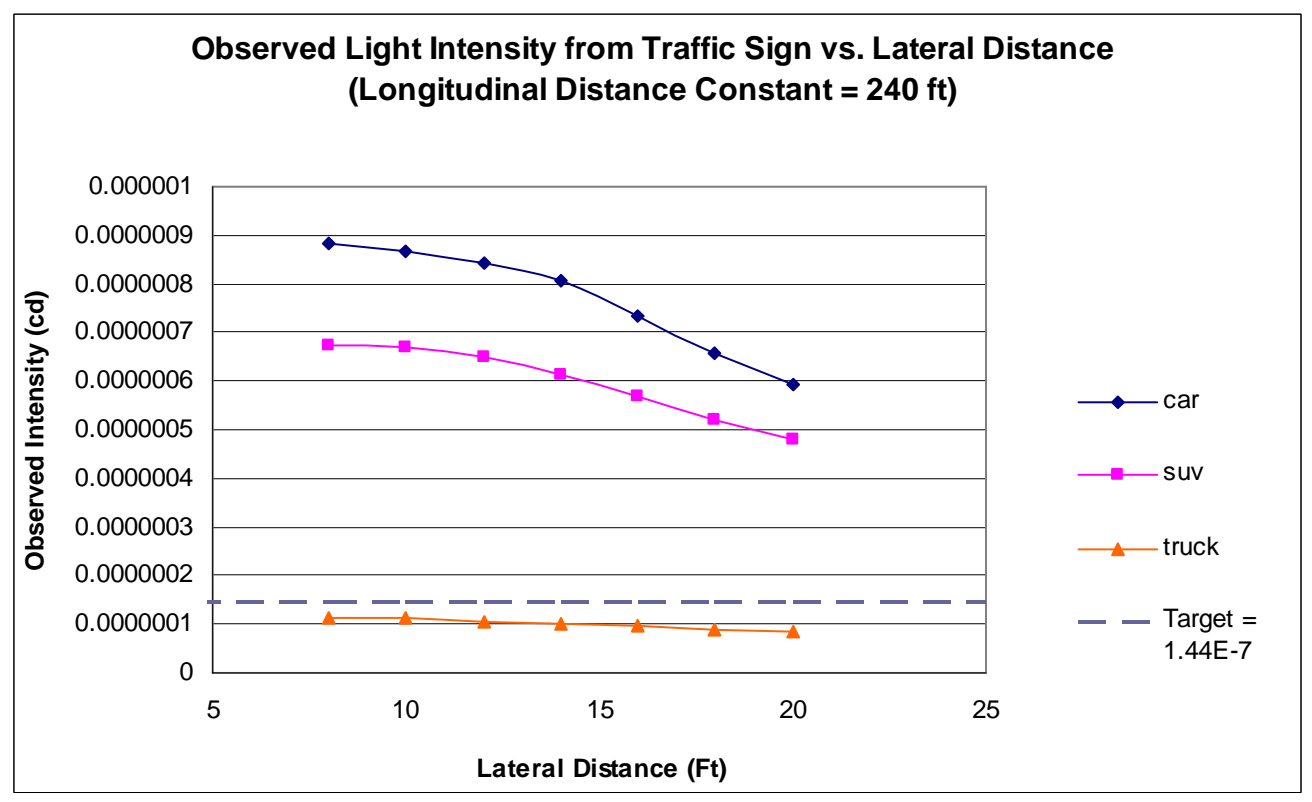

Figure 40: Observed Light Intensity from Traffic Signs at Longitudinal Distance $=240$ feet vs. Lateral Distance 


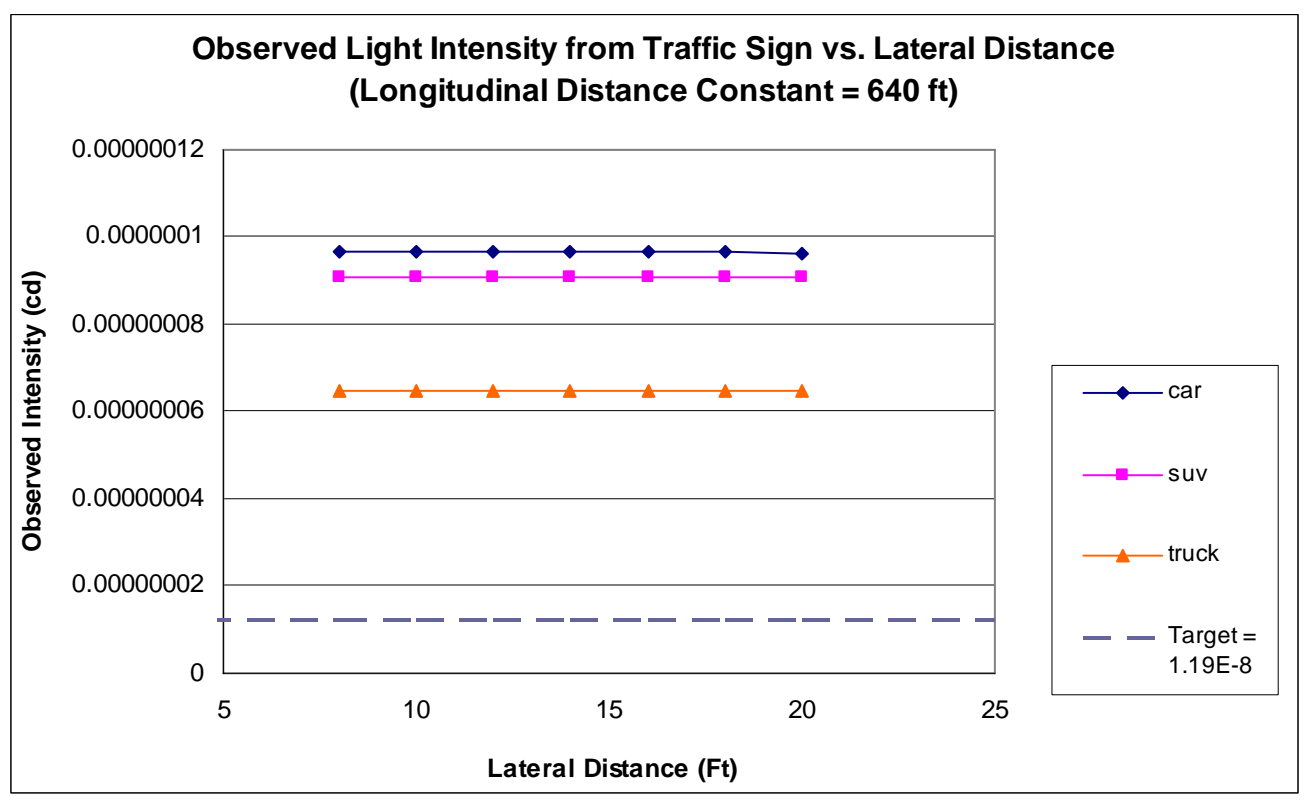

Figure 41: Observed Light Intensity from Traffic Signs at Longitudinal Distance $=640$ feet vs. Lateral Distance 


\section{CHAPTER 6: \\ CONCLUSIONS AND RECOMMENDATIONS}

\section{TRAFFIC SIGN SURVEY CONCLUSIONS}

The traffic sign inventory survey showed that most local road agencies in the state of West Virginia do not have a traffic sign inventory. A traffic sign inventory is the basis of a comprehensive SMS, including management of traffic sign retroreflectivity. Additionally, most agencies are not aware of the new MUTCD requirements on traffic sign retroreflectivity. Of those agencies that were aware of the new MUTCD traffic sign retroreflectivity standards, none had a traffic sign management compliance method in place.

With the first milestone deadline of implementing a sign assessment or management method less than 3 years away for road agencies, it seems many local agencies in West Virginia may not meet the deadline. The consequences of not complying with the new federal standards have the potential to be costly. If a motor vehicle incident was to occur under dark conditions on a road under the jurisdiction of a local road agency, the agency may be at risk for a tort claim. In the state of West Virginia, there is no cap on the award for a tort claim. If a traffic sign under the jurisdiction of a local road agency is found to cause or contribute to a motor vehicle incident, that agency could be responsible for paying the award to the victim(s).

\section{TRAFFIC SIGN INVENTORY AND RETROREFLECTIVITY ASSESSMENT CONCLUSIONS}

Building a basic sign inventory using a spreadsheet such as Microsoft Excel and a handheld GPS unit, such as the Garmin eTrex may reduce the initial costs of establishing a SMS compared to more sophisticated SMS software. Data collection of the sign inventory including assessment of traffic sign retroreflectivity can be done using a two person work crew, requiring 
less than 40 man hours including training for a town of similar roadway mileage ownership and sign density as Shinnston, WV. The rate of data collection in building the inventory and measuring retroreflectivity of traffic signs was 5.9 signs per man hour. This rate seems reasonable based on a study of NCDOT measured traffic sign retroreflectivity, which observed rates of 8.3 signs per man hour (Rasdorf et al., 2006).

In analyzing the retroreflectivity of the traffic signs included in the case study inventory, about 83 percent met the MUTCD minimum levels. Of the 89 STOP signs in the inventory, 87, or 98 percent, met the MUTCD requirements. The overall performance of the entire traffic sign inventory will reduce the cost of sign compliance.

In conclusion, the effort to build the inventory, including the assessment of traffic sign retroreflectivity, resulted in compliance with the MUTCD retroreflectivity sign compliance method milestone. The study also evaluated the retroreflectivity of each regulatory, warning, and ground mounted guide traffic sign, which will provide useful information in future sign replacement activities.

\section{THEORETICAL MODEL CONCLUSIONS}

For the most part, the model of theoretical observed light intensity from traffic signs performed as expected. For a given constant lateral offset, changing only the longitudinal distance, the observed sign luminance was highest in the passenger car, followed by the SUV, and was lowest in the heavy truck. Similarly, for the distances of 240 and 640 feet, changing only the lateral offsets in each case, the observed sign luminance was highest in the passenger car, followed by the SUV, and was lowest in the heavy truck. Both of these observations met expectations of observed sign luminance in that larger vehicles generally place the motorist's eye 
farther from the illumination axis, thus reducing theoretical observed light intensity from the traffic sign.

An interesting observation was made while building the model with regards to traffic sign illumination and vehicle dimensions. For a given longitudinal and lateral distance, the traffic sign illumination was actually higher for larger vehicles than for smaller vehicles. The higher illumination for larger vehicles was caused by the increase in headlamp height, thus resulting in smaller vertical angles and ultimately higher light intensities striking the sign surface. While larger vehicles actually illuminate the target sign better than smaller vehicles, the theoretical observed light intensity from traffic signs in larger vehicles is less than the observed luminance in smaller vehicles due to larger observation angles.

It is worth noting that the rate of change of theoretical observed light intensity from traffic signs with respect to lateral offset is greater at 240 feet compared to 640 feet (Figures 38 and 39). This can be explained by the more rapid change in horizontal angle at shorter longitudinal distances. At longer distances, i.e. 640 feet, there is little change in observed sign luminance with increasing lateral offset as the above mentioned angles become not only smaller, but more steady.

\section{RECOMMENDATIONS}

\section{Traffic Sign Inventory and Retroreflectivity Management}

To better assess the best method for local road agencies to build and maintain a traffic sign inventory, including managing retroreflectivity, the life cycle cost of several SMS options needs to be evaluated. The study should include the comparison of basic systems, such as one used in the case study presented in Chapter 4 of this paper, to more sophisticated SMS systems like RoadSoft (2009), RoadPAK(2009) and PWS Signs (2009). 


\section{Modeling Observed In-Field Traffic Sign Intensity}

While many models of traffic sign luminance exist, none utilize an optimization algorithm to meet the needs of road way users for specific driving environments. Though sign luminance is an important consideration in detection and legibility of traffic signs under dark conditions, luminance does not consider how much light is being detected by the motorist. Factors such as posted speed limit, three-dimensional roadway geometry, and traffic volumes by vehicle type should be considered in selecting an appropriate sign size, sheeting type and offset of traffic signs. Also, studies such as those performed by the Texas Transportation Institute (Chrysler et al., 2003) and the University of Michigan Transportation Research Institute (Sivak et al., 1997) should be conducted on a large-scale basis to determine headlamp patterns of inservice vehicles. A model that calculates the amount of light being detected by the motorists using two cones of retroreflection, one for each headlamp, and uses roadway specific data, such as topographical information, may help to optimize sign locations and offsets to insure maximum effectiveness of traffic signs in informing motorist; thus potentially improving nighttime driving safety. A comprehensive model may also consider the affect of having dirt on the windshield and headlamp covers. Also, the model presented in this paper should be compared with in-field measured traffic sign intensities.

\section{Other Ideas for Improving Traffic Sign Recognition Under Dark Conditions}

Recognizing that most headlamp patterns achieve maximum intensity at positions down and to the right of the center of the headlamp, it may be beneficial in many driving situations to add retroreflective material to sign posts. This practice would often expose retroreflective material to higher headlamp intensity and may aid in the detection and legibility of traffic signs. 
While this method has been implemented by some road agencies, there is not a federal standard on retroreflectorizing sign posts.

The geometry cone of retroreflection creates a compromise between the light intensity per unit area within the cone and size of the cones radius at a given longitudinal distance. For example, a tighter cone of retroreflection, i.e., one that has a smaller radius at a given longitudinal distance, results in more light per unit area within the cone. However, the tighter cone decreases the “acceptable” distance from illumination axis. Therefore, the tighter cone of retroreflection has the potential to aid in traffic sign detection and legibility at larger longitudinal distance, but would likely reduce sign detection and legibility at shorter longitudinal distances, especially for larger vehicles. Considering how the geometry of the cone of retroflection affects the distance at which signs can be detected, research should be conducted on different sheeting materials that can change the geometry of the cone of retroreflection. The geometry of the cone of retroreflection created by a given sheeting material could then be matched to specific traffic sign applications. For instance, consider a high-speed road requiring a longer minimum required visibility distance (MRVD), a tighter cone of retroreflection may be beneficial in aiding motorists' detection of the traffic sign at a distance at which they can safely use its message, that is, a distance that gives adequate time for the motorist to recognition and read the sign, decide on the appropriate action, then initiate and complete the maneuver (Paniati and Mace, 1993). 


\section{REFERENCES}

2008-2009 West Virginia Municipal League Directory. West Virginia Municipal League. Charleston, WV, 2008.

Aktan, Fuat. and Schnell, Thomas. A Web-Based Legibility Threshold and Road Sign Luminance Contrast Calculator for Nighttime Driving Conditions. $16^{\text {th }}$ Biennial Symposium on Visibility and Simulation, Iowa City, IA, 2002.

Andersen, D.A.. Sign Retroreflectivity Study. North Dakota State University, North Dakota DOT, 1993.

Bischoff A. and D. Bullock. Sign Retroreflectivity Study. Report No. FHWA/IN/JTRP-2002/22, Indiana Department of Transportation, Indianapolis, IN, 2002.

Black, K.L., H.W. McGee, and S.F. Hussain, Implementation Strategies for Sign Retroreflectivity Standard. NCHRP Report 346, Transportation Research Board, Washington, D.C. 1992.

Black, K.L., H.W. McGee, S.F. Hussain, and J.J. Rennilson. Service Life of Retroreflective Signs. Report No. FHWA-RD-90-101, U.S. Department of Transportation, Federal Highway Administration, Washington, D.C., 1991.

Carlson, Paul J. and H. Gene Hawkins, Jr. Updated Minimum Retroreflectivity Levels for Traffic Signs. Publication no. FHWA-RD-03-081.Washington, DC: Federal Highway Administration, 2003.

Carlson, Paul J. and Matt S. Lupes. Methods for Maintaining Traffic Sign Retroreflectivity. Publication no. FHWA-HRT-08-026.Washington, DC: Federal Highway Administration, 2007.

Carlson, Paul J. Evaluation of Clearview Alphabet with Microprismatic Retroreflective Sheetings. Report No. FHWA/TX-02/4049-1, Texas Department of Transportation, Austin, Texas, 2001.

Chrysler, Susan T., Carlson, Paul J. and Hawkins, H. Gene. Headlamp Illumination Provided to Sign Positions by Passenger Vehicles. Report No. FHWA/TX-03/0-1796-3, Texas Department of Transportation, Austin, Texas, 2003.

City of Shinnston,WV. Citynet. Accessed May 23, 2009. <http://www.shinnstonwV.com/>

Facts About The Cornea and Corneal Disease. National Eye Institute. Accessed June, 182009. $<$ http://www.nei.nih.gov/health/cornealdisease $>$

Fambro, D.B., K. Fitzpatrick, and R.J. Koppa. Determination of Stopping Sight Distance. NCHRP Report 400. Transportation Research Board, Washington, D.C., 1997.

Fatality Analysis Reporting System Encyclopedia. National Highway Traffic Safety Services Administration. Accessed February 17, 2009. < $\underline{\text { http://www-fars.nhtsa.dot.gov> }}$

Federal Highway Administration and the Bureau of Transportation Statistics, 2001 National Travel Survey. The survey results can be viewed at $<$ http://nhts.ornl.gov/ $>$ 
Hawkins, Gene H. and Gogula, Madhui. Assessment of Sag Curve Design Criteria Considering Modern Headlamp Performance. 87 ${ }^{\text {th }}$ Annual Meeting Transportation Research Board, Transportation Research Board, Washington D.C., 2008.

Hawkins, H.G., P. J. Carlson, J.B. McCaleb, and C.R. McIlroy. Impact of Minimum Retroreflectivity Values On Sign Replacement Practices. Publication no. FHWA/TX97/1275-1F, College Station, TX, 1996.

Hawkins, Neal, Omar Smadi, Zach Hans, and Jon Resler. Sign Inventory, Legacy versus New Technology. 86 ${ }^{\text {th }}$ Annual Meeting Transportation Research Board, Transportation Research Board, Washington D.C., 2006.

How Retro is Your Reflectivity. Texas Transportation Researcher. Vol. 40, No.1, 2004. Accessed May 6, 2009. <http://www.atssa.com/galleries/defaultfile/HowRetroIsYourReflectivity.pdf $>$

Improving Traffic Sign Management Process. U.S. Department of Transportation, Federal Highway Administration. Accessed January 16, 2009. <http://safety.fhwa.dot.gov/roadway_dept/retro/sign/imp_improve.htm>

Institute of Transportation Engineers. Traffic Signing Handbook. Institute of Transportation Engineers, Washington, D.C., 1997.

Kilgour, Matthew D., Joshua D. White, and Darcy M. Bullock. Sign Retroreflectivity: Fiscal Impact of Proposed Minimum Retroreflectivity Values on Local Governments in Indiana and Investigation of the Accuracy of Nighttime Inspections. $86^{\text {th }}$ Annual Meeting Transportation Research Board, Transportation Research Board, Washington D.C., 2006.

Kirk, A.R., E.A. Hunt, E.W. Brooks. Factors Affecting Sign Retroreflectivity. SR514, Oregon DOT, Salem, OR, 2001.

Lloyd, John. Understanding Retroreflectivity: A Brief History of Retroreflective Sign Face Sheeting Materials. Retroreflective Equipment Manufacturers Association. Lancashire, United Kingdom, 2008.

Manual on Uniform Traffic Control Devices, 2003 Edition, Rev. 2007. U.S. Department of Transportation, Federal Highway Administration, Washington, D.C., 2007.

Manual on Uniform Traffic Control Devices, 2003 Edition. U.S. Department of Transportation, Federal Highway Administration, Washington, D.C., 2003.

McGee, H.W. and J.F. Paniati. An Implementation Guide for Minimum Retroreflectivity Requirements for Traffic Signs. FHWA-RD-97-052, Department of Transportation, Federal Highway Administration, Washington, D.C., 1998.

McGee, H.W. and Taori, S. Impacts of Maintaining Traffic Signs Within Minimum Retroreflectivity Guidelines. In Transportation Research Record No. 1650, Transportation Research Board, National Research Council, Washington D.C., 1998a, pg 19-27.

McGee, Hugh W. and Sunil Taori. Impacts on State and Local Agencies for Maintaining Traffic Signs Within Minimum Retroreflectivity Guidelines. Report No. FHWA-RD-97-053, U.S. Department of Transportation, Federal Highway Administration, Washington, D.C., 1998b. 
MUTCD Rulemaking - Signs. American Traffic Safety Services Association. Accessed January 6, 2009.

New MUTCD Sign Retroreflectivity Requirements: Maintaining Traffic Sign Retroreflectivity. Publication no. FHWA-SA-07-020. Washington, DC: Federal Highway Administration

Nighttime Visibility Fact and Statistics. U.S. Department of Transportation, Federal Highway Administration. Accessed December 15, 2008. $<\underline{\text { http://safety.fhwa.dot.gov/roadway_dept/retro/gen/night_facts.htm> }}$

Opiela, Kenneth S. and Carl K. Anderson. Maintaining Traffic Sign Retroreflectivity: Impacts on State and Local Agencies. Publication no. FHWA-HRDS-05. Washington, DC: Federal Highway Administration, 2007.

Paniati, J.F. and D.J. Mace. Minimum Retroreflectivity Requirements for Traffic Signs. Report No. FHWA-RD-93-077. U.S. Department of Transportation, Federal Highway Administration, Washington, D.C., 1993.

Piñero, David P., Belén Plaza Puche, Ana and Alió, Jorge L. Corneal Diameter Measurements by Corneal Topography and Angle-to-Angle Measurements by Optical Coherence Tomography: Evaluation of Equivalence. Journal of Cataract \& Refractive Surgery. Vol. 34, January 2008.

PWS Signs. University of New Hampshire T² Center. Accessed April 22, 2009. $<$ http://www.t2.unh.edu/software.html $>$

Rasdorf, William J., Joseph Hummer, Elizabeth A. Harris, Venkata Pavan K Immaneni, and Chunho Yeom. Designing an Efficient Nighttime Sign Inspection Procedure to Ensure Motorist Safety. Report No. FHWA/NC/2006-08, North Carolina Department of Transportation, Raleigh, NC, 2006.

Reflectivity. 3M . Accessed on May 11, 2009. <http://www.3m.com.au/intl/AU/reflective/reflectivity.pdf $>$

RoadPAK Roadway Asset Management System. Loftus Huefner Management Systems. Accessed April 22, 2009. <http://www.huefner.com.au/Brochures/RoadPAK\%200verview\%20A3.pdf>

RoadSoft Roadway Asset Management System._Michigan Tech Transportation Institute at Michigan Technological University. Accessed January 4, 2009.

$<\underline{\text { http://www.roadsoft.org/> }}$

Schertz, Greg, Debra Chappell, Carl Andersen, Abdul Zineddin, Frank Julian, and Dean Larsen. Traffic Sign Retroreflectivity "Sign Retro 101". U.S. Department of Transportation Federal Highway Administration. Accessed March 19, 2009. <http://www.atssa.com/galleries/default-file/Sign_Retro_101\%28Final\%29.pdf>

Science of Retroreflectivity. Guidelines to Safer Roads Understanding Minimum Reflectivity. Accessed May 7, 2009. <http://www.minimumreflectivity.org/retroreflective.asp>

Sivak, M., M.J. Flannagan, S. Kojima \& E.C. Traube. A Market-weighted Description of Lowbeam Headlighting Patterns in the U.S. Technical Report No. UMTRI-96-36. The University of Michigan Transportation Research Institute, Ann Arbor, MI, 1997. 
Standard Practice for Describing Retroreflection. ASTM E808-99, West Conshohocken, PA, 1999.

Standard Specification for Retroreflective Sheeting for Traffic Control. ASTM D4956-04, West Conshohocken, PA, 2004.

Standard Test Method for Measurement of Retroreflective Signs Using a Portable Retroreflectometer at a 0.2 Degree Observation Angle. ASTM E1709 - 08, West Conshohocken, PA, 2008.

U.S. Department of Transportation, Federal Highway Administration, Highway Statistics 2006, Washington, DC: 2008, table HM-10.

U.S. Department of Transportation, Federal Highway Administration, Highway Statistics 2006, Washington, DC: 2008, table HM-10.

Vereen, S.C., J.E. Hummer, and W.J. Rasdorf. A Sign Inventory Study to Assess and Control Liability and Cost. Report No. FHWA/NC/2002-17, North Carolina Department of Transportation, Raleigh, NC, 2002.

What is Retroreflectivity? - THE BASICS. American Traffic Safety Services Association. Accessed January 6, 2009. $<\underline{\text { http://www.atssa.com/cs/root/retroreflectivity/what_is_retroreflectivity/basics }>}$

Wolshon, B., R. Degeyter, and J. Swargam. Analysis and Predictive Modeling of Road Sign Retroreflectivity Performance. $16^{\text {th }}$ Biennial Symposium on Visibility and Simulation, Iowa City, IA, 2002. 


\section{APPENDIX \\ Traffic Sign Management Survey: \\ WV Local Technical Assistance Program \\ 2009 Traffic Sign Management Survey}

Agency Name:

Name of Person Filling Out Survey:

Title:

Phone \#:

Email:

1. Was your agency aware of the new federal regulations on traffic sign retroreflectivity?

Yes No

a. If yes how did you hear of the new regulations?

2. Does your agency currently have traffic sign inventory? Yes No

a. If yes:

i. How many signs are currently in your jurisdiction?

ii. Does your traffic sign inventory keep record of:

$\underline{\text { Yes } \quad \text { No }}$

Sign type

(i.e. regulatory, warning, or guidance)..........

$\underline{\text { Yes } \quad \text { No }}$

Sign sheeting type......................... 
Sign location

(i.e. mile 1.32 on Main Street).............

Distance from road

(i.e. vertical and horizontal)...............

Sign size............................

Date installed/replaced..............

Maintenance activity................

iii. Is the traffic sign inventory maintained in an electronic management system, such as a geographic information system (GIS), global positioning system (GPS) software package, or spreadsheet? Yes No

3. Does your agency currently have a sign assessment or management method in place to $\begin{array}{lll}\text { maintain traffic sign retroreflectivity? } & \text { Yes } & \text { No }\end{array}$

a. If yes:

i. What method does your agency use?

Visual Nighttime Inspection

Blanket Replacement

Measured Sign Retroreflectivity

Combination

Expected Sign Life

Other

Control Signs

If other, please explain: 
b. If no:

i. Which method do you plan on implementing to meet the federal requirements?

$\begin{array}{ll}\text { Visual Nighttime Inspection } & \text { Blanket Replacement } \\ \text { Measured Sign Retroreflectivity } & \text { Combination } \\ \text { Expected Sign Life } & \text { Other } \\ \text { Control Signs } & \end{array}$

If other, please explain:

4. How many employees do you currently have on your road crew?

5. How many miles of streets are maintained by your agency?

6. What is your agency's total annual funding?

7. What is your agency's annual funding allocation for traffic sign maintenance? (if any)

8. Does your agency have any questions regarding the implementation of a traffic sign retroreflectivity assessment or management system? If so please enter them below and we will get back to you as soon as possible.

Thank you for your participation in this survey!

John

H.

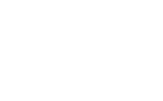

Hagen 